\title{
Terrestrial Insects with Tracheae Breath by Actively Regulating Ventilatory Movements: Physiological Similarities to Humans ${ }^{1}$
}

\author{
Karel Sláma ${ }^{2}$ and Jorge A. Santiago-Blay ${ }^{3}$
}

\begin{abstract}
Ventilatory movements were recorded in four species of lepidopteran pupae, as large as $11.5 \mathrm{~g}$ (Pseudosphinx tetrio) and as small as $0.0015 \mathrm{~g}$ (Phyllonorycter strigulatella). The ventilatory movements and ventilatory extracardiac pulsations in haemocoelic pressure were monitored by several electronic methods (strain-gauge recording of abdominal movements, recording of pulsations in haemocoelic pressure, thermographic recording of heartbeat, microrespirographic recording of $\mathrm{O}_{2}$ consumption and $\mathrm{CO}_{2}$ output, and nanoanemometric recording of inspirations and expirations through individual spiracles). It appears that all investigated insect pupae, whether large or small, carefully avoided breathing based on gaseous diffusion. Instead, the pupae actively ventilated their tracheal systems, exchanging respiratory gases and preventing respiratory water loss. Further, it was found that larvae and pupae of Cossus cossus, which were used circa 100 years ago as experimental evidence for creating the well-known "Krogh's diffusion theory of insect respiration", exhibited beautiful concerts of previously overlooked ventilatory abdominal movements and ventilatory extracardiac pulsations. These results conflict with the indicated diffusion theory, which claimed that these insects did not need to exhibit ventilatory movements at all. Unfortunately, the diffusion theory has persisted until the present due to the lack of exact experimental data. The evidence that we now provide by means of advanced electronic methods shows a widespread occurrence of ventilatory movements. Even immobile insect pupae with low respiratory metabolism exhibit distinctive ventilatory movements. The movements are quite inconspicuous, occurring in the range of micrometers or nanometers, which obviously were imperceptible to earlier investigators. These results confirm our previous findings of human-like insect breathing, based on convective inhalation and exhalation of air driven by the respectively decreased or increased haemocoelic pressure. The results further confirm the control of insect respiration by an autonomic (brain independent), neuroendocrine system known as the coelopulse system, which consists of the nervous centre located in the mesothoracic ganglion of the ventral nerve cord, the neuromotoric spiracular nerves and the intersegmental or dorsoventral abdominal muscles. The system functions as the abdominal
\end{abstract}

\footnotetext{
${ }^{1}$ Submitted on April 28, 2017. Accepted on June 13, 2017. Last revisions received on June 20, 2017.

${ }^{2}$ Laboratory of Insect Physiology, INTERECO, Evropská 674, 16000 Prague, Czech Republic. Email: karel.slama34@gmail.com

${ }^{3} 217$ Wynwood Road, York, Pennsylvania 17402 USA. E-mail: blayjorge@ gmail.com
}

DOI: 10.9784/LEB5(1)Slama.01

Electronically available on June 23, 2017. Mailed on June 23, 2017. 
pressure pump. The high-resolution nanoanemometric recordings revealed original data on the movement of air across insect spiracles. The results can be summarized as follows: 1 . Spiracular valves open and close in short flutters lasting usually 50 to $250 \mathrm{msec} ; 2$. Active opening of the valves is faster and shorter than their more or less passive closure; 3 . Each spiracle can be used for inspirations as well as for expirations of air, depending on its synchronization with the increasing or decreasing phase of the haemocoelic pressure; 4. The contralateral spiracles on each segment can flutter in synchrony or independently, or flutter in synchrony with spiracles on other segments; 5. A spiracles on the same body segment can be used for inspiration, while the contralateral one can be simultaneously used for expiration; 6. Multiple spiracles on different body segments can flutter in concert with other groups of spiracles; 7. A diapausing pupa of Manduca sexta can use only one master spiracle for several hours (usually the left thoracic one), which could open in flutters of $250 \mathrm{msec}$, once in $3 \mathrm{~min}$; 8 . Some spiracles can open the valves in synchrony with the rising phase of haemocoelic pressure (expiration), while others open at the decreasing pressure phase (passive suction inspiration), which results in a unidirectional ventilation of the whole tracheal system; 9. During extracardiac pulsation in haemocoelic pressure, spiracular valves are programmed to open and close in synchrony with the pulse frequency (previously known as the fluttering spiracles); 10. Coordination of spiracular valve fluttering with the rising or falling haemocoelic pressure is integrated by the coelopulse neuroendocrine system. In summary, these facts seem to provide sufficient experimental evidence to show that insect respiration is controlled by actively regulated ventilation, not by passive diffusion of gas through the spiracles. Curiously enough, we found that the anatomical structure and physiological functions of the insect coelopulse system appear to display similarities with that of the autonomic, parasympathetic neuroendocrine system of the human body. The striking similarity between the two, phylogenetically distant respiratory systems is described and the possibility that insects and humans could evolve respiratory systems based on identical principles is emphasized.

Key Words: Tracheal ventilation, ventilatory movements, spiracular valves, inspiration of air, abdominal pressure pump, extracardiac haemocoelic pulsations, Krogh's diffusional theory, nanoanemometric recording, fluttering spiracles, coelopulse neuroendocrine system, human respiration, ventilation of lungs, pupal respiration, Pseudosphinx tetrio, Manduca sexta, Cossus cossus, Phyllonorycter strigulatella

\section{Introduction}

Respiration in terrestrial animals can be divided into two phases. The first, consists of the movement of air from the outside into the proximity of the active tissues and cells. The second phase is the actual exchange of oxygen, $\mathrm{O}_{2}$, and carbon dioxide, $\mathrm{CO}_{2}$, at the active gas/liquid interphases. The study of insect respiration has undergone several periods, associated with accumulation of respirometric data. Unfortunately, this history has been neglected and forgotten for several reasons. The current state of the art in insect respiration reflects, in 
part, the rediscovery of information already contained in neglected publications. Herein, first, we refresh some of the forgotten historical facts related to insect respiration. Then, second, we provide experimental evidence supporting ventilation as an essential part of respiration in tracheated insects.

\section{Historical Overview}

The study of insect respiration can be traced back to the 17th century Italian microscopist, biologist, and physician Marcello Malpighi. He found that insects with oil-sealed spiracles, the tiny "nostrils" of insects, did not survive (West 2013). Great progress in the study of insect respiration was made by European scientists during the 19th century. For example, Newport (1836) published a detailed review on the structure of the tracheal system, described the tracheal sacs, identified musculature associated with the respiratory system, and described the nervous innervation of the spiracles. Later, Rathke (1861) outlined the basic functional morphology of the insect respiratory system. Finally, Plateau (1884) reviewed the principles of insect respiration and summarized the role of ventilation in various developmental stages of taxonomically unrelated insects.

The most crucial step forward in the field of insect respiration occurred after World War I, nearly 100 years ago, when the Czech physiologist Edward Babák (1921) published a comprehensive, 700-page review on anatomy and physiology of the respiratory systems of all tracheated invertebrates, including detailed descriptions of the main tracheal trunks, innervation and the mechanism of spiracular valve opening. He described autonomic (brain independent) regulation of discontinuous ventilation cycles in adult Dytiscus beetles. In addition to insects, Babák (1921) also extensively reviewed the knowledge of the respiratory systems of birds, mammals, and humans.

A contemporary of Babák, the famous Danish physiologist, A. Krogh (1920), published a short paper in which he calculated the diffusion velocities of gases using a simplified model of the insect tracheal system. The model consisted of a small cylindrical tube. Krogh computed the rate of gas diffusion in air and concluded that the diffusion of $\mathrm{O}_{2}$ in and $\mathrm{CO}_{2}$ out of the insect body was sufficient to cover all respiratory demands of insects without the necessity of ventilatory movements.

Krogh (1920) did not mention the previously published experimental data reporting the presence of ventilatory movements in various stages and species of insects (Newport 1836, Rathke 1861, Plateau 1884, Babák and Foustka 1907). He supported his conclusions by performing experiments on Cossus cossus (Linnaeus) caterpillars with one intubated spiracle. After submerging the specimen in water, Krogh did not observe any remarkable movement of the oil meniscus in the tubing and concluded that the larva did not exhibit ventilatory movements (quoted by Kuznetzoff 1953). The findings of Krogh (1920) became generally known in textbooks of insect physiology as the "Krogh's diffusional theory of insect respiration" (Wigglesworth 1963). Due to the lack of challenging 
experimental data, the diffusional theory survives until today as the main theoretical concept of insect respiration (Krogh 1941; Wigglesworth 1953; Kuznetzoff 1953; Sláma 1988, 2010; Nation 2002, 2016; Klowden 2013).

Soon after foundation of Krogh's diffusional theory, E. Hazelhoff, a student of Professor H. Jordan, challenged its validity by demonstrating that spiracular valves of insects and ticks were tightly closed most of the time (Jordan 1927, Krogh 1941). Questions about the validity of the diffusional theory were raised several times (reviewed by Wigglesworth 1947, 1953, 1965; Kuznetzoff 1953), but they went unanswered by the virtual absence of experimental data. Wigglesworth $(1953,1965)$ reviewed his excellent observations on spiracular functions in a pharaoh's flea, Xenopsylla cheopis (Rothschild). He found that, despite the small dimensions of this flea, the spiracular valves opened and closed at determined intervals. Much later, Krogh (1941) distinguished between animals without ventilatory movements, where the whole of the gas transport took place by diffusion and larger terrestrial insects occasionally using ventilation. He assumed that: "The housefly weighing about 15 - $20 \mathrm{mg}$ is supposed never to make respiratory movements, but the bee, weighing $100 \mathrm{mg}$, does so regularly" (Krogh 1941). Evidently, sometime after 1920, Krogh (1941) acknowledged in writing the serious drawbacks associated with his diffusional theory. In addition to the constricted spiracular valves, another major problem with Krogh's diffusional hypothesis was its direct consequence: the diffusional escape of water (see Wigglesworth 1939, 1965).

Respirometric data accumulated later, during the first half of 20th century, were also in serious conflict with Krogh's diffusional theory. Those data were extensively reviewed by the outstanding Russian physiologist, N. Ya. Kuznetzoff (1953) who published a comprehensive review on insect respiration containing several hundred annotated references. Kuznetzoff (1953) included extensive respirometric data, which were not included by Wigglesworth. Unfortunately, the works by Babák (1921) and Kusnetzoff (1953) on insect respiration remained underscored or completely unknown to most western scholars because they were published in German and Russian, respectively.

In 1959, Schneiderman and Williams investigated $\mathrm{O}_{2}$ consumption in the giant diapausing pupae of the cecropia silkworm, the saturniid Hyalophora cecropia (Linnaeus). They observed discontinuous emissions of $\mathrm{CO}_{2}$, previously known from respiration of diapausing sphingid pupae. Schneiderman and several of his co-workers (see reviews by Levy and Schneiderman 1966a, 1966b; Schneiderman and Schechter 1966) investigated discontinuous respiration in more detail. They found mysterious rhythmical openings and closures of the spiracular valves, which was called "fluttering", which were later identified as rhythmical pulsations associated with extracardiac pulsations in haemocoelic pressure (Sláma 2010). In 1976, the study of insect respiration obtained new dimensions by the discovery of extracardiac pulsations in haemocoelic pressure (Sláma 1976, Provansal et al. 1977). 
From 1960 onwards, the mainstream research on insect respiration has been directed to very sensitive instruments for flow-through, infrared analysis of $\mathrm{CO}_{2}$ (reviewed by Lighton 1996, 1998, 2008; Marais et al. 2005; Hetz and Bradley 2005, Chown et al. 2006). In these experiments, ants or termites, adapted to live in nests or burrows under conditions of balanced humidity and $\mathrm{CO}_{2}$ content, were exposed to an unnatural stream of desiccating scrubbed air $\left(0 \% \mathrm{CO}_{2}, 0 \% \mathrm{H}_{2} \mathrm{O}\right)$ to measure their $\mathrm{CO}_{2}$ release. Under these conditions, insects try to avoid desiccation by keeping spiracular valves closed as much as possible. They release the metabolically produced $\mathrm{CO}_{2}$ in short, discontinuous bursts. The theoretical background of discontinuous respiration is based on the old model of Sláma (1960) and Schneiderman (1960), who created the concept of stereotypical, discontinuous gas cycles (DGC). The DGC model based on the diffusional theory of Krogh is composed of three stereotypically repeated phases: a) open spiracle$\mathrm{CO}_{2}$ outbursts; b) closed spiracles, and; c) fluttering spiracles (OCF cycles). This mechanical concept of discontinuous respiratory cycles is still used as a theoretical basis of insect respiration (Lighton 1996, 1998; Marais et al. 2005; Hetz and Bradley 2005; Contreras and Bradley 2009; Chown et al. 2006; Klowden 2013). The authors of these papers speak about open, closed, or fluttering spiracles without the slightest experimental evidence about real performance of the spiracular valves. The unknown data accumulated by two generations of earlier authors (reviewed by Kuznetzoff 1953), slowly became rediscovered or replaced by several sophisticated hypotheses (Lighton 1998, Chown et al. 2006). In summary, the recent state-of-the-art in insect respiration has been shifted from physiological studies of $\mathrm{O}_{2}$ consumption to capricious emissions of $\mathrm{CO}_{2}$ (imagine that some insects make a burst of $\mathrm{CO}_{2}$ only once in 16 hours!).

New electronic methods used after 1976 monitor changes in insect haemocoelic pressure in the ranges under one $\mathrm{Pa}$ or monitor the pupal ventilatory movements in ranges of a few nanometers or micrometers. These data were not available to earlier investigators. Among the most important findings was the discovery of rhythmical changes in insect haemocoelic pressure, responsible for an active inflow or outflow of air through the spiracles (Sláma 1976). The pulsations, which became known as extracardiac pulsations in haemocoelic pressure, underwent specific modifications during pupal development (Provansal et al. 1977). In contrast to the heartbeat, which is myogenic, extracardiac pulsations are neurogenic. They originate in neurons of the mesothoracic ganglion, propagate through the nerve connectives into ganglia of the abdominal nerve cord and cause contractions of the intersegmental abdominal muscles (Sláma et al. 1979). Synchronized contractions of these muscles cause telescopic contractions of flexible abdominal segments, called abdominal pressure pump, which drives the air through the spiracles. This coordinated nervous system was called the coelopulse system (from the Greek koiloma or Latin coeloma for body cavity and pulsus for beating or striking (Sláma1994). 
Another technical improvement in insect respiration was the synchrotron $\mathrm{x}$ ray imaging of tracheal movements (Westneat et al. 2003). These movements were first observed by Babák (1921), later confirmed by Herford (1938) in the flea, Xenopsylla cheopis, and in other insects (reviewed by Wigglesworth 1947, Kuznetzoff 1953). Recent investigations on synchrotron imaging revealed important new data on the movements within the tracheal system of adult beetles (Westneat et al. 2008, Socha et al. 2010), which indicated the effects of decreasing or increasing haemocoelic pressure on inflation and deflation of the tracheal system. More recently, substantial progress in the regulation of $\mathrm{O}_{2}$ consumption and $\mathrm{CO}_{2}$ emissions was obtained in relatively small insects by using electronic, nanorespirographic methods. For example, miniature termites (Isoptera: Prorhinotermes, body mass of $0.6 \mathrm{mg}$ ) exhibited continuous consumption of $\mathrm{O}_{2}$ as well as the release of $\mathrm{CO}_{2}$ (the rate of $18 \mathrm{nl} / \mathrm{min}$ ) when measured under humid conditions. In dry air, however, the miniature termites exhibited discontinuous $\mathrm{CO}_{2}$ bursts, lasting less 2 minutes, in which they exhaled volumes of pure $\mathrm{CO}_{2}$ larger than the whole-body volume and 20-fold more than the total volume of the tracheal system (Sláma et al. 2007). A comparable situation was found in the pea aphid, Acyrthosiphon pisum Harris (body mass $3 \mathrm{mg}, \mathrm{O}_{2}$ consumption $3000 \mu \mathrm{I} \mathrm{O}_{2}$ $/ \mathrm{g} / \mathrm{h}$ ), which produced $\mathrm{CO}_{2}$ bursts of $60 \mathrm{nl}-120 \mathrm{nl}$ once every 5 minutes when measured in dry air (Sláma and Jedlička 2012). The most important finding of these microrespirographic results was that these very small insects did not release the metabolic $\mathrm{CO}_{2}$ by diffusion, but by a bulk flow of the concentrated gas enzymatically volatilized from carbonate buffers. Special respiratory features are represented by insect hypermetabolism (extremely large respiratory rates manifested by $10000 \mu 1 \mathrm{O}_{2} / \mathrm{g} / \mathrm{h}$ or released $\mathrm{CO}_{2} / \mathrm{g} / \mathrm{h}$ ). These effects were caused by biochemical uncoupling of respiration from oxidative phosphorylation. It appears that hypermetabolism is a special respiratory adaptation used by insects that feed on dry food. Hypermetabolism is used to produce metabolic water by means of complete combustion of the dietary lipid (Sláma and Lukáš 2011, 2016). The microrespirographic method was used for measurement of $\mathrm{O}_{2}$ consumption by the salivary glands in Drosophila melanogaster Meigen, used for the study of gene activation (Farkaš and Sláma 2015). Unfortunately, the role of the neuroendocrine system in regulation of insect respiration by extracardiac pulsations in haemocoelic pressure (Sláma 1988, 2009, 2010; Sláma and Denlinger 1992; Sláma and Jedlička 2012) remains mostly unknown due to technical problems involved in the recording of haemocoelic pressure.

In this paper, we describe results obtained in the study of respiratory regulation in four species of lepidopteran pupae which, as a group, have an extreme body mass range. Special attention has been paid to the monitoring of inspirations and expirations of air through individual spiracles, which reveals little known functions of the spiracular valves. 


\section{Methods}

To shed additional light onto the problem of respiration in tracheated terrestrial insects, we recorded respiratory movements (extracardiac haemocoelic pulsations) in lepidopteran pupae of similar anatomy but substantially different body size (10000-fold difference). For this work, we used advanced electronic methods that enabled monitoring of respiratory movements simultaneously with the inspirations and expirations of air through spiracles in subnanoliter ranges. Special attention was paid to ventilatory movements in larvae and pupae of Cossus cossus, which were used by Krogh (1920) as a model of his purely diffusive respiration and absence of ventilatory movements.

Experimental Animals. Pupae of moths (Lepidoptera) of four species with extremely different body sizes were used to measure ventilatory movements. A giant pupa of Pseudosphinx tetrio Linnaeus, 1771 (Sphingidae) was available as only one specimen of $11.5 \mathrm{~g}$ body mass. Pupae of the American tobacco hornworm, Manduca sexta Linnaeus, 1763 (Sphingidae) were obtained from larvae raised on artificial diets (more than 50 specimens were measured). The rare pupae of Cossus cossus (Linnaeus, 1758) (Cossidae) were obtained from a few, accidentally collected mature larvae (five specimens were repeatedly measured). Finally, miniature $(0.0015 \mathrm{~g})$ diapausing pupae of Phyllonorycter strigulatella (Lienig and Zeller, 1846) (Gracillariidae) were collected from mines in the leaves of Alnus sp. (alder) in the Czech Republic (12 specimens were repeatedly measured), see Figure 1 and figure on page 30. Unless otherwise stated, all pupae were kept and studied at room temperature $\left(22-27^{\circ} \mathrm{C}\right)$.

The recording methods. Immobile pupae of endopterygote insects are the best subjects for placement of various sensors and electronic transducers on their bodies. The methods used in the present investigations are briefly described below.

1. Hydraulic transducers of insect "blood" (hemolymph) pressure used a thin steel needle, which was inserted leak proof into the pupal body cavity. The needle formed a part of a Ringer-filled hydraulic system, composed of a 4-way Hamilton inert valve, which connected the needle, alternating with the zero (atmospheric) pressure container, a $10 \mu \mathrm{l}$ syringe for cleaning the needle and delivering injections during the measurements. The fourth position of the valve connected the measuring needle either with the zero-pressure container or with the haemocoelic cavity (Sláma 1976, Anderson et al. 1990). By switching the valve into measuring position, the transducer recorded changes in haemocoelic pressure. Switching the valve into zero position was used for zero pressure control. Before and during prolonged measurements, the transducer could be calibrated for various mechanical pressures without interruption of the recordings (Anderson et al. 1990; Provensal et al. 1977; Sláma 1976, 2008; Sláma and Miller 1987).

2. Posimetric transducer recorded miniature movements of the body segments, especially the movements of the terminal abdominal segment (abdominal pressure pump). This strain-gauge transducer recorded movements of 
the metallic membrane, which was connected at the opposite end with the measured body segment. It appeared that the movements of flexible abdominal segments were proportional to changes in the pupal haemocoelic pressure. The transducer could thus be used for indirect recording of haemocoelic pressure from the body surface, without the need to penetrate the integument. The tip of the pupal abdomen was connected to a posimetric transducer by a metallic wire. The length of the wire was adjusted to the given pupal size. Large pupae required relatively long wires to eliminate destructive impacts of the side abdominal movements. The longitudinal abdominal movements were recorded in the range of a few nanometers (for more details see Anderson et al. 1990, Sláma 1984).

3. Thermographic transducer uses temperature compensated, miniature semiconductor thermistors $(300 \mu \mathrm{m})$, which are placed or glued to various integumental positions of the pupa. The sensors are slightly warmed by the internal electrical current, which creates a temperature gradient around the miniature body of the sensor. A disturbance of the gradient by subintegumental movements of haemolymph or tissues (heartbeat) produces a change in the balanced electrical properties of the sensor, which is amplified and recorded on a personal computer (for more details, see Sláma 2003, 2006; Sláma and Miller 2001).

4. Optoelectronic transducer uses a touch-free, pulsed light optic fiber technique for recording changes in optical density. The optoelectronic transducer was mainly used for touch-free recording of ventilatory movements of various pupal segments. Miniature optoelectronic sensors (SUNX Co., Japan) equipped by lenses on optic fibers, helped to focus the pulse-light beam to an area as small as $0.3 \mathrm{~mm}^{2}$. The light delivered to this area by outgoing optic fibers was received by ingoing fibers and transferred to a photomultiplier of the transducer. The red, $5 \mathrm{kHz}$ pulse-light made the transducer insensitive to incident light. The custommade amplifiers and offset control circuitry helped to record optical changes associated with the ventilatory movements. The external or subintegumental movements of tissues (heartbeat) were converted into electrical signals, decoded into the DC current voltage and recorded on a personal computer (Sláma 2003).

5. Scanning microrespirography. This technique is based on a constant volume, differential manometric principle based on the pressure/volume physical law of Boyle-Marriott. In principle, the electronic transducer placed between the respiratory and compensatory vessels recorded the differential changes in mechanical pressure/volume of air consumed or released by the investigated organism. The recording performed in presence of $\mathrm{CO}_{2}$ absorbent revealed the rate of $\mathrm{O}_{2}$ consumption; recording in the absence of $\mathrm{CO}_{2}$ indicated the important ratio of $\left(\mathrm{CO}_{2}-\mathrm{O}_{2}\right)$. The cumulative records of $\mathrm{O}_{2}$ consumption required precise offset regulation which was achieved by electronic zeroing and setting the offset of the scanning episodes. The method revealed subnanoliter rates of $\mathrm{O}_{2}$ consumptions/min, which was used for determination of metabolic rates in very small insects, such as ants, aphids or termites (Sláma and Denlinger 1992, Sláma 
and Jedlička 2012, Sláma et al. 2007), or explanted insect organs, such as the salivary glands of Drosophila (Farkaš and Sláma 2015).

6. Microanemometric sensors represent a unique electronic technique for differential recording of inspirations and expirations of air through insect spiracles. The method does not obliterate the normal airflow through the spiracles, which is very important, because the pupae easily recognize a closed spiracle and the valve is permanently open. In principle, the microanemometric method uses similar miniature thermistors, like the above described thermographic technique. The sensors are positioned in orifices of the thin Teflon tubing $(1 \mathrm{~mm}$ outer diameter). The opposite ends of the tubing end up in special connectors cemented to the spiracles. The plastic connectors are needed for easy dismantling and ventilation of the spiracles to prevent possible accumulation of $\mathrm{CO}_{2}$ during prolonged recordings (for more details see Sláma 1988, 1999).

7. The flow-through $\mathrm{CO}_{2}$ recorders were custom made from Gascard $\mathrm{II} \mathrm{CO}_{2}$ analyzers manufactured by Edinburgh Sensors Ltd (Livingston, Scotland, UK). There was a constant, $30 \mathrm{ml} / \mathrm{min}$ air-flow of scrubbed (eventually unscrubbed air with allowance for atmospheric $\mathrm{CO}_{2}$ ), sensitivity $1 \mathrm{nl} \mathrm{CO}_{2} / \mathrm{ml}$. A modified, DATAQ starter kit (Columbus, Ohio, USA) software and hardware was used for PC recording (Sláma 1999).

The records of haemocoelic pressure, $\mathrm{O}_{2}$ consumption or ventilatory movements supply very special, purely individual data, which are distorted by mean values or massive statistical elaboration. There was no average pupa and, therefore, we give in our Figures authentic results valid for the given specimen, which can be further used for additional calculations.

\section{Results}

Lepidopteran pupae have a large, rigid anterior compartment and a flexible, posterior compartment represented by the usually flexible abdominal segments 45, 5-6, and 6-7. These segments are separated from each other by elastic intersegmental membranes. Inside the body, the segments contain extensively developed intersegmental musculature, which is innervated by lateral ganglionic nerves of the ventral nerve cord. Flexible segments and intersegmental muscles form an essential part of the autonomic neuroendocrine system, called the coelopulse system (Sláma 2009). Mechanical ventilation of the tracheal system is made by telescopic contractions of the segments. The contraction causes compression of the internal pupal air space, which is followed by emissions of air through spiracles whose valves had been just open. The contracted abdominal segments prolonged again, with the unidirectional inflow of fresh air through other sets of open spiracles.

The above described, simple mechanism of pupal breathing can be perhaps better understood using schematic outlines of the pupal respiratory movements in Figure 2. The movements can be used for calculation of the ventilatory volumes of air entering or leaving the pupal body in response to longitudinal movements 
of the distal abdominal end. The flexible abdominal segments (5th to 7 th abdominal segments; compare A and B in Figure 2), form a conical structure outlined by broken lines a, b, and c, in Figure 2. The diameter (d) and the radius (r) can be used for calculation of the medium cross section area $\left(\pi \cdot r^{2}\right)$ of the conus. The movement of the median cross-section area along the longitudinal axis (e) occurs to be directly proportional to the volume of air which is leaving or entering the pupal body (at constant atmospheric pressure). The values obtained by recording abdominal movements by the posimetric sensors can thus be used as a simple and convenient measure of the pupal ventilatory efforts.

\section{Ventilatory movements in a giant pupa of Pseudosphinx tetrio}

Figure 1 shows the record of abdominal ventilatory movements in a giant pupa of Pseudosphinx tetrio. It can be observed that the abdomen made large contractions associated with shifting of the flexible abdominal segments from one side to the other with a periodicity close to $3 \mathrm{~min}$. The abdominal side movements made by the intersegmental muscles are so strong that they could destroy the sensor. To decrease the impact of the side movements, the measuring membrane of the sensor was attached to the abdomen by a long wire (Figure 2, insert).

Based on the schemes in Figure 2, we can calculate that the pupa of Pseudosphinx in Figure 3 (11.6 g, $80 \mathrm{~mm}$ long, and $381 \mathrm{~mm}^{2}$ cross section area of the middle abdominal segment) ventilated the tracheal system by large, $0.8 \mathrm{~mm}$ abdominal contractions in 3 min intervals. The movement of $381 \mathrm{~mm}^{2}$ area for $0.8 \mathrm{~mm}$ caused a $304.8 \mu \mathrm{l}$ of air passage through the spiracles at intervals of $3 \mathrm{~min}$ (expressed per unit of time it is $101.6 \mu \mathrm{l} / \mathrm{g} / \mathrm{min}$, or $6 \mathrm{ml}$ of air $/ \mathrm{g} / \mathrm{h}$ ). In addition to this, the record in Figure 3 shows that this ventilatory value could be further enhanced by the extracardiac pulsations that followed each large abdominal contraction $(0.05-0.1 \mathrm{~mm}$ pulses, 30 pulses per min, which yields 1.5 to $3 \mathrm{ml}$ of additional ventilatory air). These calculations were enhanced by separate respirometric measurements which showed that this pupa consumed $160 \mu 1$ of $\mathrm{O}_{2} / \mathrm{g} / \mathrm{h}$. This indicates that the pupa could easily satisfy its oxygen requirements by 7.5 to $9 \mathrm{ml}$ of the ventilatory air supply. 


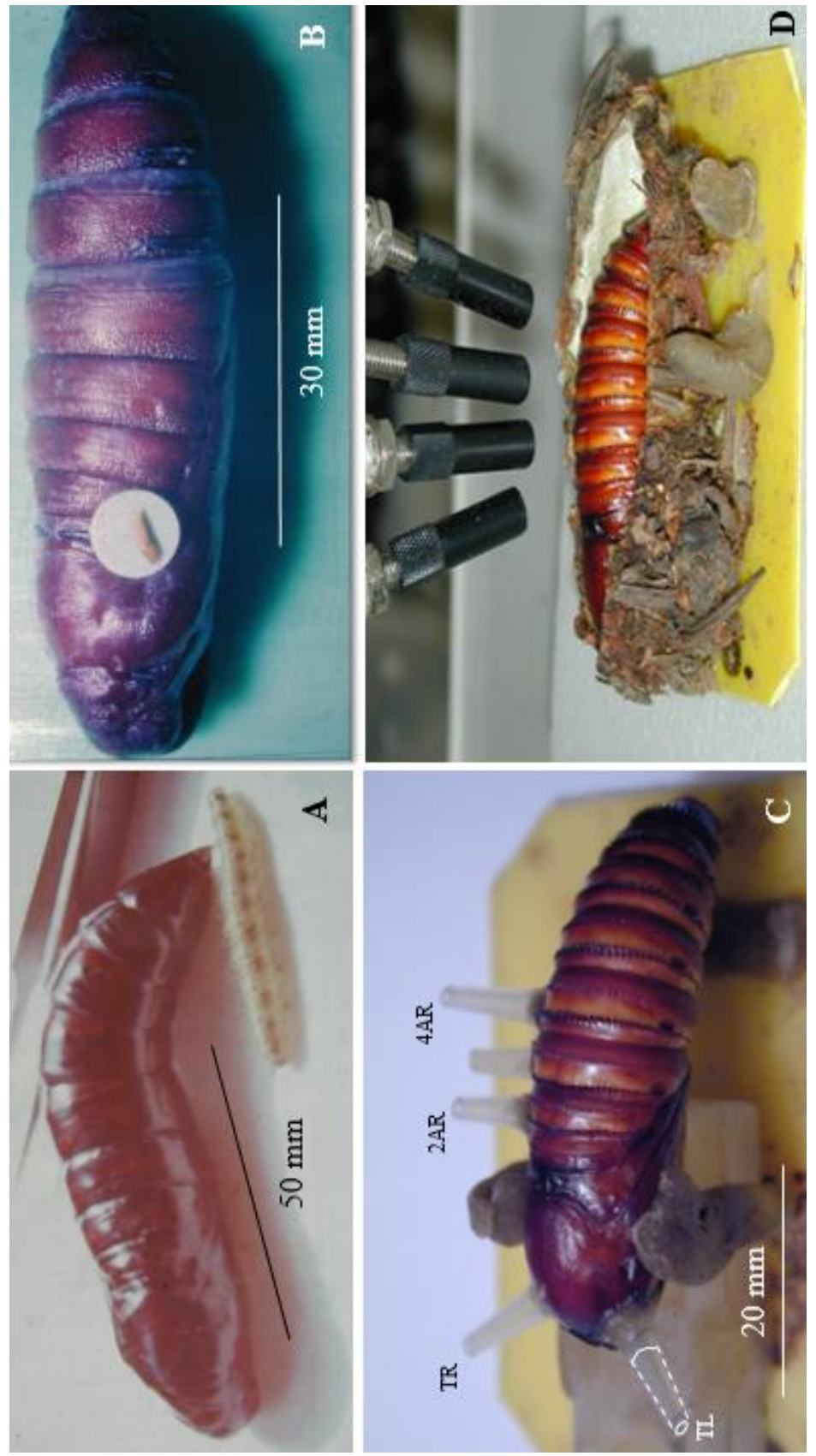

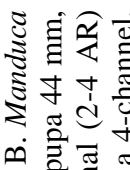

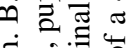

ธิ 乡ี

胥 000

들

ठ등

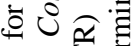
\& $ن$

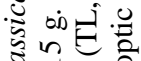
$\pm \overline{0} \cdot \frac{1}{1}$ ऊ0. ¿ 讨

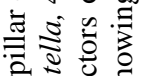
늉 ปี

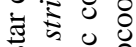
覀 ज : สิ 을 छ 昰击 उ oิ่ n : 二 छี है का

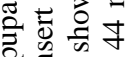
今. उ इ 0 ०

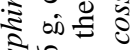
की छ ङ 20 0 $<$ 范

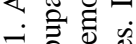
0 능

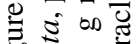

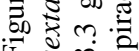



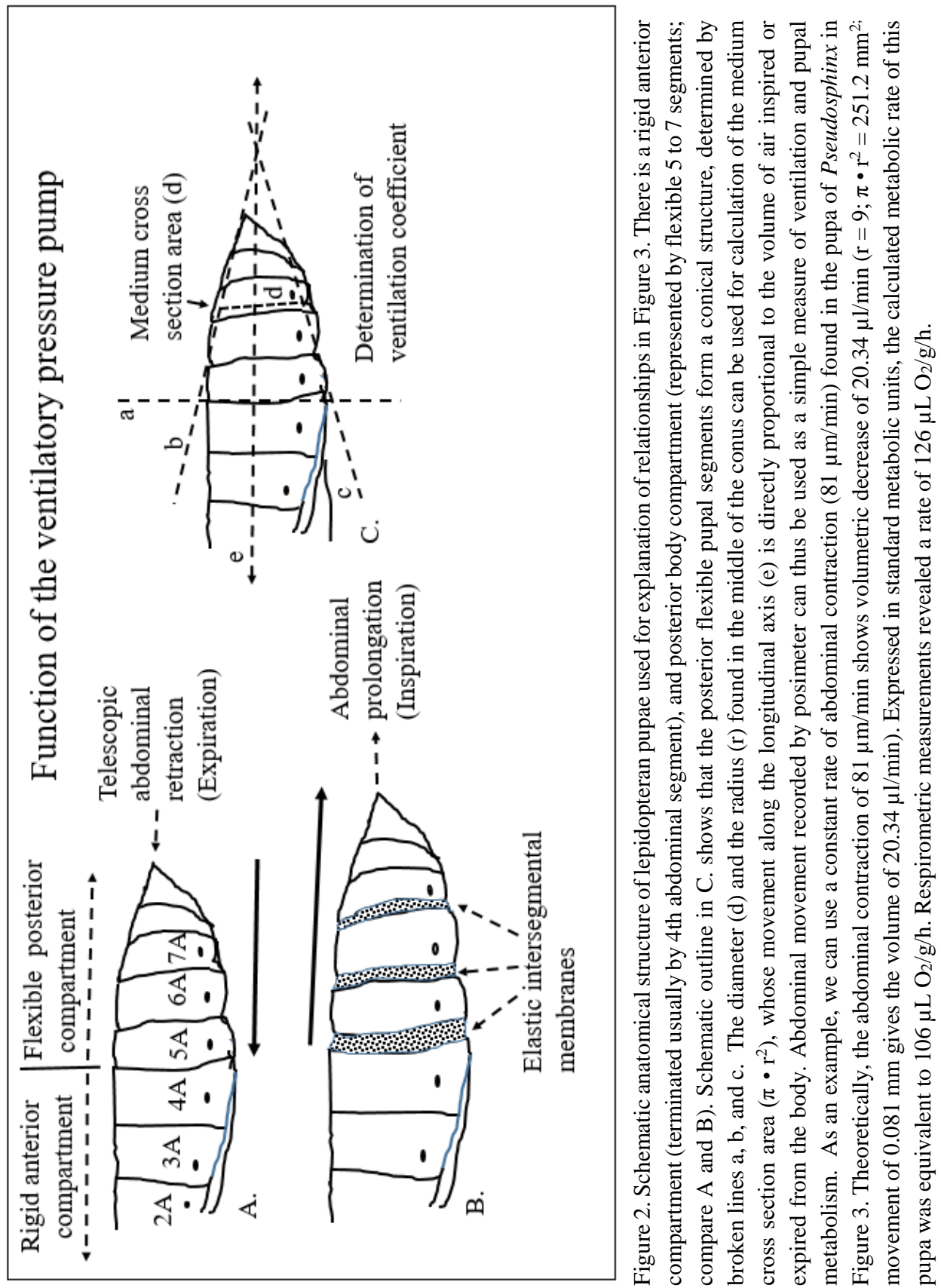
The record in Figure 3 also shows that the tip of the abdomen moved alternatingly from one side to the other. This relatively inconspicuous behavioural feature has large physiological importance in all sphingid pupae, which contain a series of large tracheal air sacs between spiracles 2 to 6 on each side of the body. The anatomical structure of these air sacs has been shown for the pupa of Manduca, later in the text (see Figure 6). It is obvious that a movement of flexible abdominal segments to one side compresses the air sacs on that side while simultaneously inflating air sacs on the contralateral side. The selective biological value of this ventilatory adaptation depends on the fact that: a) the gaseous $\mathrm{CO}_{2}$ is selectively ventilated out of the body, while; b) water vapour is resorbed and retained within the tracheal epithelium. This ventilatory arrangement helps diapausing lepidopteran pupae to survive 8 months of diapause without a water intake.

Figure 4 shows the record of abdominal movement of the same pupa as in Figure 3, at the time before the large abdominal contraction. The valves of certain spiracles are kept open. The air is flowing inside the body and abdomen gets slowly prolonged. This situation is common to pupae of all insects, which are maintaining subatmospheric internal pressures, usually from $-50 \mathrm{~Pa}$ to $-0.5 \mathrm{kPa}$. The phenomenon is due to continuous $\mathrm{O}_{2}$ consumption, while $\mathrm{CO}_{2}$ remains bound in the liquid carbonate buffers. The respiratory acidaemia produced by metabolic formation of carbonic acid is neutralized by discontinuous bursts of $\mathrm{CO}_{2}$. The imperative physiological function of the closed spiracles (facultative anaerobiosis) depends on prevention of the escape of water vapour from the body. When a pupa closes all spiracular valves, internal pressure develops a vacuum, which is directly proportional to the rate of $\mathrm{O}_{2}$ consumption. In the pupa of Pseudosphinx (Figure 4), the vacuum formation shows a constant rate expressed by abdominal retraction of $81 \mu \mathrm{m} / \mathrm{min}$. Using the relationships explained in Figure 2 and 3, we find that this rate of abdominal retraction corresponds to $30.86 \mu \mathrm{l} / \mathrm{min}$ $\left(81 \mu \mathrm{m} \times 381 \mathrm{~mm}^{2}\right)$ or $1.851 \mu \mathrm{l} / \mathrm{h} / \mathrm{pupa}$, which gives the calculated volumetric decrease of $159 \mu \mathrm{l} \mathrm{O}_{2} / \mathrm{g} / \mathrm{h}$ (respirometric measurements revealed $160 \mu \mathrm{l} \mathrm{O}_{2} / \mathrm{g} / \mathrm{h}$ ).

\section{Ventilatory movements in pupae of Manduca sexta}

In Manduca sexta, we have measured many pupae either developing or diapausing. During the last two decades, one of us (K.S.) has performed multiple recordings of ventilatory movements, heartbeat, haemocoelic pressure, and respirographic measurements (for references see discussion). We found that there was no average pupa and the results pertaining to regulation of autonomic physiological functions can be best expressed only by values related directly to the investigated pupa. Here we show selected graphs that best represent the given method. 


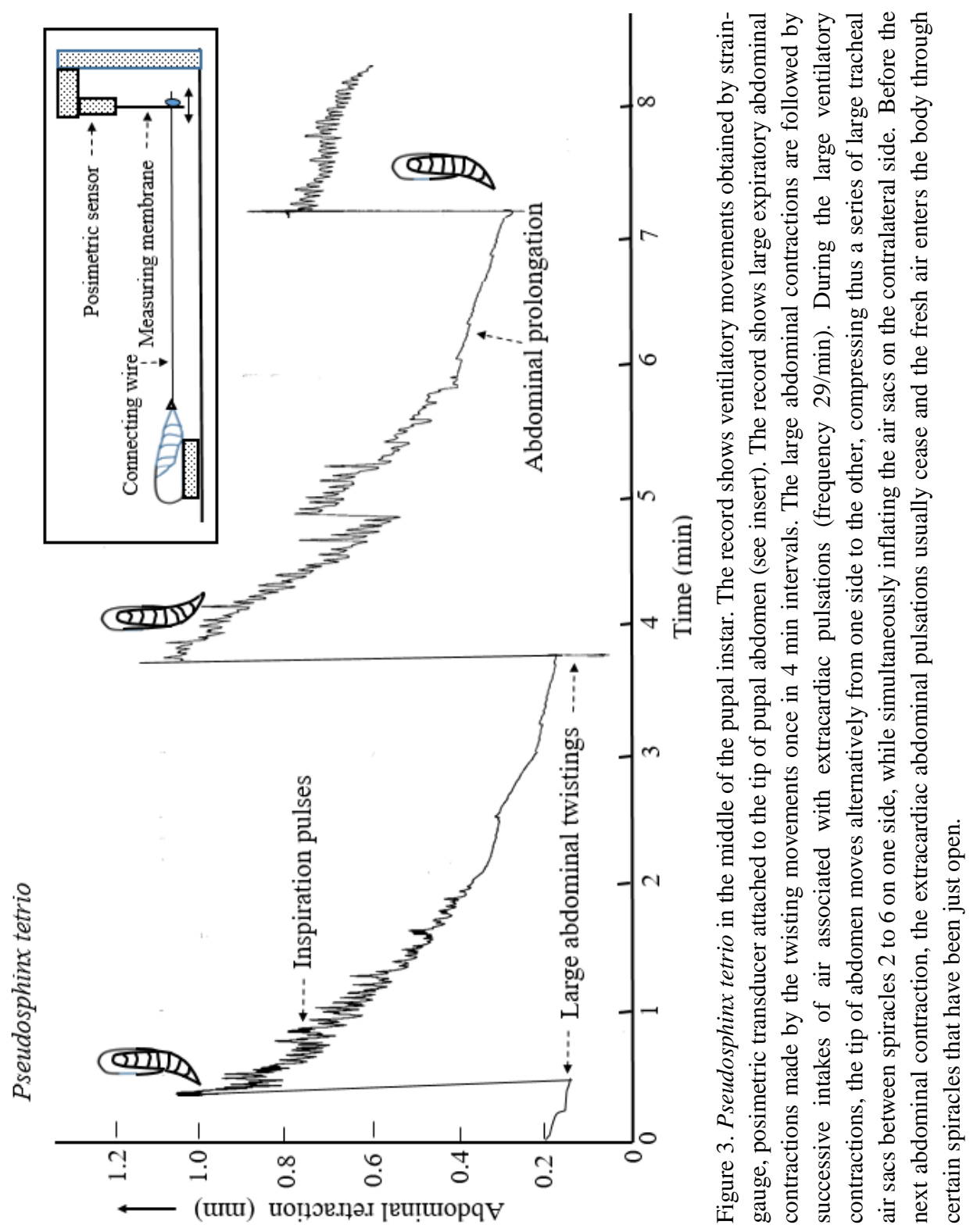




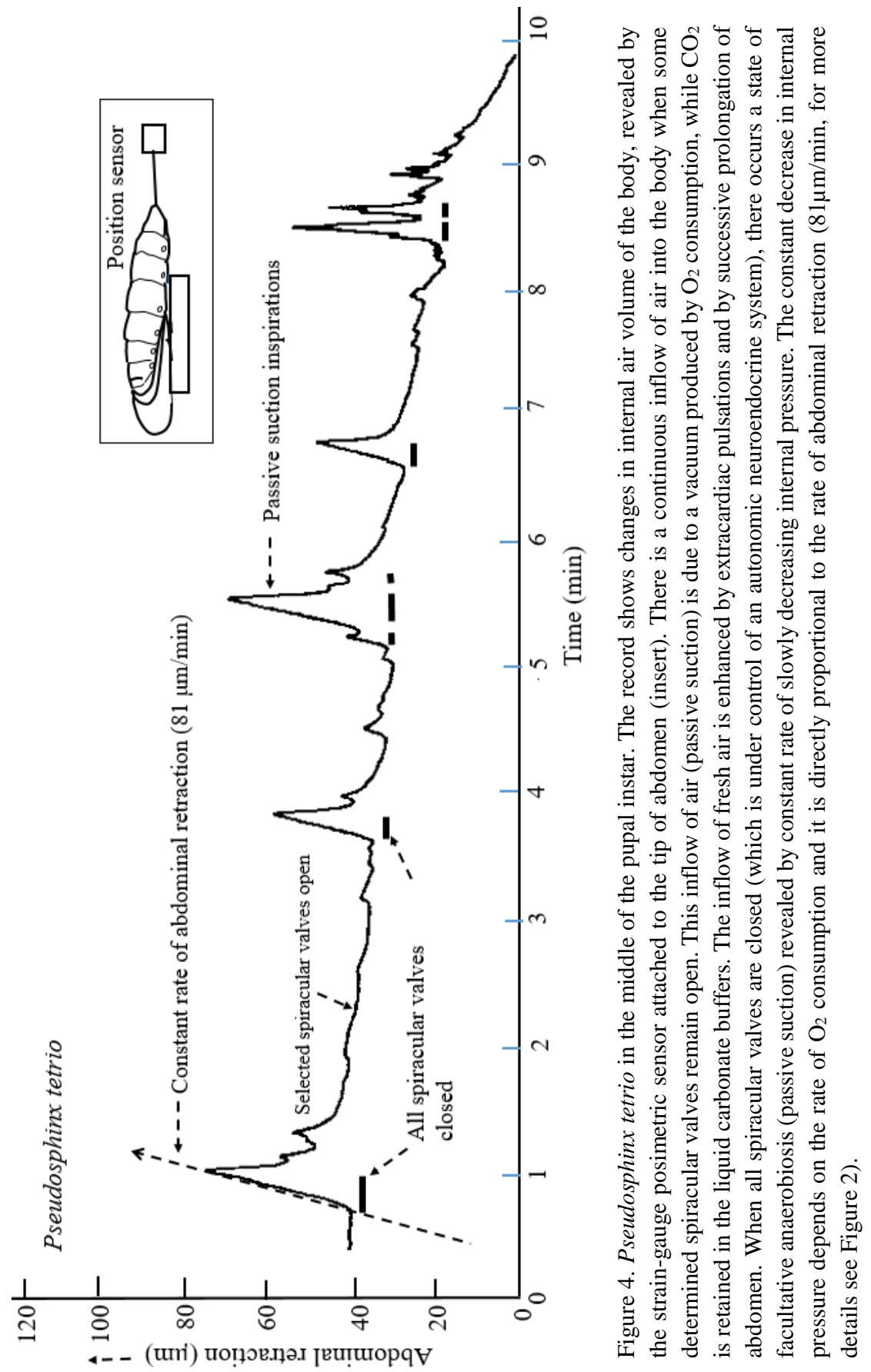




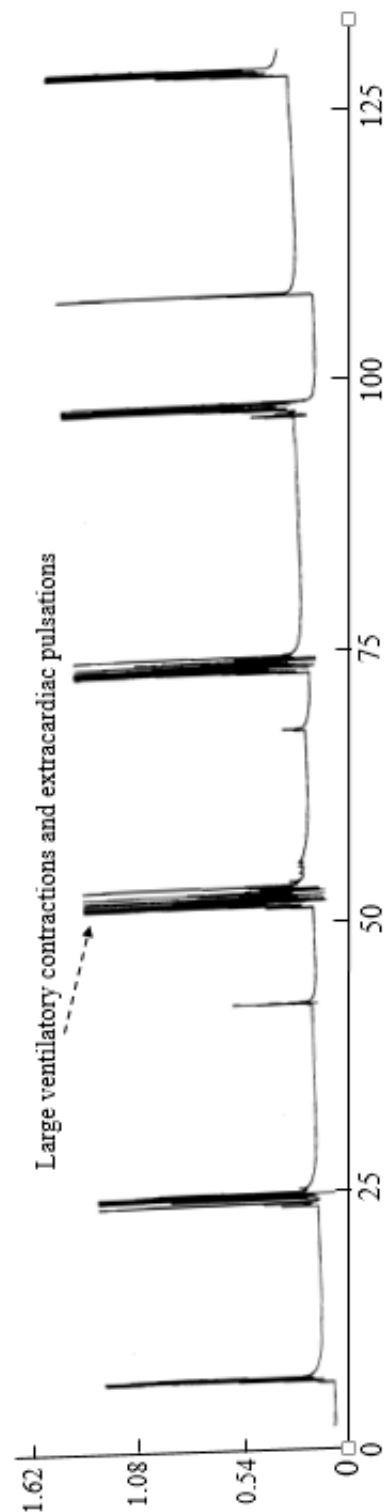

(แน) ]นวшวАош [еш!шорqV

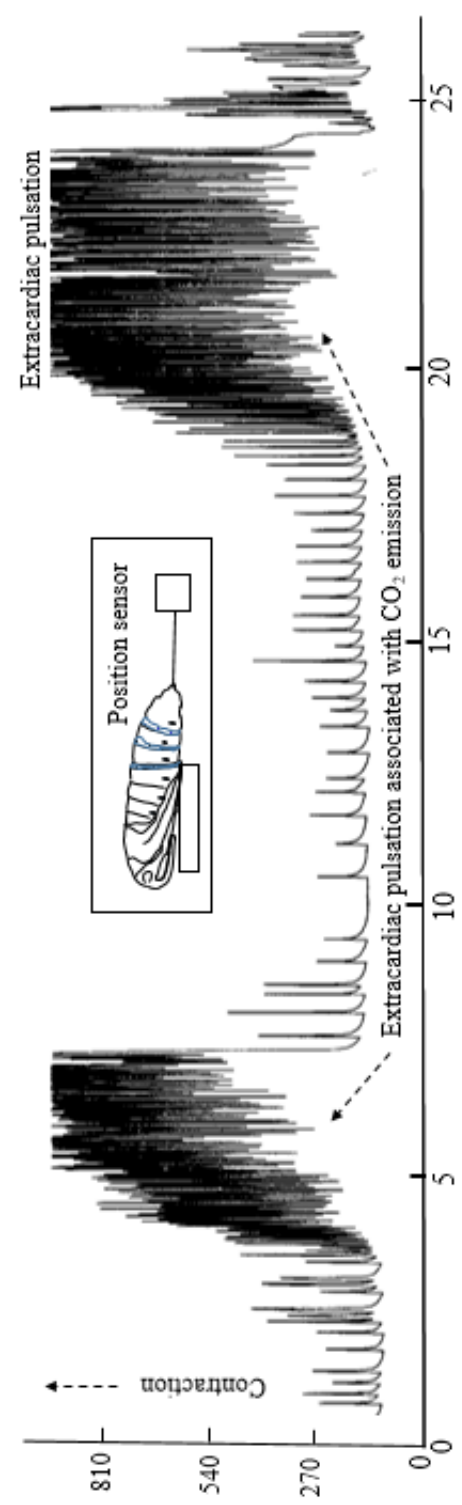

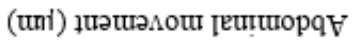

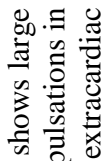

융.

记

艺这芯

ن ठٓ

กิ

흉 믕

$\exists=$

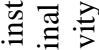

을 융

范

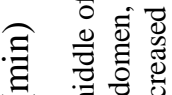

छ

ఏ

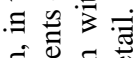

ह ฮ ฮี

छ

6 웡

oî on

ㄱ. $\cong . \Xi$

范

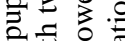

에

卷它

은 혼

ठ웡

สิ

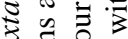

ธิ

ธ

跣

융

$\sum \geqslant$ ?

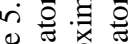

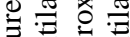

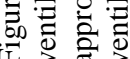


Figure 5 (previous page) shows large ventilatory abdominal contractions in a developing pupa of Manduca sexta. As in the pupae of Pseudosphinx (see Figures 3 and 4), the periodically repeated large ventilatory movements of Manduca are also produced by contractions of flexible abdominal segments. However, there are not only the shifts of the abdomen from one to the other side, but occasionally, the abdomen performs extensive ventilatory movements when disturbed. The lower record in Figure 5 shows that in between the periodically repeated abdominal rotations there appear extracardiac pulsations, enhancing the inefficient tidal tracheal ventilation by unidirectional ventilatory air streams.

The exact physiological role of abdominal contractions and extracardiac pulsations can be better understood if one is familiar with the anatomical structure of the pupal tracheal system. Figure 6 shows that there are extremely large air sacs on each side of the pupal abdomen. These sacks, which can be inflated or deflated repeatedly by side movements or contractions of the abdomen, are associated with large peaks in haemocoelic pressure, which was previously known as contractions of the abdominal pressure pump. The air sacks are washed from outside by haemolymph whose $\mathrm{pH}$ is buffered by carbonate ions. Epithelial cells of the air sacs do not form taenidia but are arranged in a special cellular network that can expand and collapse again and move the air in or out of the body (like the bellows of an accordion). The internal layer of the sacks shows strong water absorbing and repellent capacity, with occasional presence of droplets of the liquid or solid congregations. The air sacs represent a resource of oxygen when spiracular valves are constricted, partial pressure of $\mathrm{O}_{2}$ falls and that of $\mathrm{N}_{2}$ rises. Tracheal air sacs, together with a large air-filled cavity under the wing lobes (containing the inverted first abdominal spiracles) represent a very important evolutionary adaptation, increasing survival of the pupae during prolonged periods of flooding.

Figure 7 shows the characteristic extracardiac pulsation in a developing pupa. The pulsations provide a very efficient and inconspicuous ventilation arrangement. In pupae of Manduca, which are relatively large specimens (6 g body mass, $60 \mathrm{~mm}$ long) extracardiac pulsations have the frequency close to 30 pulses per min, at room temperature, and their amplitude expressed by abdominal movement is rather small ( 0 to $5 \mu \mathrm{m}$ in Figure 7 ). This shows that the movement is too small to be perceived by a naked eye. The enhancement of ventilatory functions by extracardiac pulsations becomes evident after considering that a few selected spiracles can be efficiently used for repairing hypoxia or hypercapnia at the determined sites of the body. In diapausing pupae of Manduca, extracardiac haemocoelic pulsations are absent or occur only during the 20 min periods of $\mathrm{CO}_{2}$ outbursts (occasional periodicity once in 12-16 hours). 


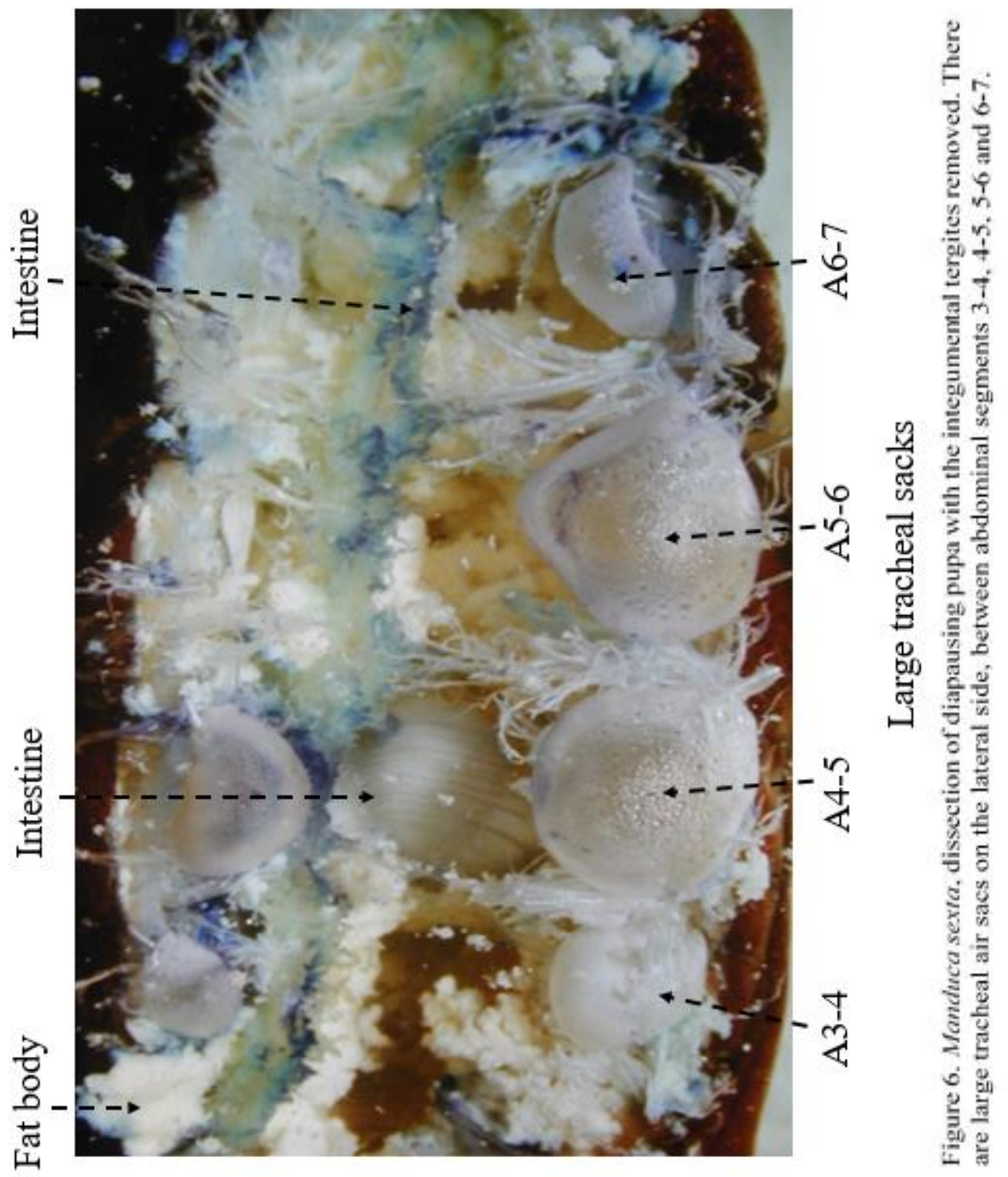




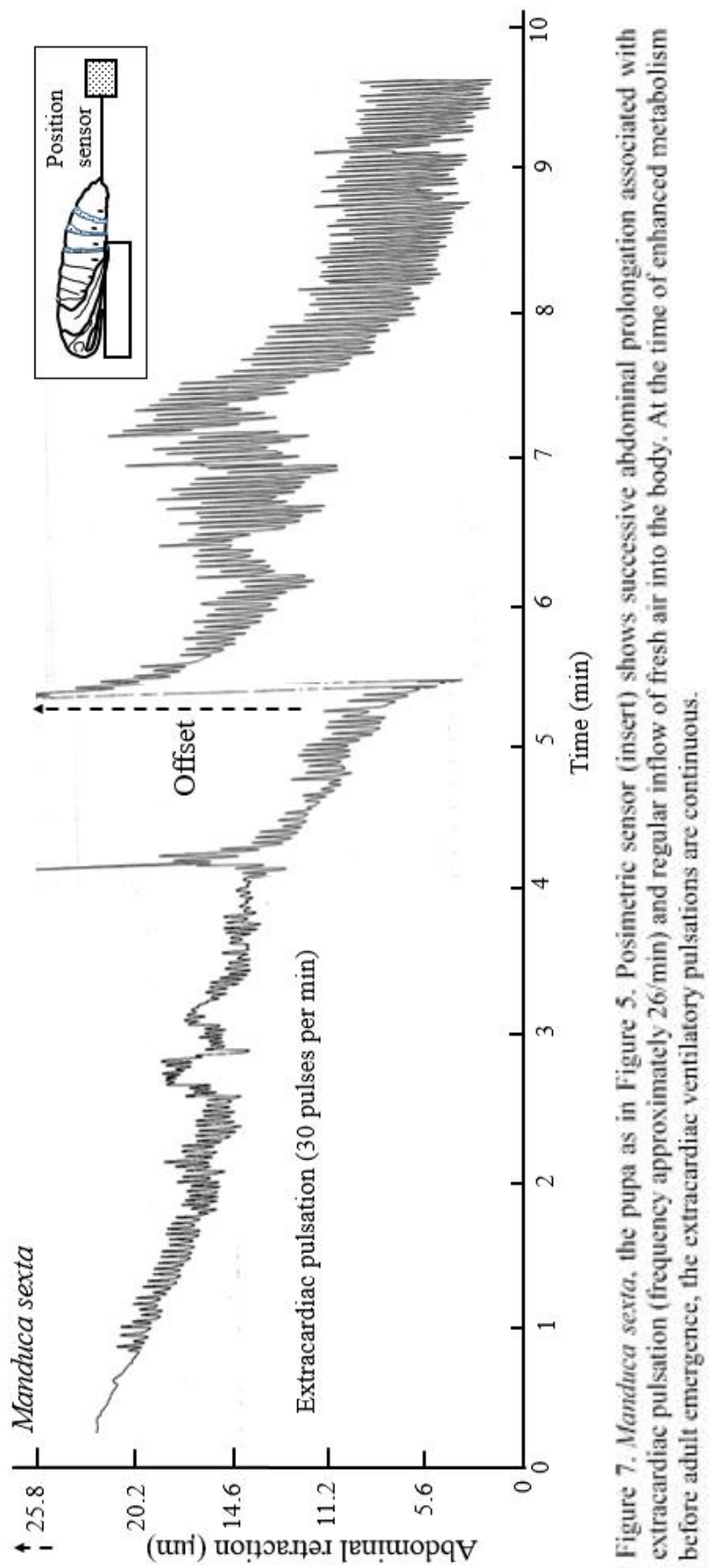


In contrast to myogenic pulsations of the heart, extracardiac pulsations are neurogenic, integrated by a cholinergic neuromuscular system (coelopulse) with the nerve centers located in thoracic ganglia of the ventral nerve cord. Although functions of the coelopulse system have been known for a long time, however, a mechanism that decides which spiracles will function and when remains still unknown.

Figure 8 provides an example of the characteristic respiratory pattern found in diapausing pupae of most lepidopteran insects. The upper record shows changes in haemocoelic pressure recorded by hydraulic transducer from the body cavity. The record shows the typical "saw-tooth" pattern caused by development of a vacuum when all spiracles have been closed and sudden inspirations when the spiracular valve of the determined spiracle flutters for $250 \mathrm{~ms}$. In Figure 8 the spiracular valve fluttered at approximately one min intervals (previously published evidence indicated that the master spiracle was the left side thoracic spiracle; see Discussion). Formation of the vacuum in Figure 8 was regulated within a rather constant range of $100-200 \mathrm{~Pa}$ of subatmospheric pressure. The "saw-tooth" patterns in haemocoelic pressure are inverted mirror images of abdominal movements (compare Figure 4, 8A, and 9B). The lower record in Figure 8 shows one complete heartbeat cycle, with the frequency of myocardial contractions much lower (retrograde pulse10, anterograde pulse 16 per min) in comparison with extracardiac pulsations (about 30/min). Before their discovery, the much stronger extracardiac pulsations were confused with the heartbeat. In diapausing pupae, there are long resting periods of extracardiac pulsations, which are sometimes coincident with the diastolic rest of the heart. During the bouts of pulsation activity, the two frequencies usually intermingle.

Figure 9A shows that the "saw-tooth" pattern of passive inspirations may proceed at different internal pressures. The increased vacuum is needed for faster air inflow, presumably through the narrower abdominal spiracles. Lower record in Figure 9B shows a mirror image of the "saw-tooth" pattern in haemocoelic pressure (Figure 8A). The diapausing pupa in Figure 9B. had a very low $\mathrm{O}_{2}$ consumption, owing to a very low, $2.2 \mu \mathrm{m} / \mathrm{min}$ constant rate of abdominal retraction. Using calculations from Figure 2 and 3, the standard metabolic rate of this pupa should be equivalent to $3.4 \mu \mathrm{l} \mathrm{O} / \mathrm{g} / \mathrm{h}$, which indicates a deep diapause. 


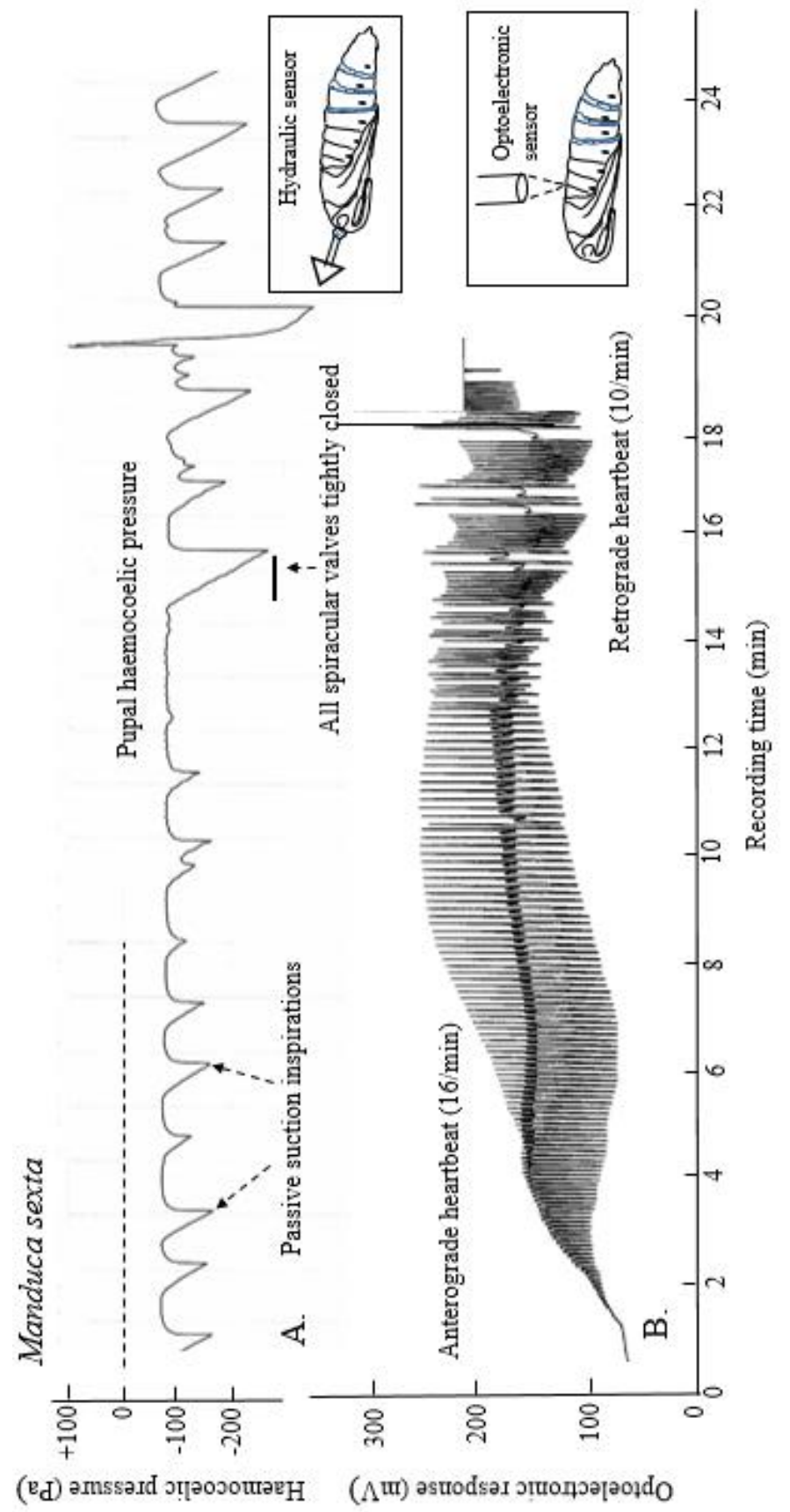

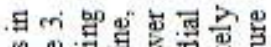

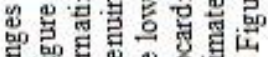

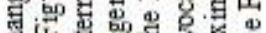

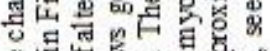
诸岁的的

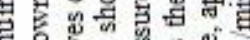

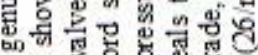

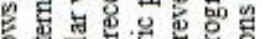

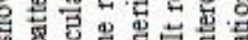

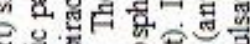

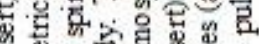

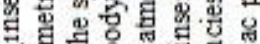

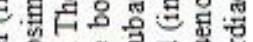

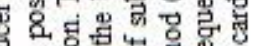

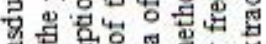

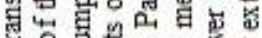

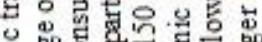

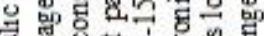

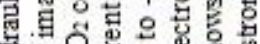

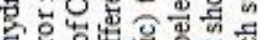
๙

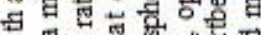

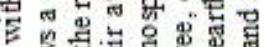
ध

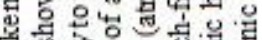
要

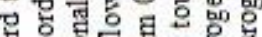
实安

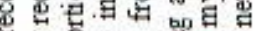

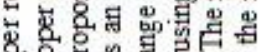

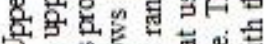

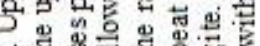

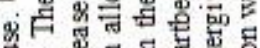

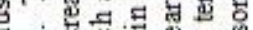

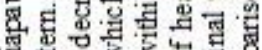

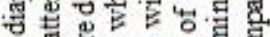

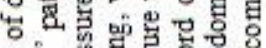

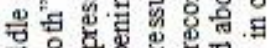

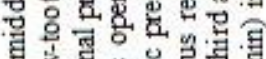

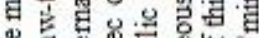

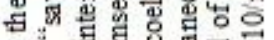
田

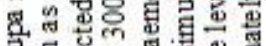

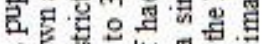

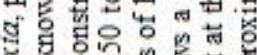

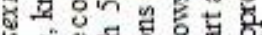

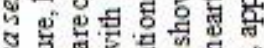

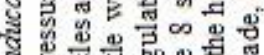

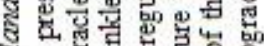

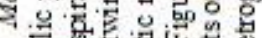

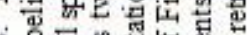

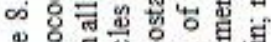

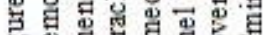

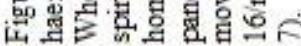




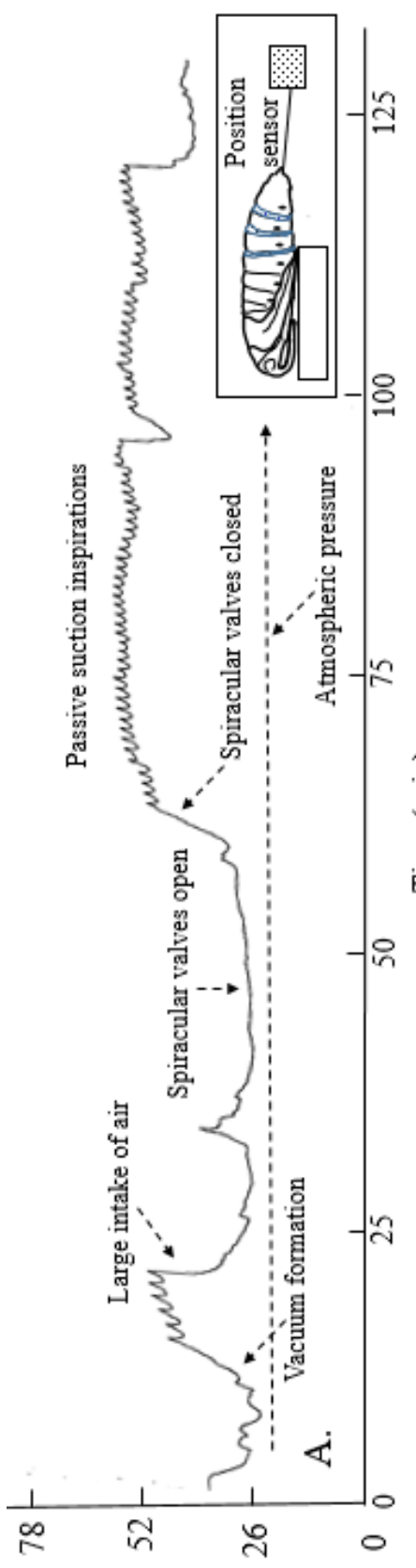

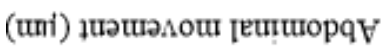

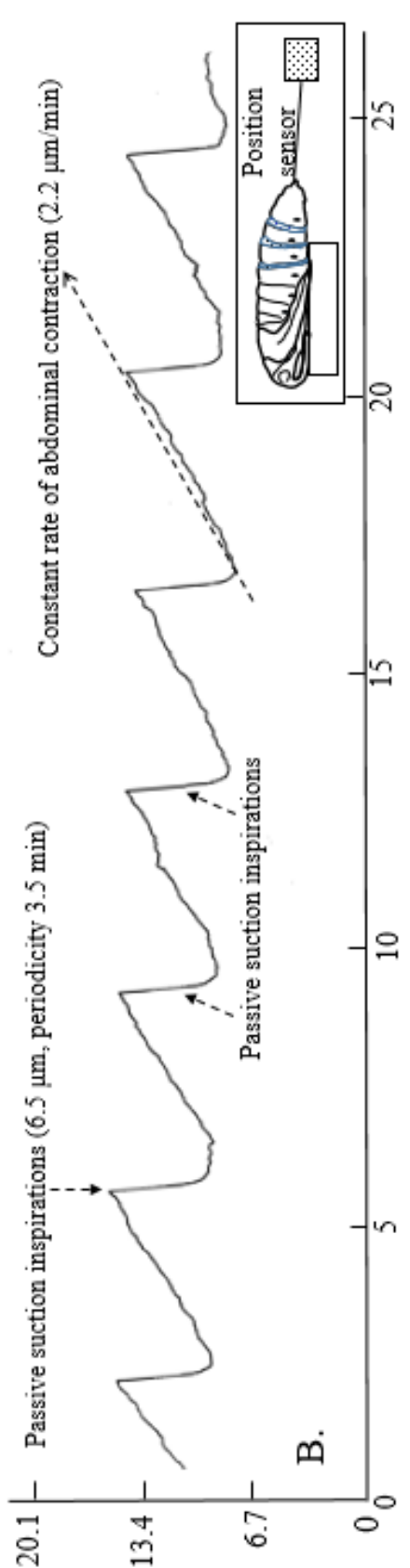

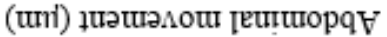

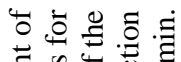

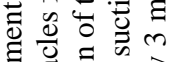

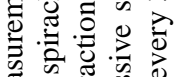

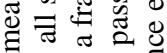
잉 들

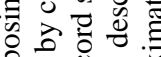
卷造 हैं के

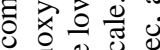

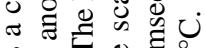
눌 0. 원 क.

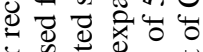

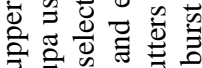
$\exists$

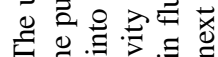
萛 의 嵌

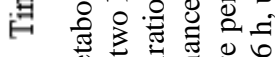
屯녕

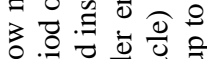

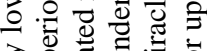

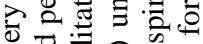
政 业

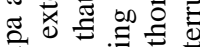
亏 $\Xi$ :

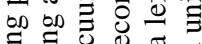

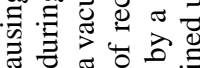

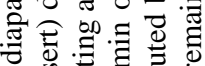

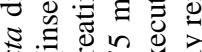

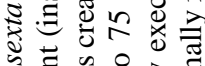

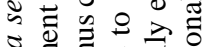
(5)

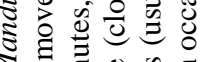

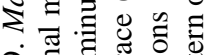

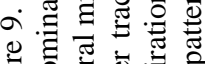

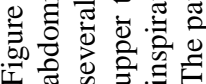


Originally, we thought that this type of prolonged pupal survival at the lowest metabolic rates could represent an exceptional case of insect respiration without the ventilatory movements. The pupae contain resources of air in the tracheal air sacs plus the cavity under the wing lobes (estimated to be $280-320 \mu$ of air), which represents an internal resource of oxygen for more than one hour of the pupal life (i.e., $300 \mu \mathrm{l}$ of internal air contains $60 \mu \mathrm{l}$ of $\mathrm{O}_{2}$; the $6 \mathrm{~g}$ pupa with $\mathrm{O}_{2}$ consumption of $3.4 \mu \mathrm{l} \mathrm{O}_{2} / \mathrm{g} / \mathrm{h}$, see Figure $9 \mathrm{~B}$; consumed $39 \mu \mathrm{l} \mathrm{O}_{2} / \mathrm{h}$ ). The prolonged posimetric recordings of the pupa shown in Figure 9B, however, revealed that even in this case of the lowest metabolic rates, the pupa performed regular ventilatory movements with the periodicity of 40 pulses per min.

Figure 10 gives an example of direct respirographic recording of $\mathrm{O}_{2}$ consumption in another diapausing pupa of Manduca. This pupa had higher $\mathrm{O}_{2}$ consumption, $3.3 \mu \mathrm{l} \mathrm{O}_{2} / \mathrm{min}\left(=198 \mu \mathrm{O}_{2} / \mathrm{h}\right.$, or $\left.17.2 \mu \mathrm{l} \mathrm{O} / \mathrm{g} / \mathrm{h}\right)$. The pupae of Manduca are too large for microrespirographic measurements. They require large respiratory vessels to supply more $\mathrm{O}_{2}$ at the start of the recordings. The advantage of this method is relatively high sensitivity but a disadvantage of this constant volume respirometric system is that the partial pressure of $\mathrm{O}_{2}$ decreases, while relative partial pressures of $\mathrm{N}_{2}$ and $\mathrm{CO}_{2}$ increase.

The scanning respirographic records in Figure 10 (respiratory vessel of $30 \mathrm{ml}$ capacity, $200 \mu \mathrm{l}$ of $2.5 \% \mathrm{KOH}$ for $\mathrm{CO}_{2}$ absorption) show 4 considerably attenuated bursts of $\mathrm{CO}_{2}$ due to the presence of $\mathrm{KOH}$. Despite the rapid $\mathrm{CO}_{2}$ absorption, the records show that the gaseous $\mathrm{CO}_{2}$ was suddenly released by a bulk-flow from the liquid buffers, not by diffusion. During the recordings, partial pressure of $\mathrm{CO}_{2}$ was low due to the absorbent, however, the partial pressure of $\mathrm{O}_{2}$ successively diminished due to $\mathrm{O}_{2}$ consumption of the pupa. The lower record in Figure 10 shows the effect of the slowly developing hypoxia. After $180 \mathrm{~min}$ of recording within the closed respiratory compartment, the rate of $\mathrm{O}_{2}$ consumption successively diminished to $1.7 \mu \mathrm{l} / \mathrm{min}$. The pupa apparently recognised the developing hypoxia and started vigorous ventilatory abdominal contractions visible as instant peaks of reduced pressure. The fact that these contractions are visible in the respirograph documents that the large ventilatory expirations of air, that have been described in the previous sections, should be associated with the foregoing compression of air inside the haemocoelic cavity. 


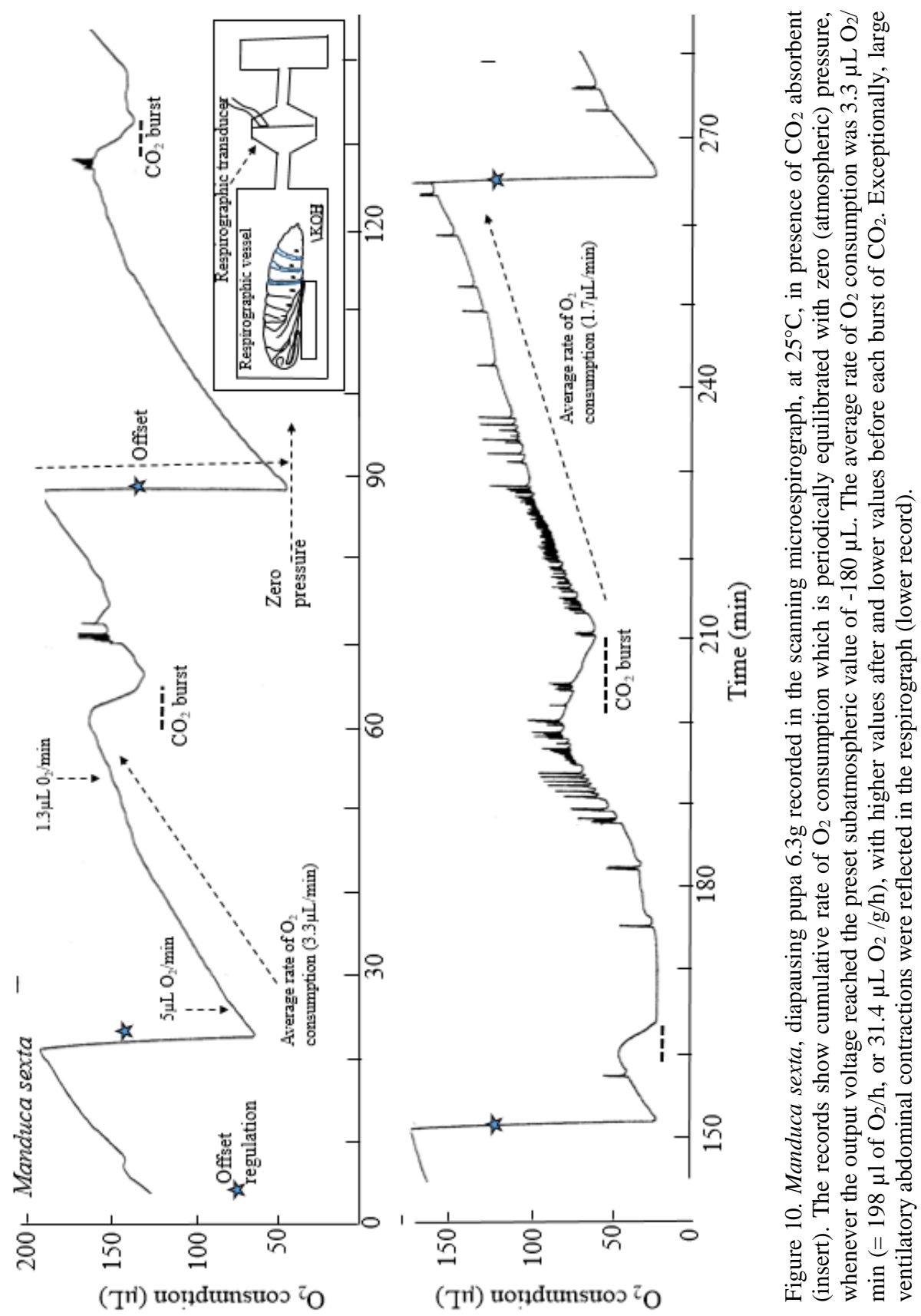




\section{Ventilatory movements in larvae and pupae of Cossus cossus}

We would like to mention here that the immobile stages of Cossus were used by Krogh (1920) as pivotal experimental evidence to show that insects did not perform any ventilatory movements and that their breathing was dependent on a simple gaseous diffusion. Although there appeared serious arguments in the literature against general validity of this "Krogh's diffusion theory of insect respiration," the main arguments based on the stages of Cossus resisted the challenges for almost a hundred years. One reason was that there was no experimental data, because Cossus became a rare, almost inaccessible species. However, we obtained during the past three decades six specimens of mature larvae of Cossus, which pupated and were subjected to examination of their respiratory functions.

In Figure 11 we show a special posimetric technique for recording the ventilatory contractions in the fully-grown caterpillar. Lepidopteran larvae are very soft and elastic. To perform a change in internal pressure, all muscles of the subcutaneous muscular sheath need to contract in unison. If only one segment would fail to contract, a pressure change will not be possible and the animal would die. In Figure 11, the posimetric transducer records external movements of the body segments (see insert). In response to an increase of internal pressure, the elastic abdominal segments expand, which is recorded by the sensor located on the integumental surface. Figure 11 provides experimental evidence that the immobile prepupa of Cossus exhibited a continuous series of ventilatory contractions, with a periodicity of $11 / \mathrm{min}$ and the amplitude of individual contractions $110 \mu \mathrm{m}$. When related to the whole body, there would be $21 \mathrm{~mm}$ contraction in one minute, which could be sufficient to enable ventilation of all nine pairs of the spiracles and satisfy the demands for $\mathrm{O}_{2}$ consumption of the caterpillar.

It is obvious that Krogh was unable to see the tiny, $110 \mu \mathrm{m}$ ventilatory contractions of individual segments with a naked eye. However, there was another argument used by Krogh to show that there were no ventilatory movements in Cossus. He intubated one spiracle with a tubing and submerged the larva under water. A meniscus of the liquid droplet introduced into the tubing did not show any movement. In this case A. Krogh was right. We repeated this experiment using our sensor and found that both caterpillars and pupae of Cossus almost immediately recognised the impairment of spiracular functions by water submersion. As a result, they arrested all extracardiac ventilatory contractions, although heartbeat might continue for a long time. Obviously, the fact that there were no ventilatory movements under water was correct, but a 100-year long traded generalization about the absence of ventilatory movements was false, as it is documented by the record presented in Figure 11. 


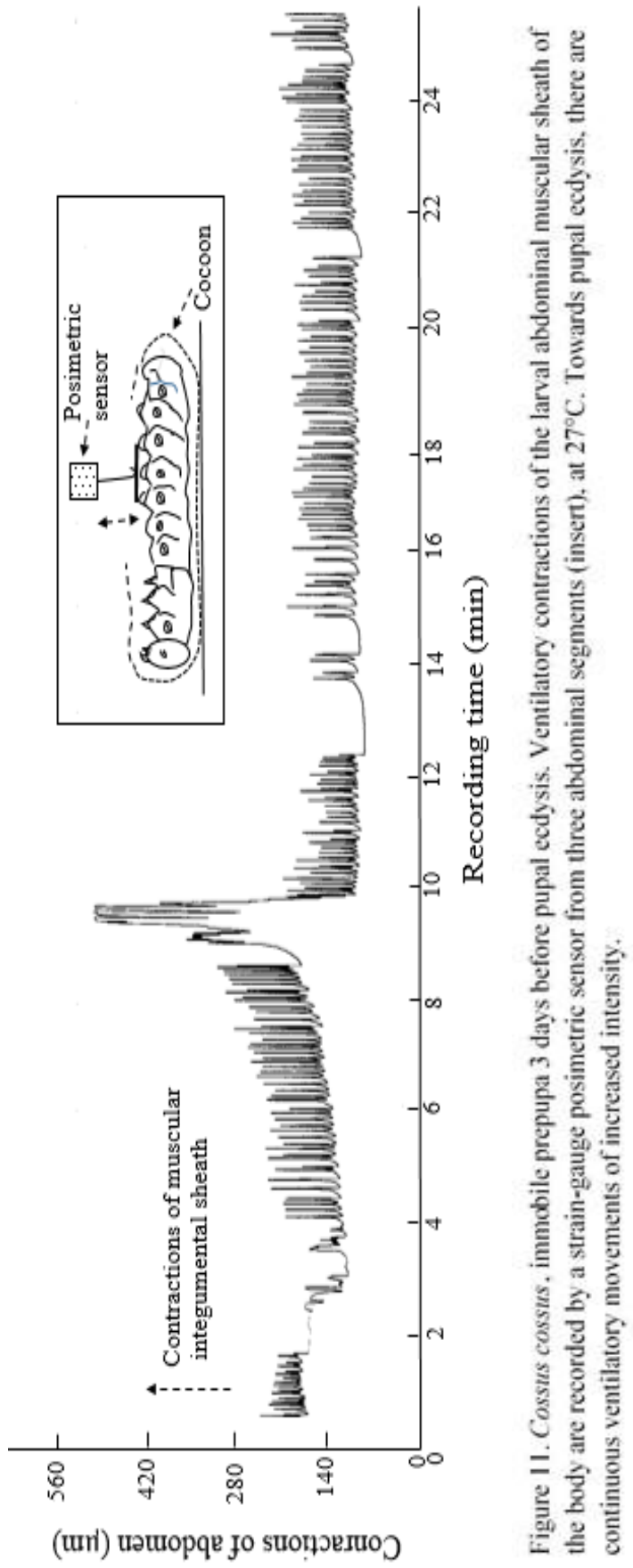


Figure 12 shows a touch-free, optoelectronic record documenting the presence of series of regular ventilatory abdominal movements in a developing pupa of Cossus. This becomes evident on the upper record of Figure 12, which shows periodically repeated, extracardiac pulsations of frontal abdominal tergites with the intercalated, large abdominal contractions. Lower trace in Figure 12 shows a small fraction taken from a prolonged record of $\mathrm{CO}_{2}$ release. It shows continuous, up and down, oscillations in $\mathrm{CO}_{2}$ release without the discontinuous $\mathrm{CO}_{2}$ bursts. Curiously enough, there was no change in $\mathrm{CO}_{2}$ output during the periods of extracardiac pulsations, suggesting $\mathrm{CO}_{2}$ emission is independent from the ventilatory movements. A working hypothesis, which needs to be further confirmed, suggests that the gaseous $\mathrm{CO}_{2}$ is continuously formed and leaves the body by a bulk outflow from the selected spiracles.

Figure 13 provides evidence that the cardiac and extracardiac pulsations are substantially different, albeit they sometimes occur during the common periods. The neurogenic, extracardiac pulsations have a much larger impact on haemocoelic pressure (sometimes 100-fold higher) in comparison with the myogenic heartbeat. In Figure 13 the difference was diminished by focusing the concentric beam of the pulse light directly on the pulsating myocardium. In this case, the sensor shows the characteristic series of retrograde heartbeat (until min 8 ), which is followed by a mixture of faster anterograde heartbeat and much faster extracardiac pulsation.

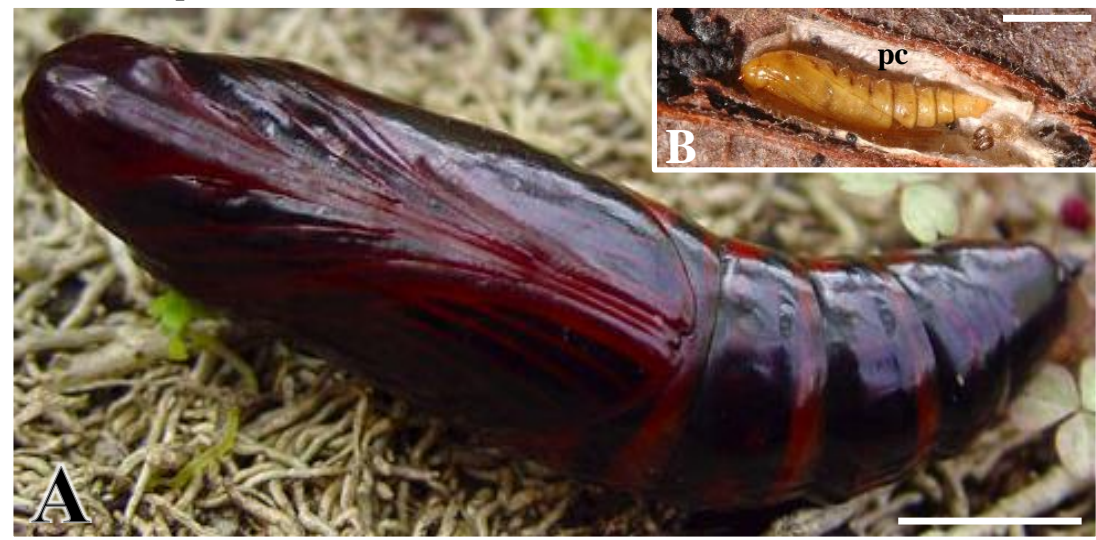

Extreme size range in lepidopterous pupae. A. Pseudosphinx tetrio on soil [circa 2.5 inches, or circa $64 \mathrm{~mm}$, long (Adam Chin-Lee personal communication to Santiago-Blay, 16 March 2017), scale bar $=10 \mathrm{~mm}$ long]. B. Phyllonorycter strigulatella in a pupal chamber (pc, scale bar $=1 \mathrm{~mm}$, rectangular insert). Collection data: A. Boca Raton, Florida, 3 May 2003. Image courtesy of Alan Chin-Lee, http://www.silkmoths.bizland.com/ptetrio.htm . B. Switzerland, Bern, Cortébert, 1260 m, Hochmoorwald, 5 October 2006 (Studiofoto: Rudolf Bryner), reared and identified by Rudolf Bryner http://www.lepiforum.de/lepiwiki.pl?Phyllonorycter_Strigulatella. Both images and collection data reproduced with permission of the copyright owners. In the case of these images, which were not the specimens studied, the calculated volume difference is, approximately, 37000x. 


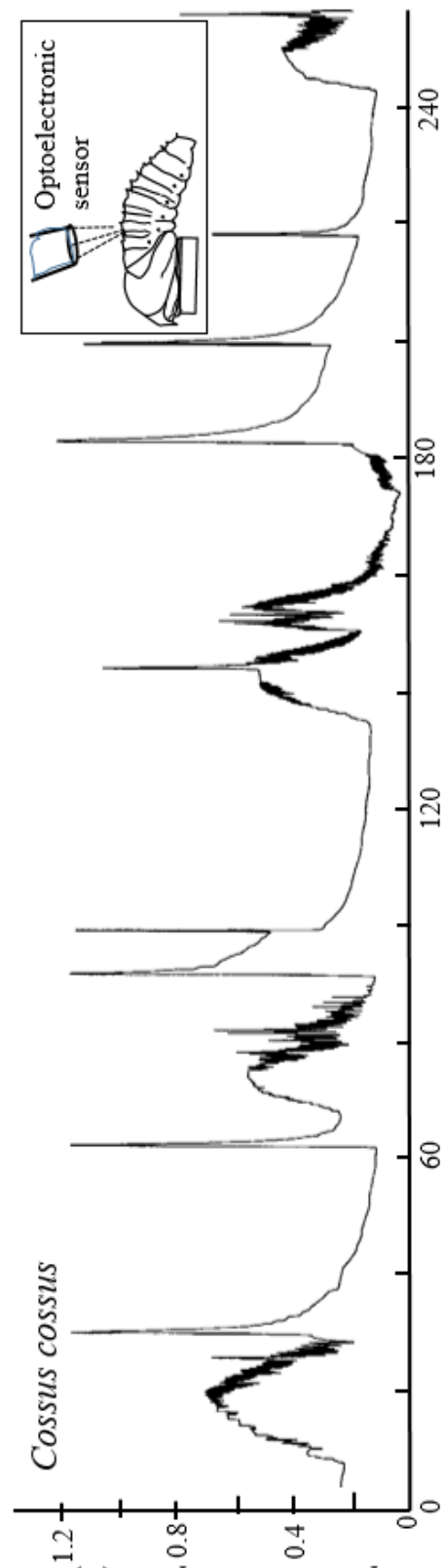

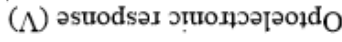
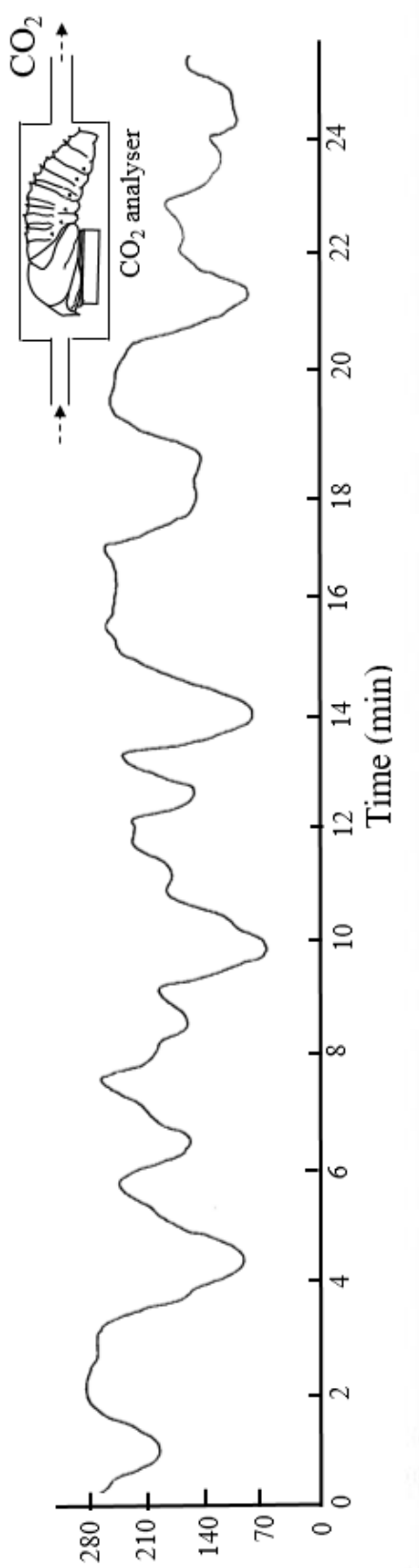

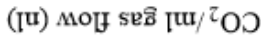

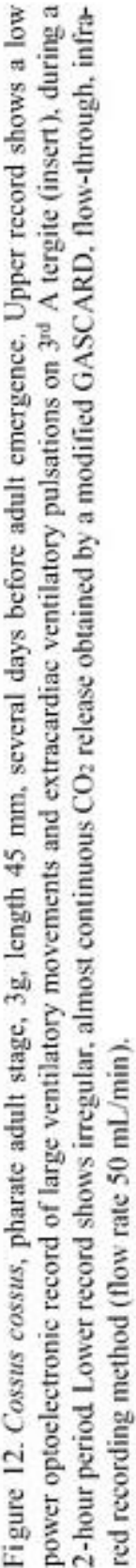




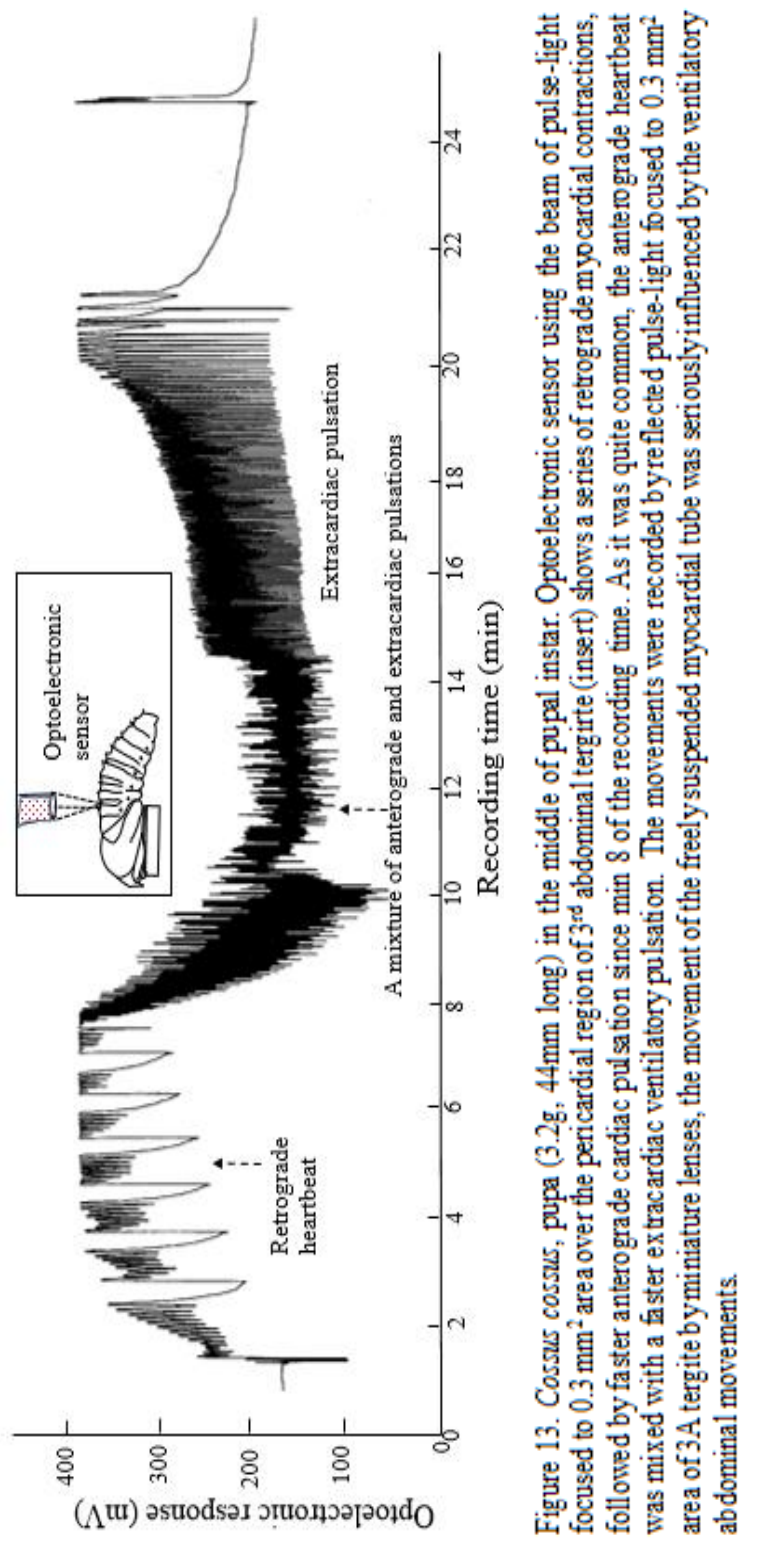




\section{Microanemometric recording of inspirations and expirations through spiracles}

Insect pupae respond to artificially closed spiracles by opening the spiracular valves. It is thus impossible to record spiracular functions by sensors which close the passage of air through spiracles. To avoid this obstacle, we developed in 1988 a microanemometric method for simultaneous monitoring of openings and closures of up to eight spiracles, without closing the passage of air (Sláma 1988). In pupae of Cossus (Figures 14 and 15) we have monitored only three spiracles (TL, TR, 2AR; see insert in Figure 15 and the connectors in Figure 1C) located on the rigid, anterior body compartment. The inspirations (upward peaks) and expirations (downward peaks) were monitored simultaneously with movements of the abdominal pressure pump (bottom trace). The pupa in Figure 14 occurred in the middle of the pupal instar, at a time of minimum metabolic intensity and the recordings were made during the resting period between extracardiac pulsations. It can be observed in Figure 14 that this pupa predominantly inspired air (upward peaks) through all spiracles of the anterior body compartment. Moreover, the gulps of air intake were coincident with the contraction of the abdomen (bottom trace). However, some inspirations were independent from the abdominal movements, corresponding evidently to passive suction inspirations described in the previous sections. Unfortunately, we do not know the responses of spiracles located on the posterior, abdominal compartment. We can speculate that the spiracles on the posterior part of the body fluttered in the inverted phase of haemocoelic pressure, which would cause a unidirectional stream of air through the longitudinal tracheal system.

The recordings shown in Figure 14 were repeated several times with basically the same results. This finding led us to assume that the spiracles located on the anterior body compartment might be perhaps only inspiratory. However, this assumption proved to be false because, as will be shown below, the pupa can open or close spiracular valves in $150 \mathrm{msec}$ flutters and synchronize the stream of air with the up or down strokes of the abdominal pump. Figure 15 documents that the statements were true by using the advanced pupa or pharate adult stage with the increased metabolic intensity (consumption of $920 \mu \mathrm{O} \mathrm{O}_{2} / \mathrm{g} / \mathrm{h}$ for pupa in Figure 15, in comparison to $470 \mu \mathrm{l} \mathrm{O}_{2} / \mathrm{g} / \mathrm{h}$ for pupa in Figure 14).

The records in Figure 15 show that the almost continuous extracardiac pulsations and the direction of individual ventilatory strokes were expiratory (pointing downwards from the midline). These results strongly oppose the 100year-old doctrine claiming that the immobile stages of Cossus do not exhibit ventilatory movements. In contrast to this assumption, we have found beautiful concerts of ventilatory inspirations and expirations of air. This statement can be further supported by high resolution, nanoanemometric recordings described in the following sections. 


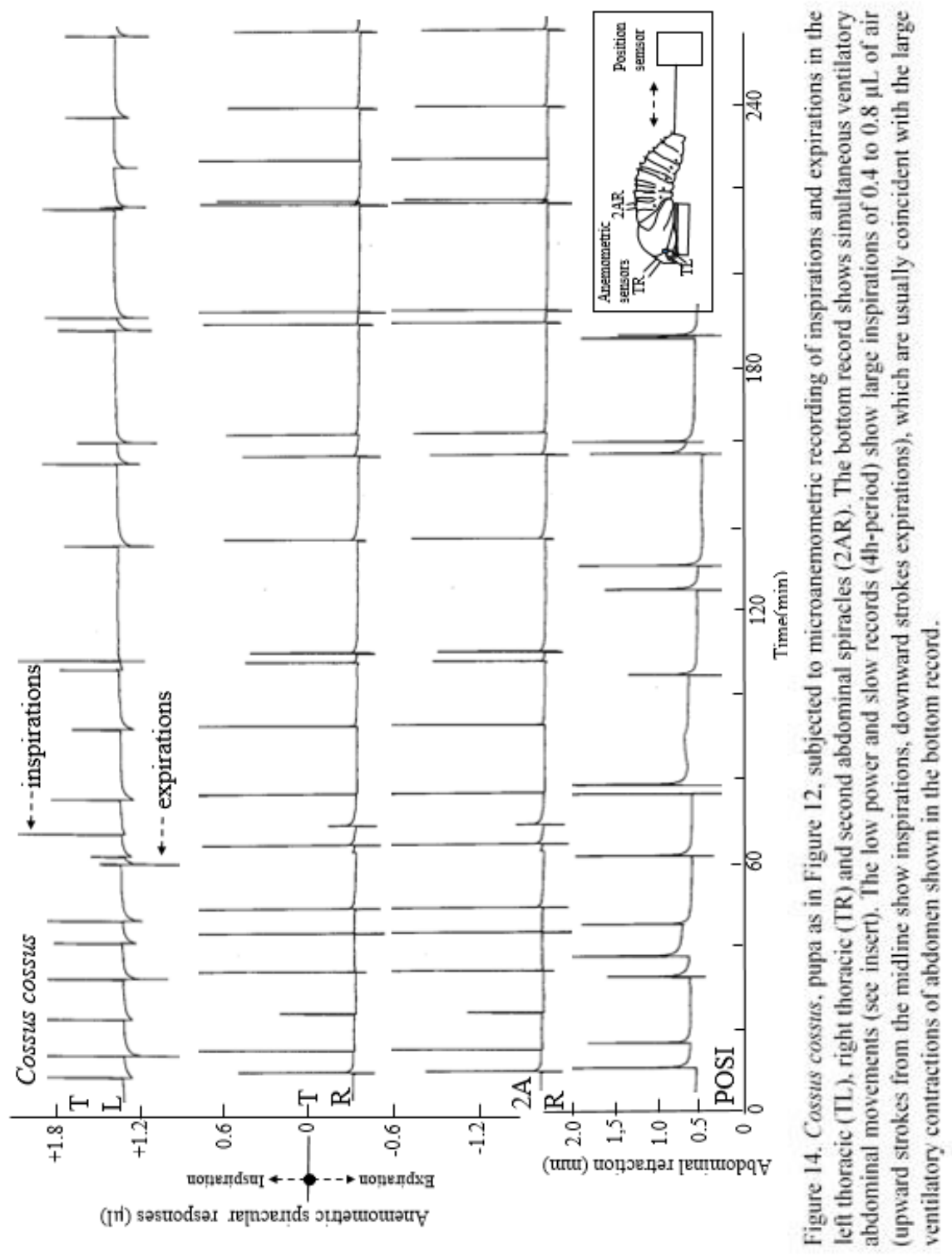



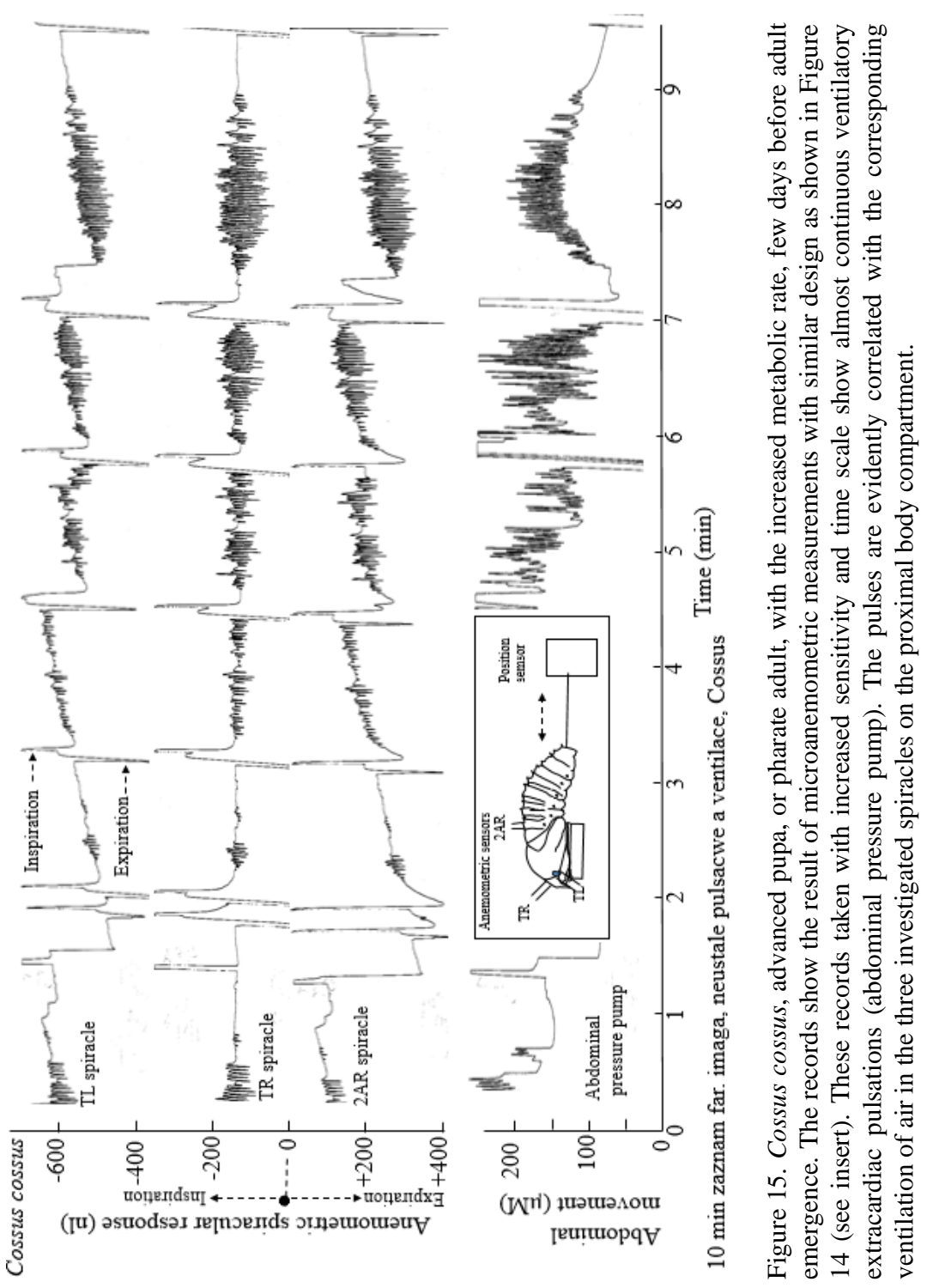


\section{Ventilatory movements in miniature pupae of Phyllonorycter strigulatella}

We have already described that the respiration of relatively large insect pupae, like Pseudosphinx, Manduca or Cossus (Figure 1), is fully controlled by mechanical ventilation of the tracheal system. Earlier it was suggested by Krogh (see Introduction), that the smallest insects could breathe by gaseous diffusion, without the necessity to perform special ventilatory movements. To test this hypothesis, we recorded respiratory movements in a tiny gracillariid pupa of Phyllonorycter strigulatella which shows, despite its miniature size, morphological and anatomical structures like those in the giant pupa of Pseudosphinx, which is about 10000-fold larger (Figure 1). The records in Figure 16 show that the ventilatory movements associated with the abdominal pressure pump (upper record) are virtually the same as found in the much larger pupae of Pseudosphinx. Lower trace record in Figure 16 shows that this miniature pupa performed special, twinned ventilatory pulsations. The reason for twinned pulsations depends on the fact that gracillariid pupae occur squeezed between the two layers of the host plant leaf. There is no space for ventilatory abdominal rotations. The pupae thus ventilate the tracheal system by shifting the tip of the abdomen from one side to the other, just like the pupa of Pseudosphinx in Figure 3.

The records in Figure 16 also show that the ventilatory movements were in this case very small, the large contractions were less than $100 \mathrm{~nm}$ and individual strokes of extracardiac pulsation show the amplitude of only some 28 nanometers. Obviously, these movements are imperceptible without a 10000-fold, electronic amplification. Figure 17 shows that extracardiac pulsations occur in the prediapause period of this species after extended periods of rest. During the overwintering diapause, the extracardiac pulsations almost disappear, although the heartbeat (lower trace) continues in more frequent bouts. Figure 18 shows a maximum skill of our recording ability, revealing a synchronized posimetric record of extracardiac pulsation with a thermographic record of the heartbeat. These records obtained in a very small pupa of Phyllonorycter provide sufficient evidence showing that the myogenic cardiac and neurogenic extracardiac ventilatory pulsations are different physiological phenomena. Whether large or small, the fact is that insects carefully avoid using diffusional principles for the exchange of respiratory gases. Apparently, selective advantage of convective, not diffusional, principle of gas exchange depends on preventing the escape of water. 


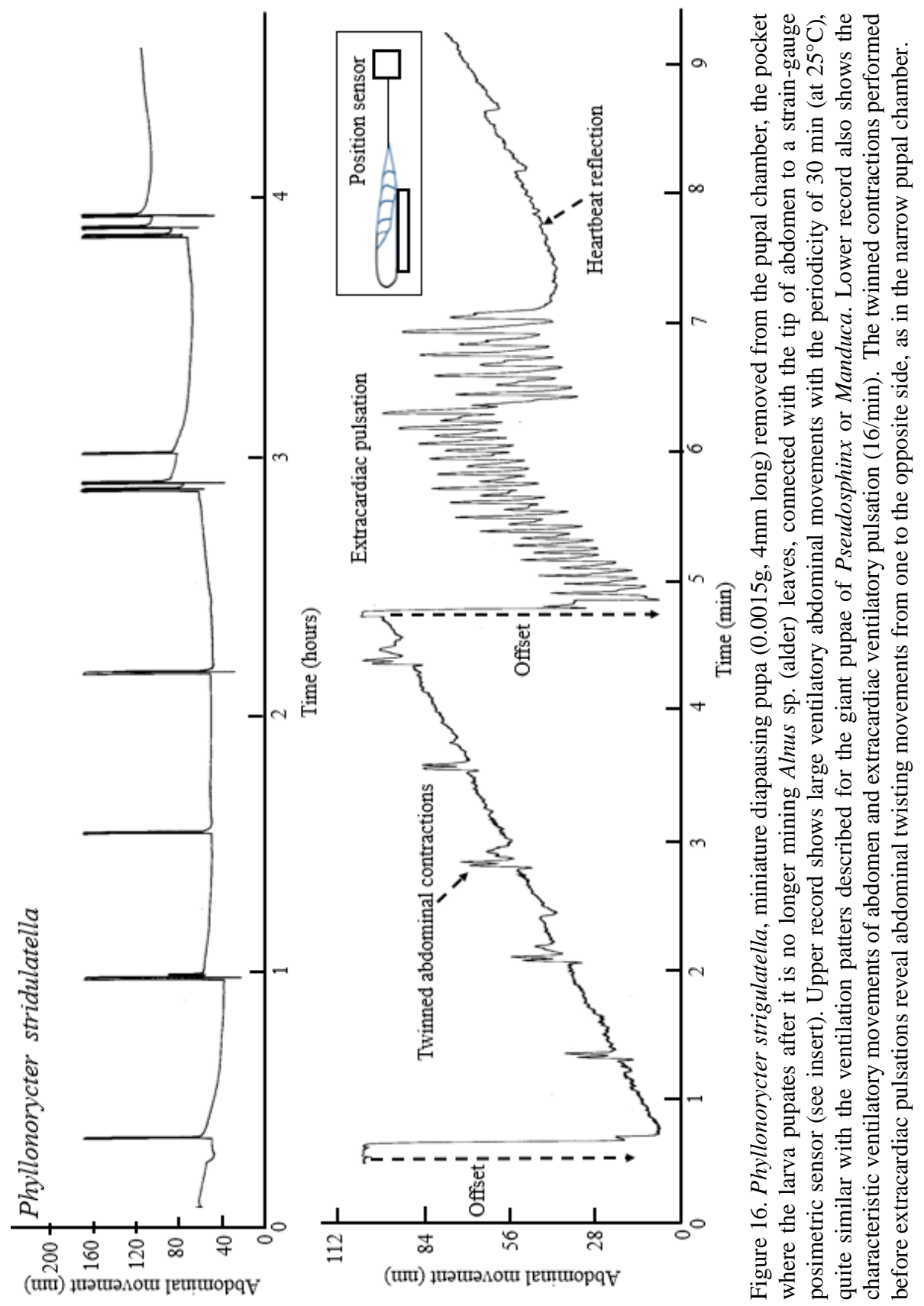




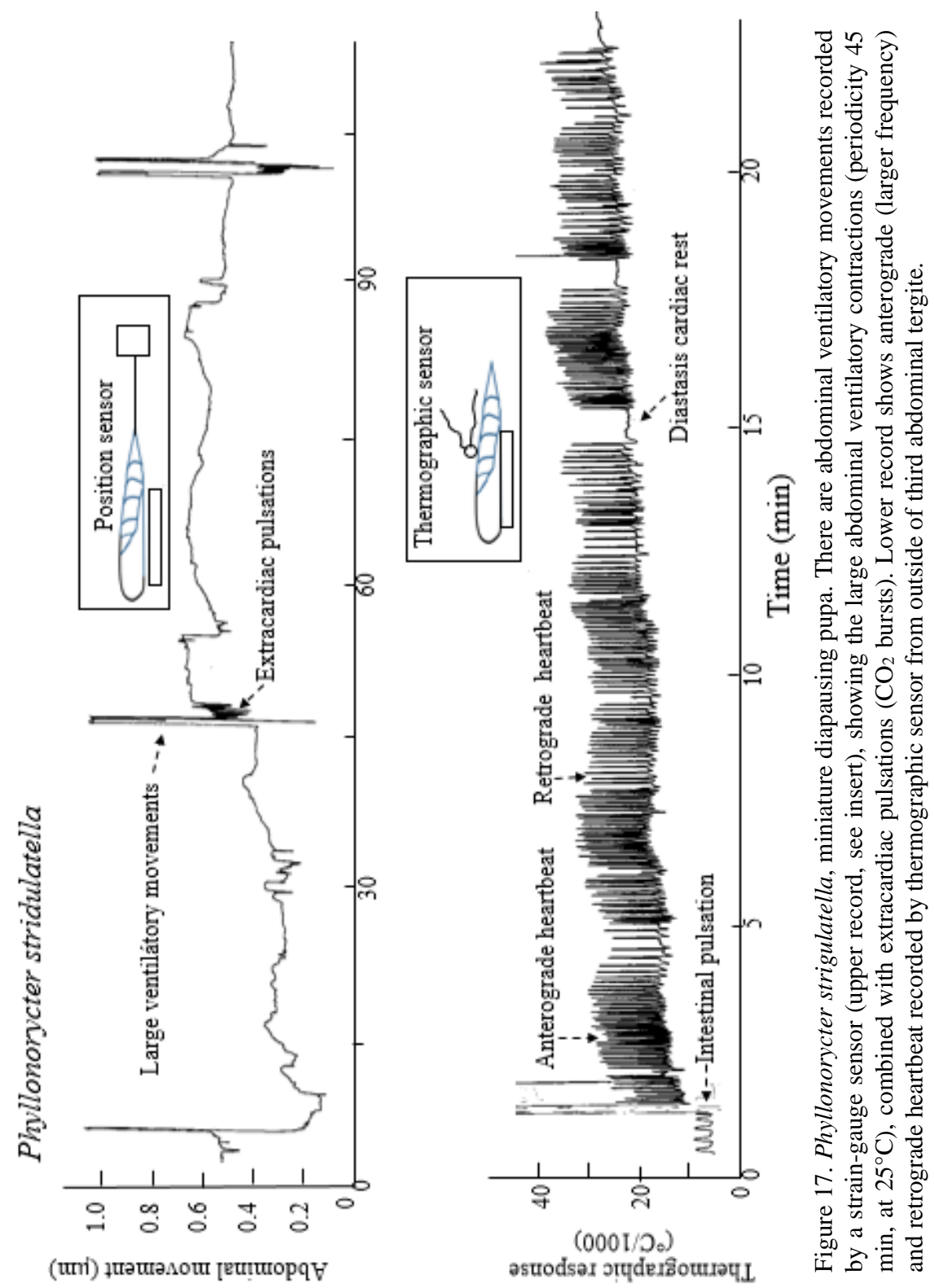




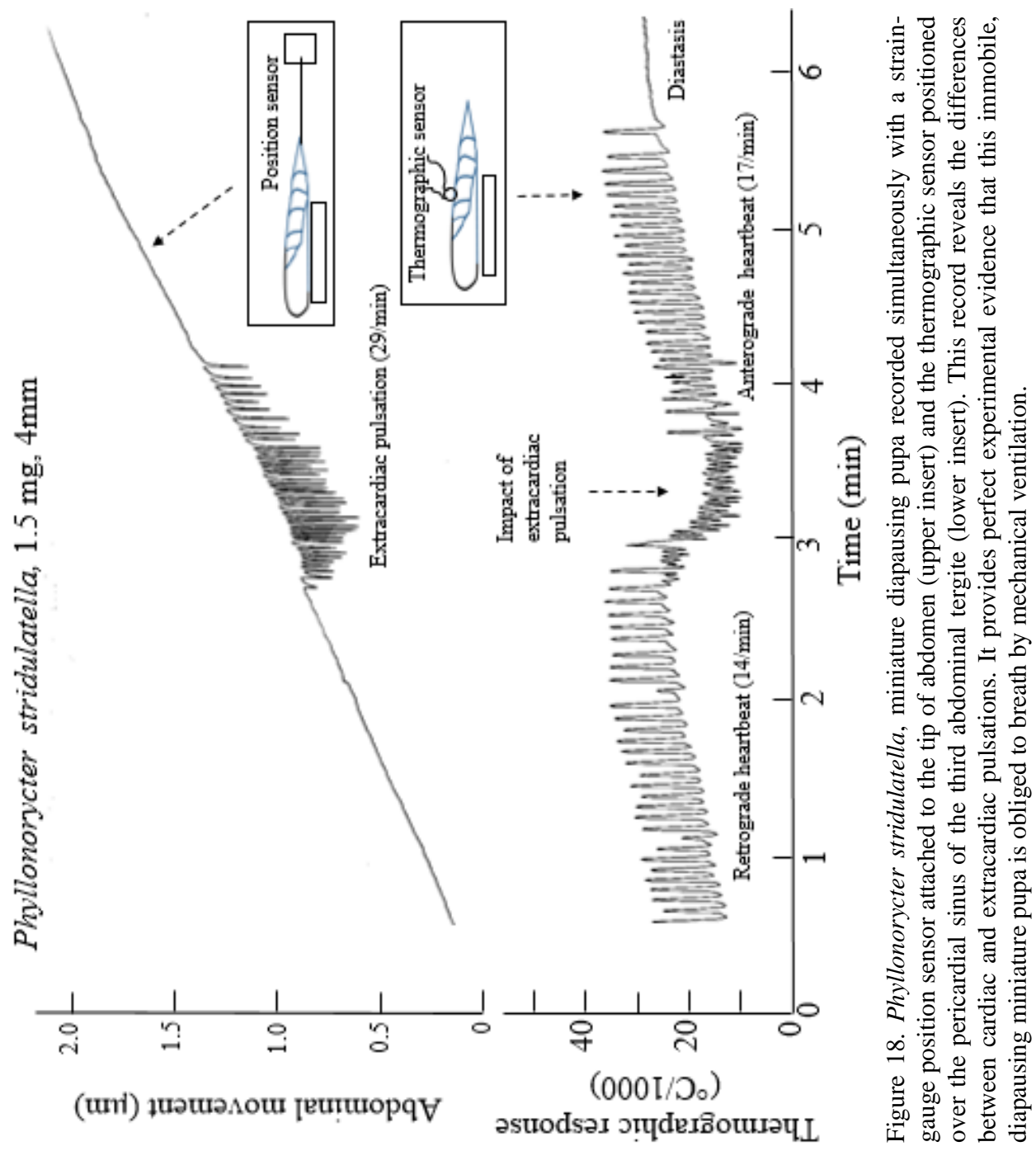




\section{Calibration of the ratio between abdominal movement and change of air volume}

We have already mentioned that lepidopteran pupae almost immediately recognize the occluded spiracle and react to it by permanent opening of its spiracular valve. We took use of this phenomenon in calibration of the relationship between intratracheal volume and abdominal movement. To this end, we have intubated one pupal spiracle and connected it to a syringe. After sufficient recording of abdominal movements of this pupa in air, we submerged the preparation under water, as can be seen in Figure 19. After water submersion, the spiracles are sealed by capillary forces between the narrow slits of the spiracular sieves, preventing water inflow into the tracheal system. Under these conditions of the sealed internal air space, tracheal volume can be changed by means of the attached syringe. The retraction or prolongation of the abdomen produced by changes of the internal air volume are recorded by the attached posimetric sensor. In this way, each pupa can be calibrated to reveal the $\mu 1 / \mu \mathrm{m}$ ratio of internal volume/abdominal movement. The relationship between abdominal movement and internal tracheal volume (see Figure 19) can be confronted with the data outlined in Figure 2. In other words, the impact of changes in internal tracheal volume on abdominal movement can be measured and recorded precisely. The pupa used in Figure 19 revealed the ratio of $1 \mu \mathrm{m}$ abdominal movement corresponded to $74 \mathrm{nl}$ change of internal volume of air. Under normal conditions, $1 \mathrm{~mm}$ of abdominal movement should cause $74 \mu \mathrm{l}$ of air flow through the spiracles.

\section{High resolution monitoring of spiracular ventilation in pupae of Cossus}

The microanemometric results presented in Figures 14 and 15 were made in 1988 using a battery of 4 capricious linear recorders. Today, several decades later, we have increased the range of maximum sensitivity of M-1000 unit from 100 $\mu \mathrm{V} / \mathrm{V}$ to $1 \mu \mathrm{V} / \mathrm{V}$ and the data acquisition software enabled expanding the time scale many times. In this way, as shown in Figure 20, we achieved a nanoanemometric method which enabled recording of inspirations of a few nanoliters of air in just a few milliseconds. For a long time, it was thought that the two thoracic spiracles of lepidopteran pupae opened and closed in synchrony (Schneiderman 1960). The record in Figure 20 shows, however, that both these spiracles indeed respired at first synchronously, but later the spiracle on the right side expired alone, ahead of inspirations on the contralateral side. This shows that the twinkling movements of each spiracular valve is controlled quite independently by the neuromuscular coelopulse system. From our previous work, we know that the neuromuscular coupling of spiracular functions with the movements of the abdominal pump is perfectly integrated by the coelopulse system. What we still do not understand is the feedback mechanism that communicates to the coelopulse system which spiracular valve should be open and when. It may be noted that the gulps of air through the spiracles are relatively small, some $100 \mathrm{nl}$ to $150 \mathrm{nl}$, which has never been previously recorded by any other method. 


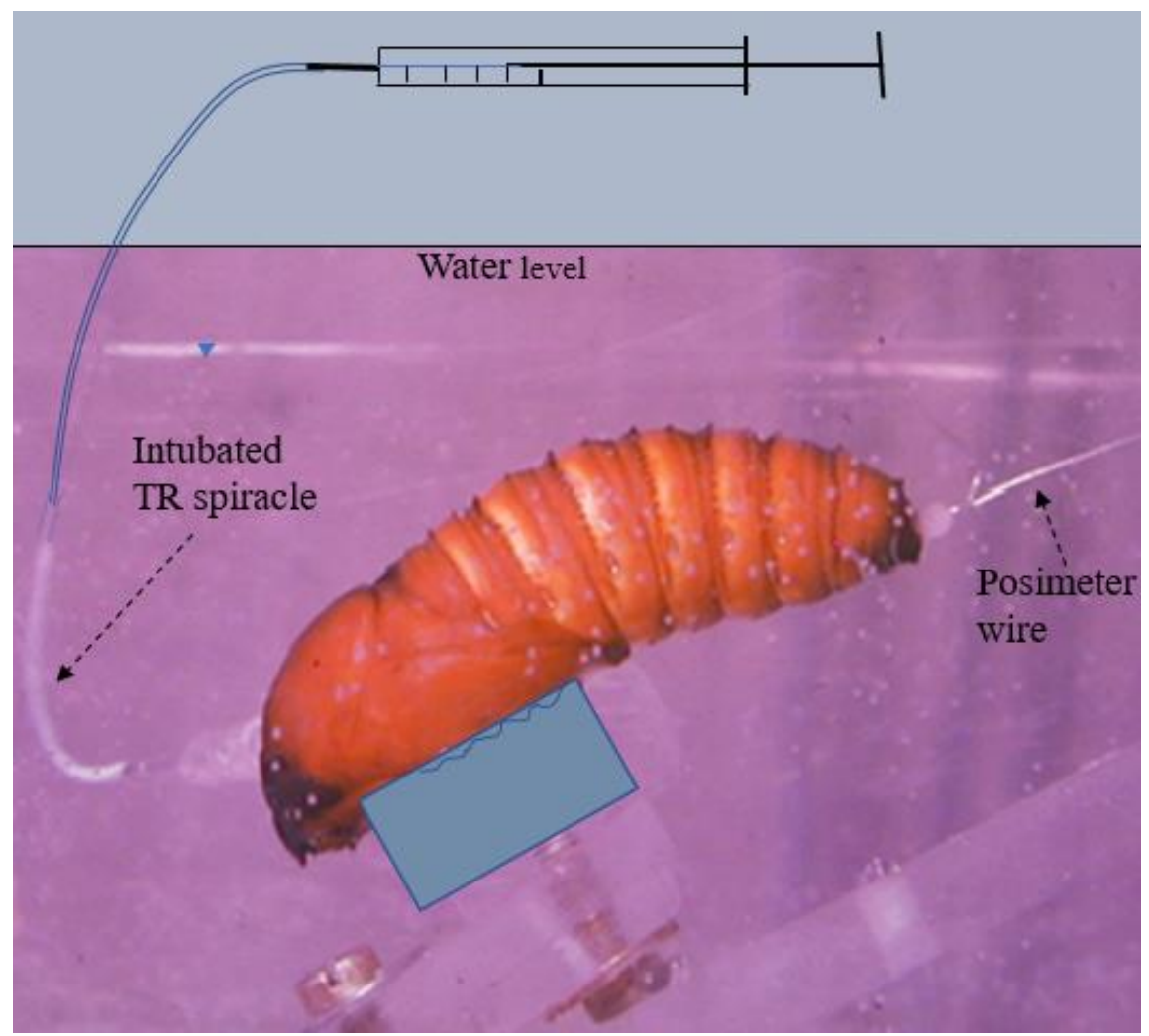

Figure 19. Cossus cossus. A method for calibration of relationships between mechanical abdominal movement and the passage of air through spiracles. The method uses one intubated spiracle connected to a calibration syringe. After water submersion, all pupal spiracles are sealed by capillary forces of the spiracular sieves. The submerged pupa immediately stops all ventilatory movements and the spiracular valves permanently open. The internal tracheal space of the pupa is changed using the syringe and the corresponding effect on abdominal movement is determined by the attached posimetric sensor. In the measured pupa, the volume/movement ratio revealed the measure of $1 \mu \mathrm{l}$ change of internal space being proportional to $13.5 \mu \mathrm{m}$ of abdominal movement $(1 \mu \mathrm{m}$ of abdominal movement $=74 \mathrm{nl}$ of air volume). 


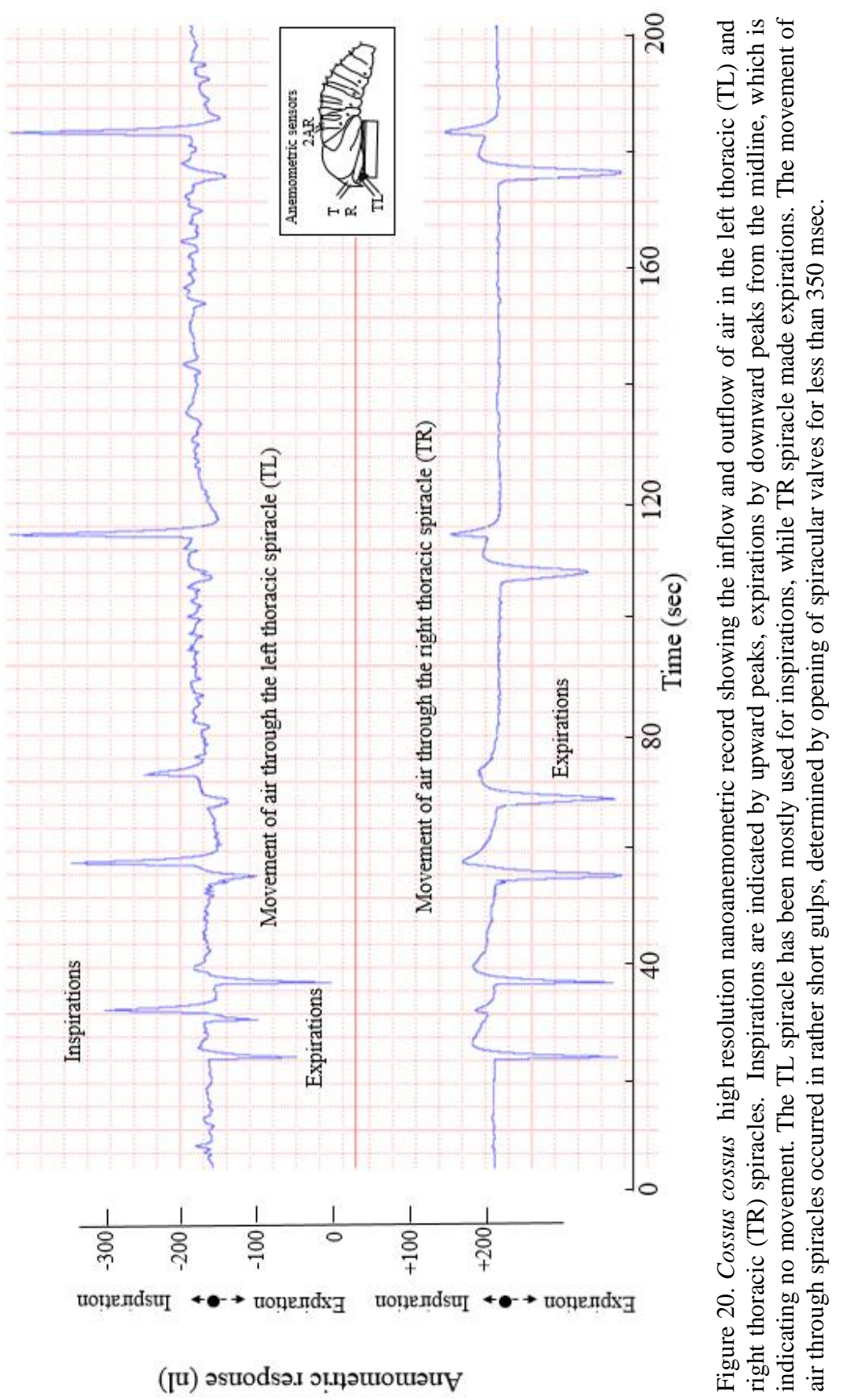


Figure 21 shows five most common ventilatory breathing responses induced in the TL, TR and 2AR spiracles by the large abdominal movements. The most frequently occurring breathing response appeared to be the type C in Figure 21, manifested by expiration and followed one or two seconds later by inspiration of air. This type $\mathrm{C}$ breathing response can be seen in more detail in Figure 22; type D in Figure 23. According to the time dependence of anemometric traces in Figure 22 and 23 , the openings of spiracular valves are usually indicated by intervals shorter than 500 msec. It is obvious, however, that the spiracular valves flutter in much shorter intervals, perhaps only $250 \mathrm{msec}$. This is due to persistence of temperature on the body of miniature thermographic sensors. The estimation of $250 \mathrm{msec}$ twinkling intervals for the spiracular valves agrees with the results presented in Figure 24, which shows the beginning of an extracardiac pulsation. It can be also noticed that a relatively small retraction or prolongation of the abdomen (bottom trace) was synchronized with the respective expiration and inspiration in the thoracic spiracles.

The nanoanemometric recordings performed during an extracardiac pulsation (Figure 25), document that the actual pattern of passage of air through spiracles can be affected by a wide opening of spiracular valves and by other factors. An example of the elevated amplitude of the pulsation can be observed in Figure 25 during 130 and $160 \mathrm{~s}$ of the recording time. Now, the amplitude of abdominal movement remains almost unchanged (bottom trace), while thoracic spiracles indicate increased ventilation. It is important to point out, however, that the effect of the abdominal pressure pump on ventilation of a particular spiracle is substantially influenced by the number of other spiracles that are just open. We describe here functions of the thoracic spiracles without knowledge about functions of multiple abdominal spiracles. The effect of the abdominal pump on air transport through one determined spiracle will be decreased proportionally by the number of other spiracles that have been simultaneously opened. In other words, the most pronounced effect on air transport occurs when the abdominal pump works in synchrony with only one responding spiracle, while all other spiracular valves are closed.

The high-resolution recordings in Figure 26 document the correlation between expiration of air through the spiracles and abdominal contractions during an extracardiac pulsation. The 2AR spiracle on the distal side of the anterior compartment remained partly closed, although it was open sometime before recording used in Figure 26 (not shown here).

Figure 27 shows a curious example of slow abdominal contractions associated with inspirations on the left side of the body, while right side shows expirations. In our experiments, we have seen this pattern independently several times. Currently, we do not know how to explain the anemometric responses shown in Figure 27, which show rather complex ventilatory features. Figure 28 demonstrates that extracardiac pulsations have a pronounced effect on spiracular ventilation, substantially different from the heartbeat, which has no effect on respiratory functions. 


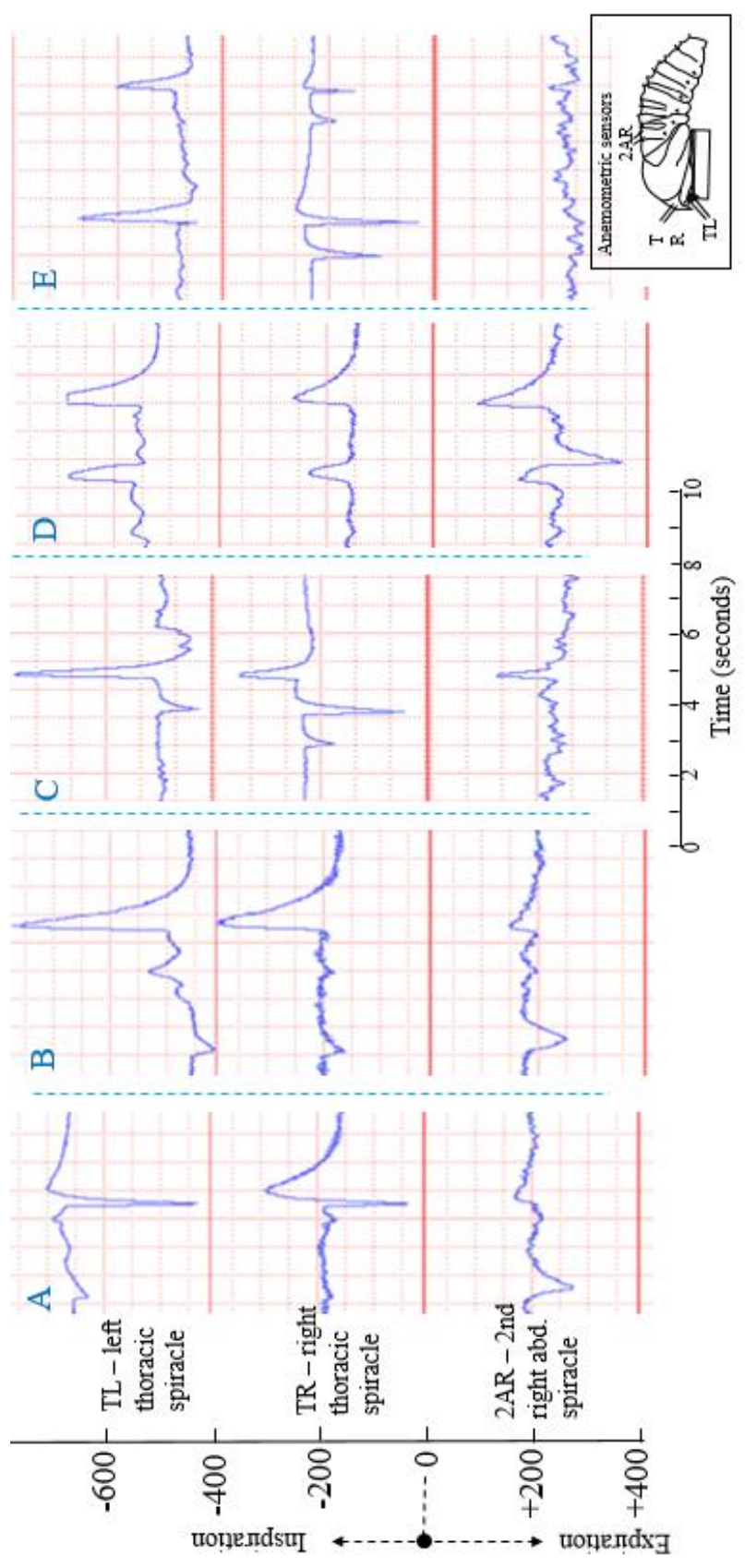

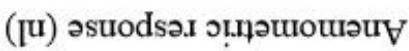

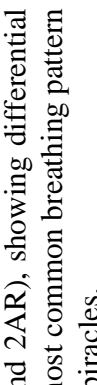

릉 क 点导 $\hat{\theta} \dot{0}$ 


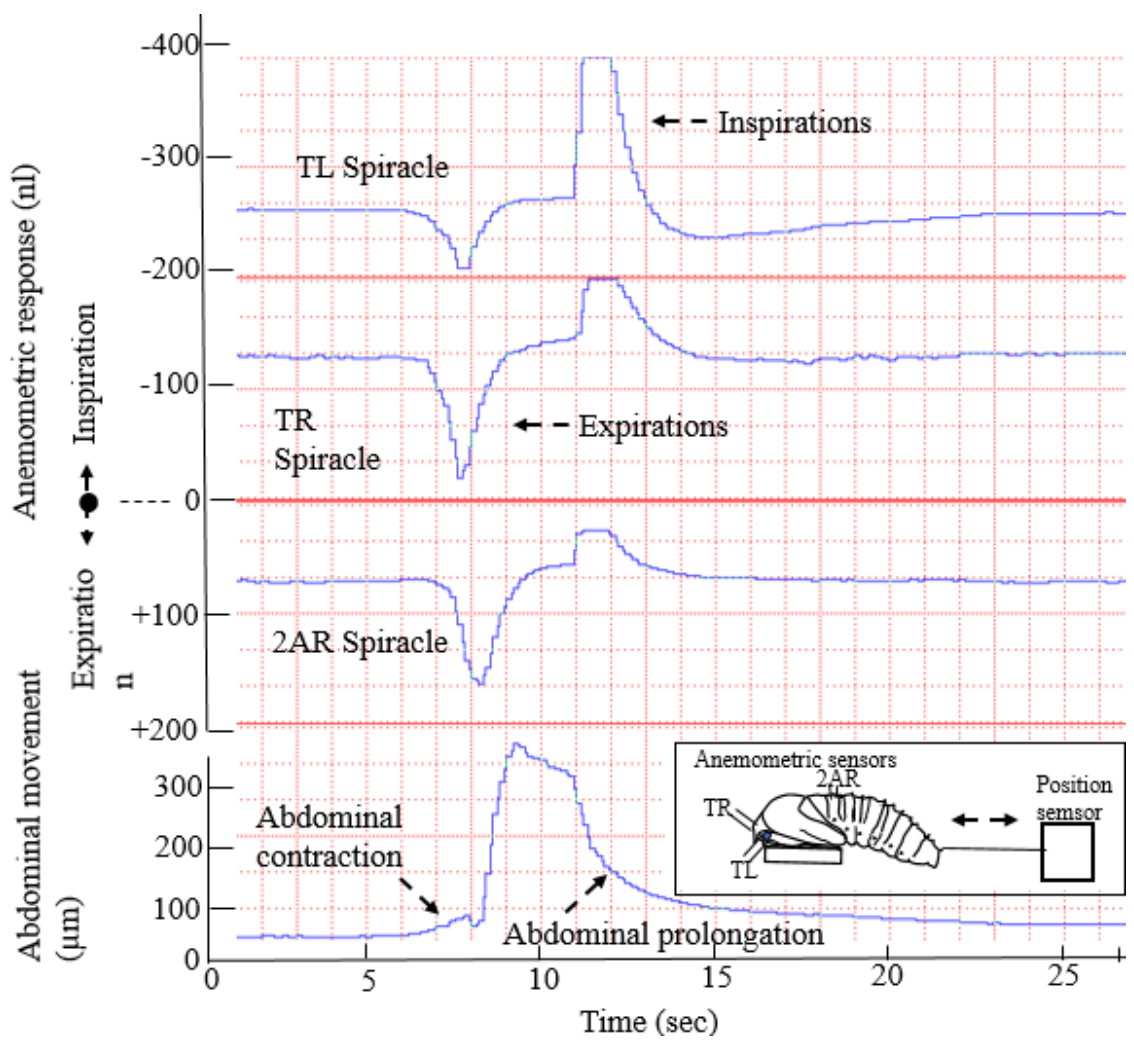

Figure 22. Cossus cossus anemometric pattern corresponding to the breathing type $\mathrm{C}$ (see Figure 20), recorded with the enhanced time scale. This figure shows that the duration of the ascending and descending peaks of inspiration or expiration lasted less than one second, initial responses after twinkling of the spiracular valves lasted less than $350 \mathrm{msec}$. The two bottom panels show that the direction of air movement through the spiracles was directly proportional to abdominal contraction or prolongation. 


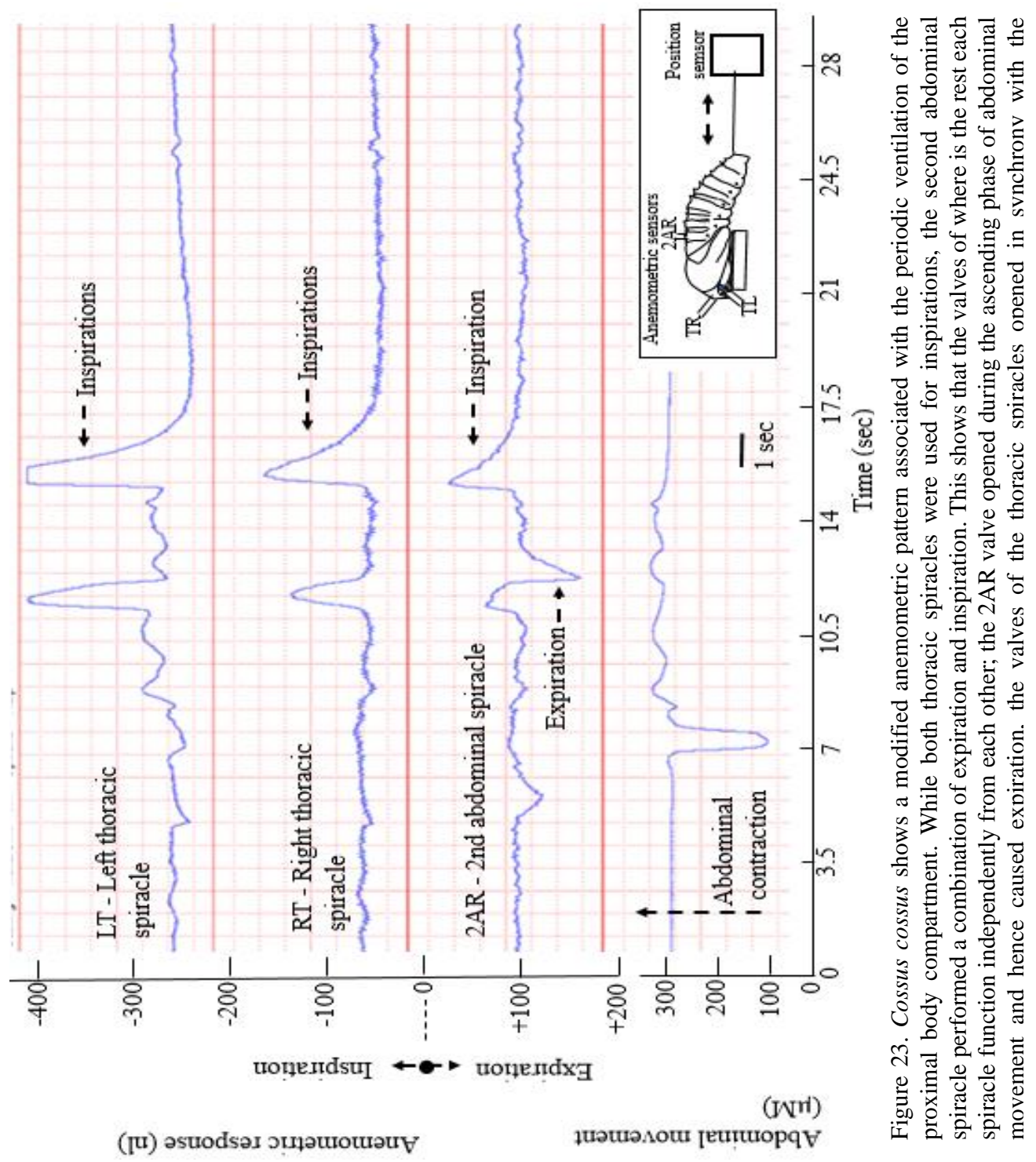




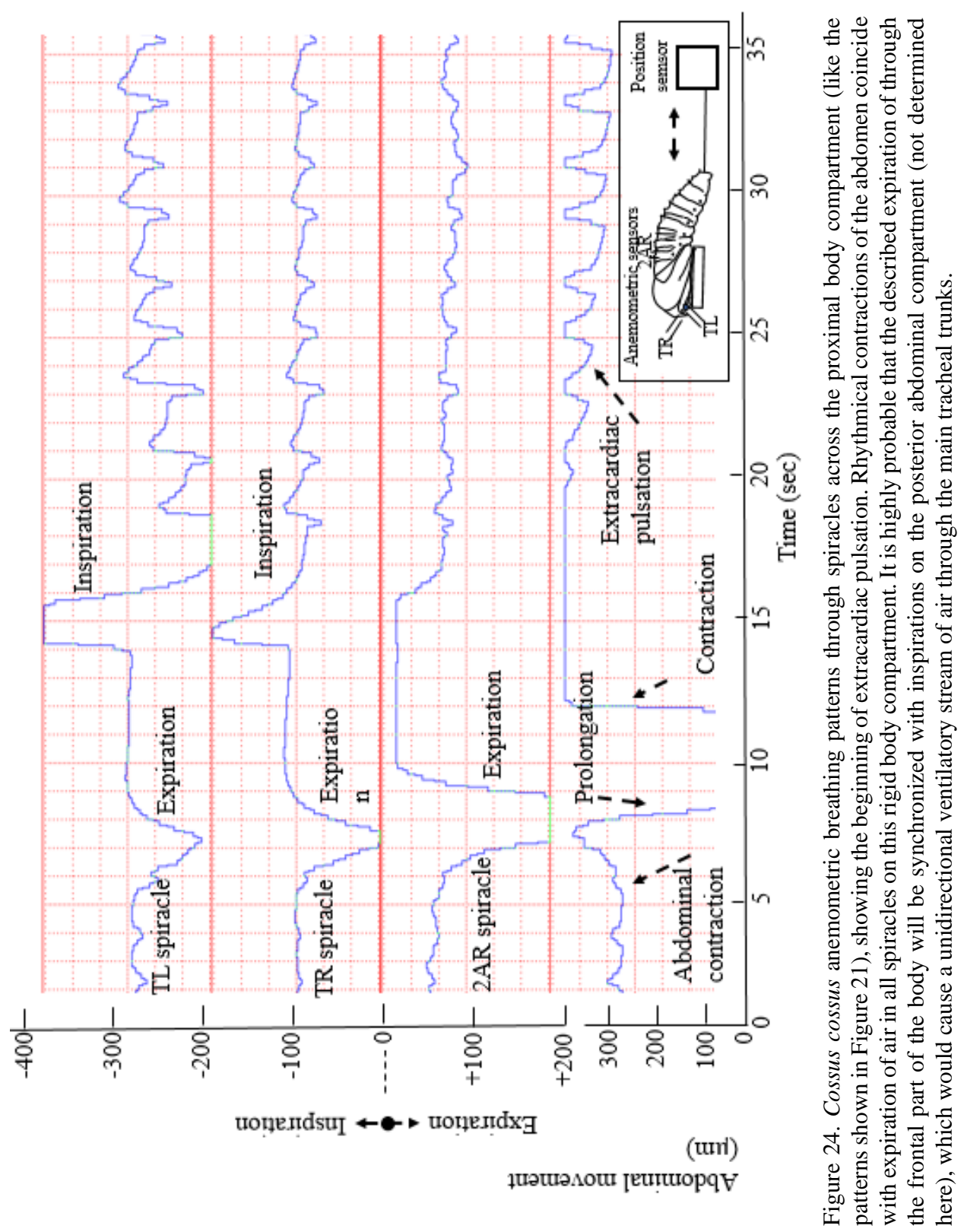




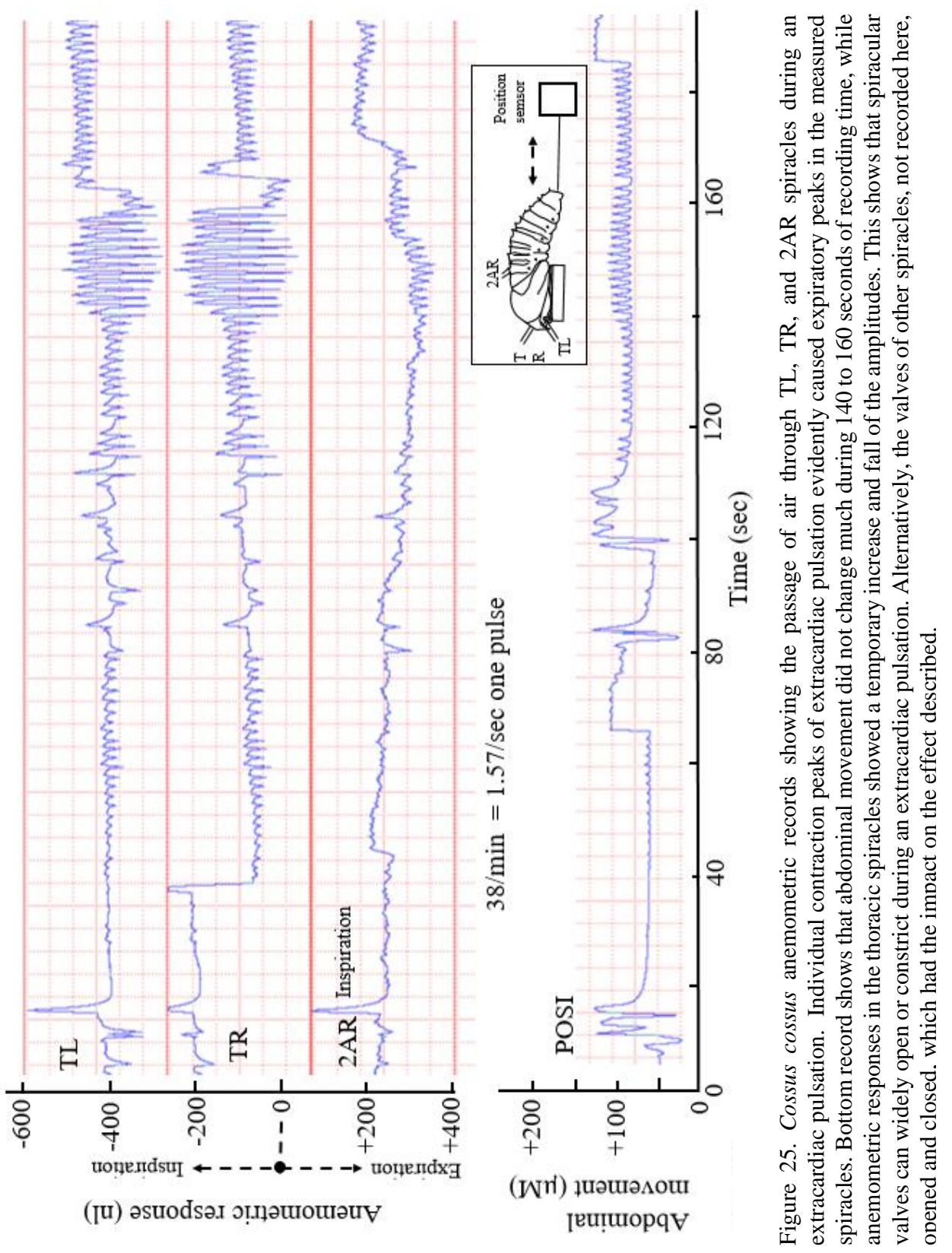




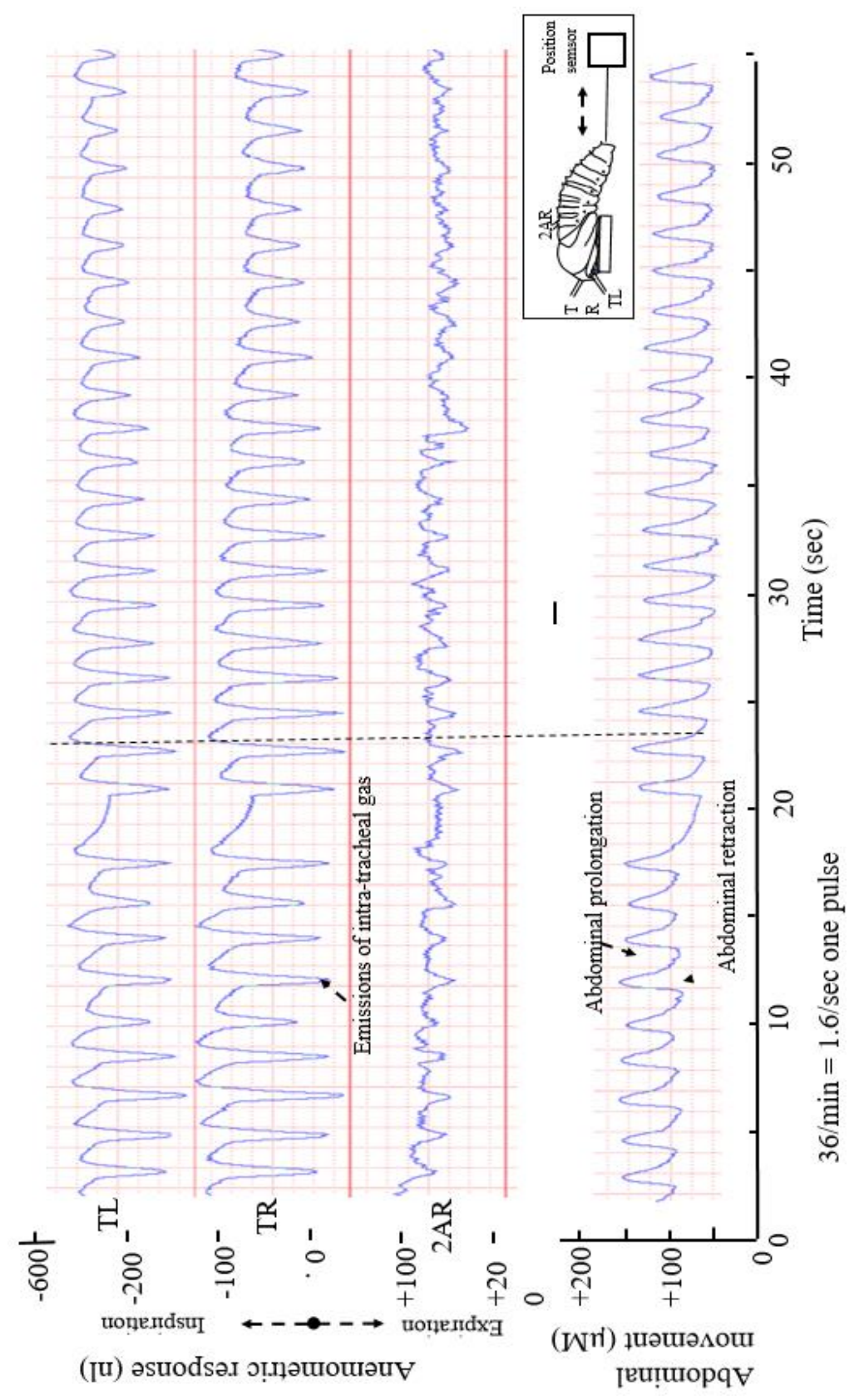

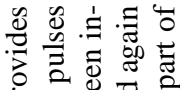

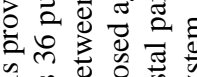

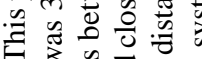

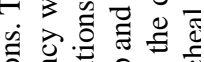

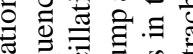

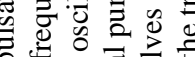
可元 记 3

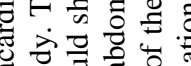

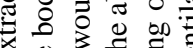
i $3 \pm . \Xi$ 잉 击

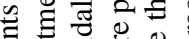

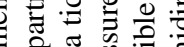
者 0 边

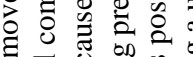
范 政 픙 这 政 पु

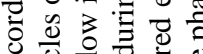

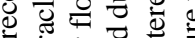

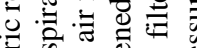

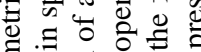
范

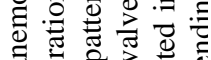
.

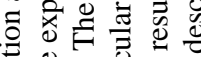

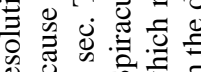

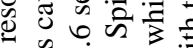
要

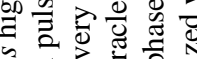

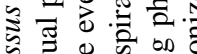
范

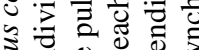
S.马

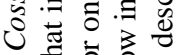
i

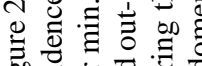

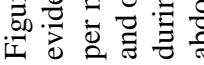




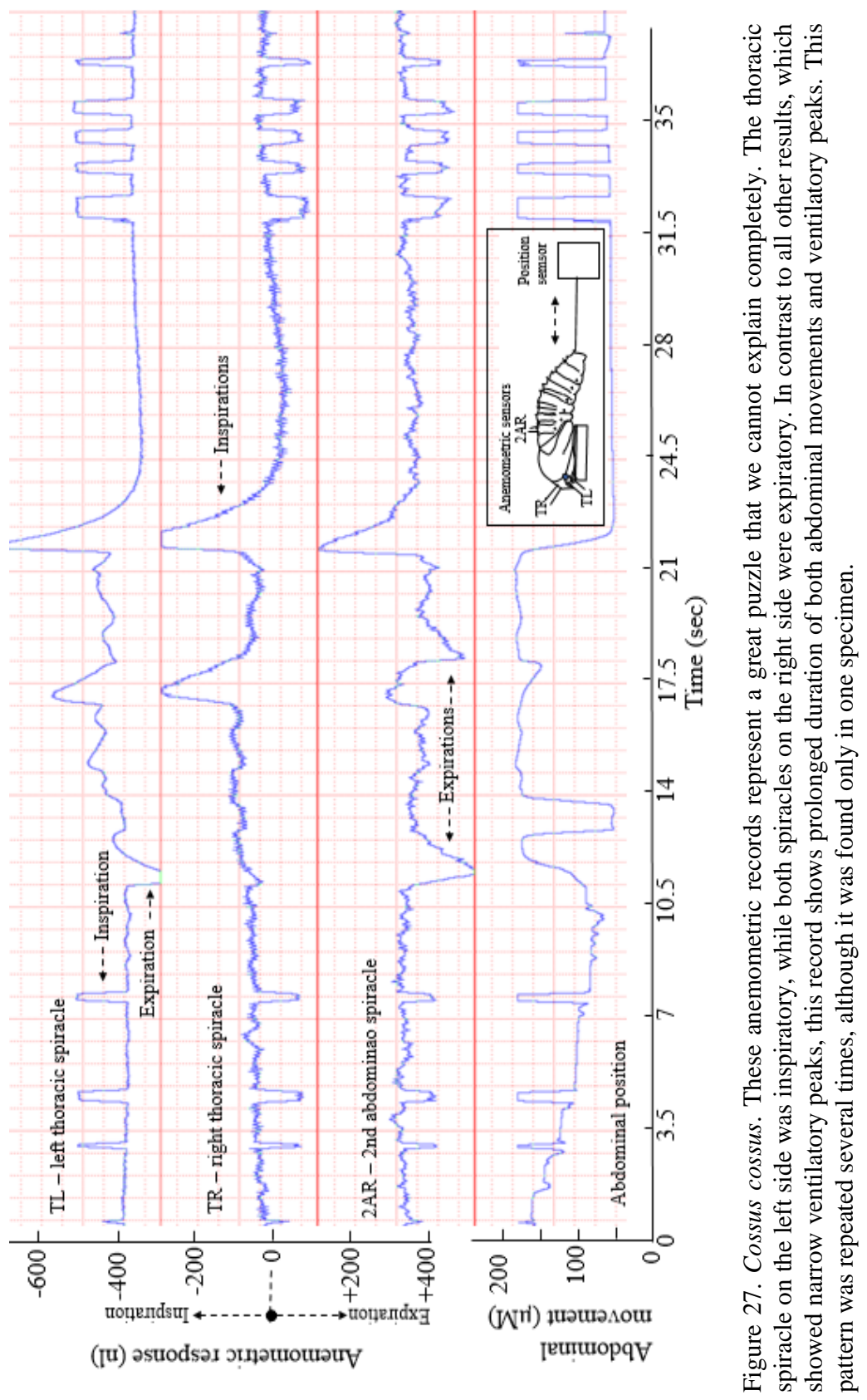




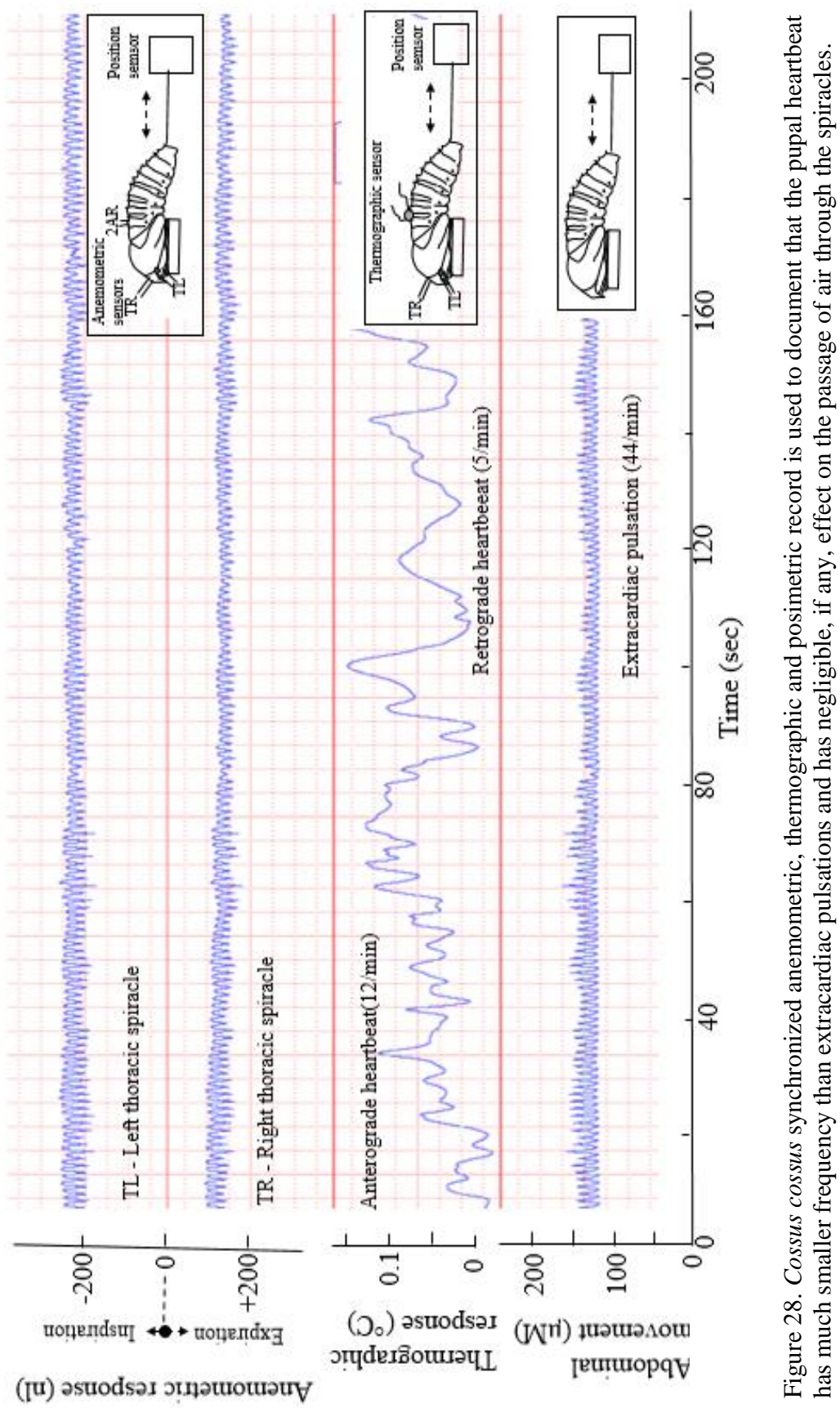




\section{Discussion}

Ventilation is a purely convective way of gaseous transport. Our results suggest that it may be a universal respiratory adaptation in larvae, pupae, and adults of all terrestrial tracheated insects. Due to sophisticated spiracular sieves, spiracular atria and constricted spiracular valves (Babák 1921), a simple physical diffusion of respiratory gases through insect spiracles is highly reduced. The main reason for this adaptation is obviously prevention of diffusional escape of water vapour. The mechanical ventilation of tracheal air is very economic, because it uses relatively small pressure changes to move the air in and out through very narrow apertures, regardless of insect size. Moreover, the mechanical ventilation of intratracheal gas helps to establish a more convenient condition for the diffusional exchange of respiratory gases at the liquid/gas interface at the tissue level. The evolution of autonomic neuroendocrine system, the coelopulse system (review by Sláma 2008), gave insects a selective advantage of homeostatic regulation of ventilation, repairing deficiencies such as $\mathrm{CO}_{2}$ hypercapnia or $\mathrm{O}_{2}$ hypoxia. This physiological type of respiratory adaptations is manifested by perfect neuromuscular coupling and synchronization of spiracular valves with the changes in internal body pressure, which are made by extracardiac haemocoelic pulsations or the abdominal pressure pump (Sláma 1988, 2010). The coelopulse system of insects apparently fulfills a similar physiological role as does the autonomic, parasympathetic neuroendocrine system in regulation of respiration in the human body. The question arises, why these phenomenal regulations remained concealed so long by insect physiologists, who persistently believe in Krogh's diffusion theory. They notoriously assumed for 60 years that, to satisfy the expected diffusion of $\mathrm{CO}_{2}$, insects ought to keep the spiracles widely open during the periods of $\mathrm{CO}_{2}$ bursts (Schneiderman 1960, Lighton 1996; Chown et al. 2006). Experimentally confirmed facts indicating that most of the spiracular valves of insects remained permanently closed, while other valves pulsated in short flutters during the "open phase" period of $\mathrm{CO}_{2}$ burst (Sláma 1988, 2010) have been ignored. The recent use of microrespirographic techniques revealed that small insects, like the termites or aphids, release the metabolic $\mathrm{CO}_{2}$ continuously, when kept in humid conditions. In the dry air, however, they retain carbonic acid $\left(\mathrm{CO}_{2}\right)$ dissolved in carbonate buffers of haemolymph and tissues. The gas is released in huge outbursts, at rather short intervals and in amounts surpassing 20-times the whole tracheal volume. The gas has been burst out into the tracheal system by its enzymatic liberation from the liquid carbonate buffers of the haemolymph. Curiously enough, the concentrated $\mathrm{CO}_{2}$ was exhaled out of the body by bulkflow, not by diffusion (Sláma 2010, Sláma and Jedlička 2012, Sláma et al. 2007).

\section{Historical Background}

Recent publications on insect respiration frequently ignore the data provided by earlier researchers, who accumulated a lot of important priorities, which now are slowly being rediscovered. We can perhaps remind here the most important, 
old review articles on insect respiration by Newport (1836), Rathke (1861), Plateau (1884), Babák (1921) and Krogh (1941). Historically, the field of insect respiration was based on determination of $\mathrm{O}_{2}$ consumption (reviews by Wigglesworth 1947, 1965; Kuznetzoff 1953). In 1985, Kestler published a review on insect respiration in which he concluded that both the diffusive as well as convective transport of gas is essential for preventing water loss (Kestler 1985). A great methodological change occurred in insect respiration by the massive application of the infrared, flow-through analysis of $\mathrm{CO}_{2}$ release (Lighton 1996, Chown et al. 2006, Hetz and Bradley 2005, Marrais et al. 2005). The previously accumulated respirometric data on $\mathrm{O}_{2}$ consumption in insects (Kuznetzoff 1953) were underestimated and the problem was completely oriented towards the discontinuous bursts of $\mathrm{CO}_{2}$. Several hypotheses explaining the existence of $\mathrm{CO}_{2}$ bursts was proposed (Lighton 1998, Chown et al. 2006), including oxygen toxicity to insects (Hetz and Bradley 2006). Respirometric data obtained by techniques other than the IR $\mathrm{CO}_{2}$ analysis, such as differential $\left(\mathrm{CO}_{2}-\mathrm{O}_{2}\right)$ gaseous exchange in small insects and ticks (Sláma 1988, 1999; Sláma et al. 2007; Sláma and Jedlička 2012), which also exhibited enormous bursts of $\mathrm{CO}_{2}$, remained unknown or were considered unimportant. Finally, new results on the movement inside the tracheal system were obtained from X-ray, cyclotron studies by Westneat et al. (2003, 2008) and Socha et al. (2010), which adhered in their studies to the diffusion concept of Lighton (1996). The most recent study on insect respiration (Aboelkassem and Staples 2013) is based on the data of Westneat et al. (2008). Like Krogh (1920), they neglected previous experimental data on insect respiration and replaced it by computer-assisted models.

\section{Mechanical ventilation of tracheal system is essential for insect respiration}

In this work, we used several extremely sensitive electronic methods to obtain experimental evidence that the transport of respiratory $\mathrm{O}_{2}$ and $\mathrm{CO}_{2}$ in and out of the insect body does not depend on a simple gaseous diffusion. This statement conflicts with the widely used diffusional theory of insect respiration, which was created almost 100 years ago (Krogh 1920). Due to the lack of experimental data, the theory has persisted as the main model of insect respiration until this time (Krogh 1941; Lighton 1996, 2008; Wasserthal 1996; Nation 2002; Marais et al. 2005; Westneat 2003, 2008; Chown et al. 2006; Hetz and Bradley 2005; Contreras and Bradley 2009; Aboelkassem and Staples 2013; Klowden 2017). Our results corroborate previous findings of Sláma $(1984,1988,1999,2010)$, which provided experimental evidence that large or small insects actively ventilated the tracheal system by the mechanical inhalation or exhalation of air through selected spiracles. The opening of spiracular valves occurred in rather short, 50 to 250 msec flutters, in perfect synchronization with the contraction (expiration) or prolongation (inspiration) of the abdominal pressure pump (Sláma 1988). During the extracardiac pulsations in haemocoelic pressure, the valves snap open in synchrony with: a) rising or ascending pressure phase (i.e., expiration), or; b) 
falling or descending pressure phase (i.e., inspiration) of the pulse. An example of this mechanism can be observed in anemometric records obtained with the pupa of Cossus (Figure 26). It confirms previous findings about the ephemeral (several msec long) synchronization of spiracular valve openings with contractions of the intersegmental abdominal muscles. Flutters of spiracular valves in synchrony with the reciprocal polarization (rising or falling internal pressure), enabled insect pupae to generate a unidirectional stream of air throughout the main trucks of the tracheal system (Sláma 1988, 1999, 2009).

The described physiological coordination of spiracular valve opening with neuromotoric functions of the effector muscles is controlled by the already mentioned, autonomic, cholinergic neuroendocrine system known as the coelopulse (review by Sláma 2009). Nervous center of the coelopulse was originally placed among thoracic ganglia of the ventral nerve cord, later it appeared that the most important center is the neurons of the mesothoracic ganglion (Provansal et al. 1977; Sláma 1984, 1986, 1988, 1994, 1999, 2009). The presence of neuroendocrine mechanisms engaged in regulation of insect respiration is a qualitatively new physiological concept, which conflicts with the mechanistic theories of purely diffusive respiration, without ventilatory movements. The mechanistic conception was a long time advocated in the textbooks of insect physiology (Nation 2002, Klowden 2013), however, new editions of the textbooks are more critical in this respect (Nation 2016; Klowden 2017). The comparative physiological data which we have gathered about insecthuman respiration have been outlined in Table 1 and Figure 29. They show that the autonomic coelopulse system of insects represents a fully functional analogy to the autonomic, cholinergic, parasympathetic system of humans.

\section{Specific characteristics of insect respiratory systems}

In comparison with the human body, insects are small but consume occasionally 100-fold more oxygen per unit of mass, producing the correspondingly larger amounts of carbonic acid (Sláma 2010). Recently, it has been found (Sláma and Lukáš 2016) that under exceptional circumstances, such as a massive production of water by total combustion of dietary lipids, insects can increase their $\mathrm{O}_{2}$ consumption rate to incredibly high, $20000 \mu \mathrm{lof} \mathrm{O}_{2} / \mathrm{g} / \mathrm{h}$. This remarkable insect phenomenon was called hypermetabolism (Sláma and KryspinSǿrensen 1979, Sláma and Lukáš 2013). This metabolic intensity of insects is estimated to be 500-fold higher when calculated per unit of mass than that of the human body $\left(40 \mu \mathrm{O}_{2} / \mathrm{g} / \mathrm{h}\right.$, at $\left.37^{\circ} \mathrm{C}\right)$. In this case, the diffusional output of $20 \mathrm{ml}$ $\mathrm{CO}_{2} \mathrm{~g} / \mathrm{h}$ through the "widely open spiracles" (Lighton 1996, Chown et al. 2006) would also take out $20 \mathrm{ml} / \mathrm{g} / \mathrm{h}$ of water vapour, which could cause a serious water loss. Our explanation for a preference of ventilatory over diffusive principle in insect respiration is underlined by two main factors: a) restraining respiratory acidaemia by enzymatic hydration of carbonic acid, which is associated with a bulk outflow of the produced, highly concentrated $\mathrm{CO}_{2}$ through the nearest 
spiracle, and; b) resorption and retention of water within the antiadhesive internal coating of the tracheal system. It was known for a long time (Babák 1921, Kuznetzoff 1953), that insect spiracles were protected against gas diffusion by sophisticated spiracular slits, sieves, foam and narrow atria, which has been recently confirmed by Wasserthal and Fröhlich (2017) who described antidiffusive spiracular trabeculae and spines.

From the above discussion, one might get a false impression that the diffusion of gas may be unimportant for insect respiration. This is not what we can say with respect to mechanical ventilation. Within the tracheal system of insects, as also in human lungs, diffusion plays an essential role inside, at the liquid/gas interphase. The diffusion velocities of the respiratory gases $\left(\mathrm{O}_{2}, \mathrm{~N}_{2}\right.$, and $\left.\mathrm{CO}_{2}\right)$ are more than million-fold slower in haemolymph or tissues than in the air (Buck 1962; Schneiderman 1960). Insects, with a multispiracular tracheal system solved the problem of liquid/gas diffusion by tracheoles protruding up to the vicinity of mitochondria in the metabolizing cells (Wigglesworth 1947, 1965). The tracheole are filled with a fluid that moves towards the tissues and in the opposite direction, which produces mechanical ventilation at the distant, tracheolar site (Wigglesworth 1947). Despite several suggested explanations for the movement of air and liquid within the tracheoles, the driving forces remain unknown.

\section{The role of haemolymph in the transport of gases}

A broad question in insect respiration is whether insects use their "blood" (haemolymph) for the transport of respiratory gases, like humans do, mostly via the red blood cells. Some entomological textbooks deny a role for haemolymph in insect respiration (Kuznetzoff 1953, Wigglesworth 1965, Nation 2002, Klowden 2017). This is certainly true for the supply of $\mathrm{O}_{2}$ up to the mitochondria through the air-filled tracheae or tracheoles. A different situation occurs, however, with respect to $\mathrm{CO}_{2}$, which is 36 -fold more soluble in haemolymph than $\mathrm{O}_{2}$. The metabolically produced $\mathrm{CO}_{2}$ (carbonic acid) is dissolved in carbonate buffers of haemolymph and tissues. Then, it is transported by haemolymph circulation to special sites of the tracheal system containing insect's carbonic anhydrase. The concentrated, gaseous $\mathrm{CO}_{2}$ is periodically released into the lumen of the tracheal system (pupal air sacks, Figure 6). The relatively concentrated $\mathrm{CO}_{2}$ is then volatilized and quickly expelled out of the body using the nearest available spiracle. The bulk outflow of $\mathrm{CO}_{2}$ from the body depends on the rise of haemocoelic pressure (Sláma 1994, 1999, 2010).

The described mechanism indicates that insect haemolymph is very important for metabolism and transport of $\mathrm{CO}_{2}$, though not so much for $\mathrm{O}_{2}$ and $\mathrm{N}_{2}$. Insects are enclosed in an exoskeleton case accentuating a crucial role of changes in internal (haemocoelic) pressure in ventilation of the body. We have been aware of this fact and systematically studied changes in haemocoelic pressure in various stages and species of insects since 1976 (Sláma 1976, 1984, 1988, 2009, 2010; Provensal et al. 1977; Sláma and Miller 1987). Unfortunately, due to technical 
difficulties preventing other authors from measuring insect haemocoelic pressure, and due to a persistent belief in the diffusion theory of insect respiration, our data on insect haemocoelic pressure have not been generally recognised so far. It is important to mention that most insects exhibit subatmospheric haemocoelic pressure, including soft-bodied caterpillars and maggots (review by Sláma 2009). Under conditions of subatmospheric pressure, the opening of a spiracular valve is immediately followed by an influx of fresh air from the environment (Schneiderman 1960, Sláma 1988). This phenomenon can be observed in Figures 4, 8 and 9. The vacuum results among other factors from the continuous $\mathrm{O}_{2}$ consumption by the respiring tissue and cells. The metabolically produced carbonate $\left(\mathrm{HCO}_{3}{ }^{-}\right.$ion) remains dissolved in the pool of carbonate buffers. The selective biological advantage of subatmospheric haemocoelic pressure depends, among other factors, mainly on the fact that a constant influx current through the spiracles hinders the possibility of reciprocal diffusion and escape of water vapour.

Regulation of inflation and deflation of the tracheae: The heart vs. the abdominal pressure pump

Theoretically, there are two models proposed for regulation of insect respiration. The first assumes that the heart beating is significant in regulating insect respiration. This view is supported by Wasserthal (1981), who concluded that relatively strong pulsations found in pupae of Attacus atlas were engaged in regulation of tracheal ventilation. The pulsations were automatically ascribed to the heartbeat, because at that time existence of stronger and faster extracardiac pulsations in haemocoelic pressure was not known. The leading role of heartbeat in tracheal ventilation was later extended to all holometabolous insects (Wasserthal 1996), while the respiratory impact of 100-fold stronger extracardiac pulsations was neglected. In a more recent paper on insect heartbeat and respiration, Wasserthal (2014) stated that: “...periodic heartbeat reversals cause cardiogenic inspiration and expiration with coupled spiracle leakage in resting blowflies." In the most recent paper, Wasserthal and Fröhlich (2017) describe functions of the spiracular valve, using a high-speed video, without attributing a role for extracardiac pulsations.

The second model for regulation of insect respiration is based on the discovery of the role of extracardiac pulsations in haemocoelic pressure (Sláma 1976, Provansal et al. 1977, Sláma et al. 1979). In addition to the coordinated pulsations, the tracheal system of insects can be inflated or deflated by substantial changes in haemocoelic pressure, which can be observed on most of our Figures. As we have already pointed out in previous sections, large compressions of internal pressure are made by sudden contractions of flexible abdominal segments, which became known in the literature as the abdominal pressure pump (Sláma 1984, 1988, 1994, 1999, 2009). The movements of the tracheal system inside the body was observed by Herford (1938) in the transparent body of a flea 
Xenopsylla cheopis. More recently, distinctive tracheal movements in adult beetles were found by the method of X-ray cyclotron imaging (Westneat et al. 2003, 2008; Socha et al. 2010).

Given the above-mentioned direct evidence for the tracheal movements, the question arises as to what is the force that moves the tracheae? Obviously, it cannot be the heart which is a tubular organ freely suspended in haemocoelic cavity, exhibiting rather inefficient, involuntary myogenic contractions. Tracheal tubes containing taenidia can be substantially prolonged during abdominal prolongation. A honeybee, sitting on a flower after flight, exhibits intensive pumping movements of the abdomen. These movements have a large impact on internal pressure when spiracular valves are closed. When some spiracular valves open, however, the movements result in vigorous pumping of air. In this case, the anisotonic state of the body changes into an isotonic, anisometric state. In other words, anisotonic pumping with closed spiracles would lead to compression of tracheal sacs, while anisometric pumping of open spiracles would lead to tracheal ventilation (Sláma 2009).

\section{Coordination of tracheated insect respiration}

Selective advantage of the cholinergic neuroendocrine mechanism, coelopulse, synchronizing opening of spiracular valves with the determined neuromotoric strokes of the abdominal pressure pump (Sláma 2009), depends on its ability to change the inefficient, tidal ventilation into the efficient, unidirectional stream of tracheal ventilation. The data presented in Figures 2 to 29 provide experimental evidence for the efficient respiratory role of the coelopulse system. Pupal stages used in our experiments represent suitable insect material for these respirometric investigations, because they are immobile and enable easy installation of the sensors (Sláma 1960). In most insect pupae, the respiratory functions of the abdominal pressure pump depend on extensively developed intersegmental musculature. These muscles are strong and always very active, periodically performing twisting movements (Figure 3 ) that provide metabolic energy even during the period of deep diapause. The effect of changes in haemocoelic pressure on tracheal ventilation has been well established (Sláma 1988, 1999, 2009). On the other hand, the assumed effects of heartbeat on regulation of insect respiration (Wasserthal 1996, 2014) still require additional experimental proof. The reason for more experimental data is that the impact of insect heartbeat on haemocoelic pressure is as a rule up to 100- to 500-fold smaller in comparison with the extracardiac pulsations (Sláma 2009). Theoretically, the general anatomical and morphological structures of most insect hearts do not fit with the assumed regulatory function in insect respiration. It appears that the insect heart is mostly engaged in stirring or translocating haemolymph between anterior and posterior body compartments, without the ability to cross a pressure barrier. In this context one could ask, what is the functional significance of the insect heart? In contrast to the strong extracardiac pulsations, which have mostly 
the local tidal effect, the heartbeat is very important in translocating the haemolymph between the frontal and caudal segments of the body (Sláma 2003, 2006).

\section{New results obtained by anemometric recordings}

There were initial attempts to record respiration by positioning a thermographic sensor close to the spiracle (Wasserthal 1981). However, the first differential microanemometric recording of air movement across multiple insect spiracles was invented by Sláma (1988), with additional results presented by Sláma (1999). The anemometric technique represents a major technical challenge because it was built on some very sensitive electronic devices of the late Czechoslovak Army. Perhaps, this was a main reason why nobody managed to carry out similar anemometric recordings on insects. In this work, we have further improved the method and obtained some new results related mainly to breathing in the pupae of Cossus. The most important findings can be summarized in the following points: 1 . Spiracles (spiracular valves) open and close in short flutters lasting usually 50 to $250 \mathrm{msec} ; 2$. The opening of a spiracular valve is faster and shorter than its passive closure; 3 . Each spiracle can be used for inspirations as well as for expirations of air, depending on neuromuscular synchronization with increasing or decreasing haemocoelic pressure; 4. The contralateral spiracles on each segment can flutter in synchrony or independently, or in synchrony with some other spiracles; 5. A spiracle on one body segment can be used for inspiration, while the contralateral spiracle can be simultaneously used for expiration; 6. Multiple spiracles on different body segments can flutter in synchrony with one or other group of spiracles; 7 . A diapausing pupa can use only one master spiracle (usually the left thoracic one) for $250 \mathrm{msec}$ flutters, with the periodicity of approximately $3 \mathrm{~min}$ for prolonged periods of time; 8 . Selected spiracles are programmed to open the valves in synchrony with the rising of haemocoelic pressure (= expiration), while others open during the falling pressure phase (= inspiration), which makes the principle of unidirectional tracheal ventilation; 9. The perfect coordination of spiracular valve opening with increasing or decreasing haemocoelic pressure is physiologically integrated by an autonomic (brain independent), cholinergic, neuroendocrine system (coelopulse); 10. All these results show that respiratory functions of this insect are regulated by active ventilation of the tracheal system, not by gaseous diffusion. Sláma (1988) used anthropological explanation of insect respiration in the following way: "These complex physiological functions can be compared to playing an accordion. There are two interconnected nerve functions; one is responsible for pulling the bellows and the other for pressing the right keys on the keyboard. We know the instrument but we must now learn to listen the melody of different insects" (Sláma 1988).

The above-indicated points can be practically tested by the data shown in Figures 20 to 24 . Figure 20 is perhaps the most instructive of these recordings as 
it shows the brief inspiratory flutters in the left thoracic spiracle, while the opposite, right thoracic spiracle was simultaneously used for expiration (i.e., unidirectional ventilation). The advanced nervous of neuromuscular adaptation herein described can be used as the best example against the concept of a simple, diffusional control of insect respiration. Moreover, the records in Figure 26 also have an important physiological implication. They show that the spiracular valves open and close in short flutters corresponding to ascending (expiration) or descending (inspiration) pressure phase during an extracardiac pulsation. This differential respiratory pattern could never occur if the valves were permanently open. In that case, there would be a simple, tidal movement of air. It should be perhaps added that these ventilatory movements were recorded in the immobile pupae of Cossus, which were believed for 100 years to lack ventilatory movements. Finally, all our Figures show that the actual abdominal movements associated with the extracardiac haemocoelic pulsation are rather small, usually some $50 \mu \mathrm{m}$ (see Figure 26). Naturally, such a small movement escaped not only the attention of Krogh $(1920,1941)$ but most other authors as well.

\section{Similarities and differences between insect and human respiratory systems}

Table 1 has been used to summarize basic similarities and differences between the respiratory systems of insects and the humans. ${ }^{4}$ Insects belong to a phylogenetically older group of invertebrates, the protostomes, while chordates, including humans, belong to a different major group, the deuterostomes. The common ancestors of these groups vanished in evolution many millions of years ago. Not surprisingly, comparative animal physiologists have rightfully hesitated to offer common links between these distant animal groups. The novel comparison of insect and human respiratory systems, herein offered is based on the use of new advanced recording methods for insects (Sláma 1988, 1999, 2009, 2010; Sláma and Neven 2001; Sláma and Jedlička 2012). We hope that the statement that insects breathe like humans will inspire increased investigations and interests of comparative physiologists and pharmacologists. We use humans, and not other terrestrial vertebrates for our comparisons (Table 1), because abundant pharmacological data is available only for humans. Changes in human blood pressure have a much smaller effect on respiration in comparison to insects. Human blood occurs enclosed within the arteries, veins and capillaries. The changes in blood circulation indirectly affect the rate of alveolar $\mathrm{CO}_{2} / \mathrm{O}_{2}$ exchange, and the appearance of hypercapnia, hypoxia or the accumulation of lactic acid is repaired by increased breathing rhythm regulated by the autonomic, parasympathetic system.

In insects, the anatomical situation is different. The vascular system of arteries, veins and capillaries has been substituted by an open, coelomic body cavity, while insect "blood" (haemolymph) is freely washing tissues or organs

\footnotetext{
${ }^{4}$ We could not find a complete data set to fill in Table 1 for other vertebrates.
} 
that are suspended in the haemocoelic cavity. The widely open haemocoelic cavity of insects is enclosed in an elastic or rigid exoskeleton. A change in the surface/volume ratio of an insect body is followed either by a corresponding change in haemocoelic pressure (when spiracular valves are closed) or by a corresponding outflow or inflow of air through open spiracles (isotonic, anisometric state). This shows that, unlike in humans, the mechanical pressure of insect haemolymph has a significant impact on the ventilation of the insect body. The situation is complicated by the fact that humans use only one naso-oral cavity for ventilation of the lungs, whereas insects use multiple, usually eight opening and closing pairs of "spiracular mouths." The data assembled in Table 1 show that air can be pushed through the narrow spiracular sieves, or foams or trichomes as a bulk flow of air. This type of ventilatory air transport requires relatively small pressure differences (less than 100 or $10 \mathrm{~mm}$ hydrostatic pressure (Table 1) similarly as is the case in human breathing. This type of ventilation is a very economic, convective method of gas transport, which might have evolved independently in both insects, birds (Babák 1921) and other terrestrial animals and humans.

Table 1. Similarities and differences between the human and insect breathing systems.

\begin{tabular}{|l|l|l|}
\hline \multirow{2}{*}{ Regulation } & \multicolumn{1}{|c|}{ Human Respiratory System } & Insect Respiratory System \\
\cline { 2 - 4 } & $\begin{array}{l}\text { Autonomic, parasympathetic } \\
\text { neuroendocrine system }\end{array}$ & $\begin{array}{l}\text { Autonomic, coelopulse } \\
\text { neuroendocrine system }\end{array}$ \\
\hline $\begin{array}{l}\text { Nervous } \\
\text { regulatory } \\
\text { centers }\end{array}$ & $\begin{array}{l}\text { Neurons in the prolonged } \\
\text { spinal cord, parasympathetic } \\
\text { nerves and ganglia }\end{array}$ & $\begin{array}{l}\text { Neurons in thoracic ganglia, } \\
\text { parasympathetic nerves and } \\
\text { ganglia }\end{array}$ \\
\hline $\begin{array}{l}\text { Neuromuscular } \\
\text { transmission }\end{array}$ & $\begin{array}{l}\text { Cholinergic, acetylcholine } \\
\text { acetylcholinesterase }\end{array}$ & $\begin{array}{l}\text { Cholinergic, acetylcholine } \\
\text { acetylcholinesterase }\end{array}$ \\
\hline $\begin{array}{l}\text { Effector } \\
\text { organs }\end{array}$ & $\begin{array}{l}\text { Intercostal thoracic muscles, } \\
\text { abdominal ventral diaphragm }\end{array}$ & $\begin{array}{l}\text { Intersegmental abdominal } \\
\text { muscles, abdominal pump }\end{array}$ \\
\hline $\begin{array}{l}\text { Ventilation } \\
\text { Liquid/gas } \\
\text { barrier }\end{array}$ & $\begin{array}{l}\text { Active expiration, passive air } \\
\text { intake }\end{array}$ & $\begin{array}{l}\text { Active expiration, passive air } \\
\text { intake }\end{array}$ \\
\hline
\end{tabular}




\begin{tabular}{|c|c|c|}
\hline Feedback & $\begin{array}{l}\text { Antagonistic sympathetic } \\
\text { system, carbonate and lactate in } \\
\text { blood }\end{array}$ & $\begin{array}{l}\text { Parasympathetic system, } \\
\text { carbonate and pyruvate in insect } \\
\text { "blood" }\end{array}$ \\
\hline $\mathrm{CO}_{2}$ in blood & More than $1 \%$ is toxic & More than $1 \%$ is toxic \\
\hline Breathing rate & $\begin{array}{l}\text { Continuous, } 30-60 / \mathrm{min} \text { (at } \\
37^{\circ} \mathrm{C} \text { ) }\end{array}$ & $\begin{array}{l}\text { Discontinuous, } 5-80 / \mathrm{min} \text { (at } \\
25^{\circ} \mathrm{C} \text { ), individual }\end{array}$ \\
\hline & \multicolumn{2}{|c|}{ Differences } \\
\hline $\begin{array}{l}\text { Ventilatory air } \\
\text { intake }\end{array}$ & $\begin{array}{l}\text { Nasal and oral cavities, trachea, } \\
\text { bronchi }\end{array}$ & $\begin{array}{l}\text { Eight pairs of independent } \\
\text { spiracles, tracheal trunks }\end{array}$ \\
\hline $\begin{array}{l}\text { Respiratory } \\
\text { organs }\end{array}$ & Lungs & $\begin{array}{l}\text { Multiple tracheal organs, air } \\
\text { sacs, tracheoles }\end{array}$ \\
\hline Breathing rate & $\begin{array}{l}\text { Continuous, } 60-120 / \mathrm{min} \text { (at } \\
37^{\circ} \mathrm{C} \text { ) }\end{array}$ & $\begin{array}{l}\text { Continuous or discontinuous, } 15 \\
-350 / \min \left(\text { at } 25^{\circ} \mathrm{C} \text { ) }\right.\end{array}$ \\
\hline $\mathrm{CO}_{2}$ release & Continuous ventilation & $\begin{array}{l}\text { Continuous or discontinuous, } \\
\text { large } \mathrm{CO}_{2} \text { bursts }\end{array}$ \\
\hline $\begin{array}{l}\text { Respiratory } \\
\text { acidaemia }\end{array}$ & $\begin{array}{l}\text { Alveolar } \mathrm{CO}_{2} \text { release, carbonic } \\
\text { anhydrase }(\mathrm{CA}) \text {, red blood cells }\end{array}$ & $\begin{array}{l}\mathrm{CO}_{2} \text { release by carbonic } \\
\text { anhydrase of the tracheal system } \\
\text { and air sacs }\end{array}$ \\
\hline $\begin{array}{l}\text { Respiratory } \\
\text { water }\end{array}$ & Exhaled & $\begin{array}{l}\text { Retained in tracheal system as } \\
\text { much as possible }\end{array}$ \\
\hline Anaerobiosis & 3-5 min allowed & $\begin{array}{l}\text { Prolonged facultative } \\
\text { anaerobiosis allowed }\end{array}$ \\
\hline
\end{tabular}

The data in Table 2 show several previously unexpected similarities between insect and human respiratory systems. Recognition of this fact was hindered for a long time by the persistent belief that insects breathed by diffusion, without ventilatory movements. Diffusion of gas transport is used both in insects and humans only at the liquid/air interphase, located deep inside the respiratory systems. The anatomical and physiological features of both respiratory systems are schematically outlined in Figure 29. 
The most convincing evidence that extracardiac haemocoelic pulsations (Sláma 1976) influence insect breathing can be found in Table 2, which shows the frequency of extracardiac pulsations in different insect species. The usual breathing frequency of insects listed in Table 2 is approximately $27 / \mathrm{min}$, which is quite close to a usual frequency of the human breathing. Also, the average pressure of air difference used in insect respiration (haemocoelic pressure) found in Table 2 is commonly less than $70 \mathrm{~Pa}$ (approximately equal to $7 \mathrm{~mm}$ of hydrostatic pressure). Evidently, breathing based on ventilation is very economic both in insects as well as in humans.

Table 2. Frequencies of extracardiac haemocoelic pulsations responsible for ventilation of the tracheal system in different insect species at room temperature $\left(22-27^{\circ} \mathrm{C}\right)$.

\begin{tabular}{|l|c|c|c|c|c|}
\hline $\begin{array}{l}\text { Insect order: Family } \\
\text { Species }\end{array}$ & Stage & $\begin{array}{c}\text { Average } \\
\text { frequency } \\
\text { (strokes/min) }\end{array}$ & $\begin{array}{c}\text { Pressure } \\
\text { (Pa) }\end{array}$ & $\begin{array}{l}\text { Body } \\
\text { mass (g) }\end{array}$ & References \\
\hline $\begin{array}{l}\text { Hemiptera: } \\
\text { Pyrrhocoridae } \\
\text { Pyrrhocoris apterus }\end{array}$ & adult & 15 & 100 & 0.067 & Sláma 1989 \\
\hline $\begin{array}{l}\text { Blattodea: Blattidae } \\
\text { Periplaneta americana }\end{array}$ & adult & 9 & 20 & 1.4 & Sláma 2008 \\
\hline $\begin{array}{l}\text { Coleoptera: } \\
\text { Chrysomelidae } \\
\text { Bruchus afinisFrölich, } \\
\text { 1799 }\end{array}$ & adult & 12 & 20 & 0.005 & $\begin{array}{l}\text { Coquillaud } \\
\text { et al. 1990 }\end{array}$ \\
\hline $\begin{array}{l}\text { Dermestidae } \\
\text { Dermestes vulpinus } \\
\text { (Fabr.) }\end{array}$ & $\begin{array}{l}\text { pre- } \\
\text { pupa }\end{array}$ & 6 & 300 & 0.08 & Sláma 1976 \\
\hline $\begin{array}{l}\text { Tenebrionidae } \\
\text { Tenebrio molitor }\end{array}$ & pupa & 33 & $20-100$ & 0.1 & $\begin{array}{l}\text { Provansal } \\
\text { et al. 1977 }\end{array}$ \\
\hline $\begin{array}{l}\text { Lepidoptera: } \\
\text { ossidae } \\
\text { Cossus cossus }\end{array}$ & pupa & 36 & -- & 3 & This study \\
\hline $\begin{array}{l}\text { Gracillariidae } \\
\text { Phyllonorycter } \\
\text { strigulatella } \\
\text { (Lienig and Zeller, } \\
\text { 1846) }\end{array}$ & pupa & 30 & -- & 0.001 .5 & This study \\
\hline $\begin{array}{l}\text { Nymphalidae } \\
\text { Nymphalis antiopa }\end{array}$ & pupa & 50 & 70 & 2 & Sláma 2008 \\
\hline
\end{tabular}




\begin{tabular}{|l|c|c|c|c|c|}
\hline $\begin{array}{l}\text { Saturniidae } \\
\text { Hyalophora cecropia }\end{array}$ & pupa & 13 & $20-60$ & 5.5 & Sláma 2010 \\
\hline $\begin{array}{l}\text { Sphingidae } \\
\text { Manduca sexta }\end{array}$ & adult & 18 & 20 & 6.1 & Sláma1989 \\
\hline $\begin{array}{l}\text { Pseudosphinx tetrio } \\
\text { pupa }\end{array}$ & 29 & -- & 11.5 & This study \\
\hline $\begin{array}{l}\text { Tortricidae } \\
\text { Cydia pomonella }\end{array}$ & pupa & 50 & 70 & 0.15 & $\begin{array}{c}\text { Sláma and } \\
\text { Neven } \\
2001\end{array}$ \\
\hline $\begin{array}{l}\text { Hymenoptera: } \\
\text { Apidae } \\
\text { Apis mellifera }\end{array}$ & pupa & 14 & 15 & 0.5 & \begin{tabular}{c} 
Sláma 2008 \\
\hline $\begin{array}{l}\text { Vespidae } \\
\text { Vespula germanica } \\
\text { (Fabr) }\end{array}$
\end{tabular} adult
\end{tabular}

Similarities between insect and human circulatory systems

There are two basic types of circulatory pumps: micropumps (i.e., cilia and flagella) and macropumps (e.g., tubular vessels, chambered hearts, etc., XavierNeto et al. 2010). In invertebrates, it appears that a true macropump-based circulatory system, minimally containing a layer of contractile cells (i.e., myocytes) first originated with the ancestor of Protostomata and Deuterostomata (Xavier-Neto et al. 2010, Crossley II et al. 2017) although many animal phyla in this hyperdiverse taxonomic neighborhood do not have a circulatory system ${ }^{5}$. Development of new electrocardiographic methods to study the insect heart have surprisingly revealed that the structure and function of the insect heart is based on similar, purely myogenic, involuntary, myocardial pulsations, driven by similar pacemaker nodi known to regulate the human heart. Selected cardioactive or cardioinhibitory drugs accelerate or inhibit, respectively, pulsations of insect hearts in the same fashion they do in human hearts (Sláma et al. 2013).

In case of the circulatory system, the origin and function of the human and insect hearts appears to be orchestrated by similar sets of genes (Sláma 2012). According to Devillers (2013), there are about $37 \%$ of genes on the chromosomes of insects (Drosophila) that are present in the human genome. If this is true, geneticists should ask, what forces have shaped the fact that so phylogenetically divergent animal groups, such as Protostomia (insects) and Deuterostomia (humans) have similar genes. Molecular biologists made great strides forward in

\footnotetext{
${ }^{5}$ Although ribbon worms (Phylum Nemertea) appear to be the most ancestral organisms with a circulatory system including vessels and endothelium (Crossley II et al. 2017), they appear to lack contractile cells and, instead, it consists of cells of coelomic origin, "coelomic homologues" (Turbeville 1991).
} 
the identification and mapping of genes. However, our knowledge of physiological systems, in Drosophila, and in other insects remains limited.

Muñoz-Chápuli (2011) suggests that members of a family of a signaling protein, called vascular endothelial growth factor (VEGF), which promotes tracheogenesis, or the formation of new tracheae, on the insect respiratory system appear to have been recruited or, in evolutionary terms, co-opted for the formation of new vessels, or angiogenesis, in the circulatory system of vertebrates. VEGF has been found in annelids and molluscs (Muñoz-Chápuli 2005) although we do not know whether VEGF has been reported in more ancestral animals with a true circulatory system ${ }^{6}$ (e.g., nemerteans). In the insect circulatory system, however, there is usually only one central aorta with a myocardium ${ }^{7}$ that does not regenerate and there are extensive pericardial cells. By contrast, in the insect respiratory system, tracheoles regenerate and grow into hypoxic tissues readily. In insects, like in humans, the respiratory system has functions beyond transporting gases. Sometime, during its millions of years of evolution, the insect respiratory system has been coopted for sound production. For example, some arctiid moths (Lepidoptera) hiss through their spiracles and exude defensive secretions when disturbed (Blum 1981). In the Madagascar Hissing Cockroach, Gromphadorhina portentosa (Schaum, 1853) (Blattodea: Blaberidae), air is expelled through modified spiracles producing hissings of different quality and functional significance (Nelson 1979, Heinrich et al. 2013, Shotton 2014).

The nature of the autonomic neuroendocrine system regulating the extracardiac pulsations is cholinergic, like the parasympathetic neuroendocrine system regulating human breathing (Sláma 1986). The actively-regulated breathing of air, based on extracardiac haemocoelic pulsations, has been documented from postembryonic stages of all terrestrial insects, regardless of their overall size and developmental stage (Sláma 1998, 1994, 1999). The described physiological mechanism more recently has been corroborated by new electronic methods (Sláma 2009, 2010). However, some authors are reluctant to recognize respiratory functions of extracardiac pulsations (Wasserthal 1996, 2014), and ascribe respiratory functions to the heart, which is a small, tubular organ suspended in haemocoelic cavity, whose anatomical structure and inefficient myogenic functions (with 100-fold smaller impact on haemaocoelic pressure in comparison with the extracardiac pulsations) can hardly affect functions of the tracheal system (Sláma 2009, 2010).

\footnotetext{
${ }^{6}$ By true circulatory system, we mean one with vessels and contracting cells (pumps) overlying the vessels.

7 An exception is the American cockroach, Periplaneta americana (Linnaeus, 1758) (Blattodea: Blattidae).
} 


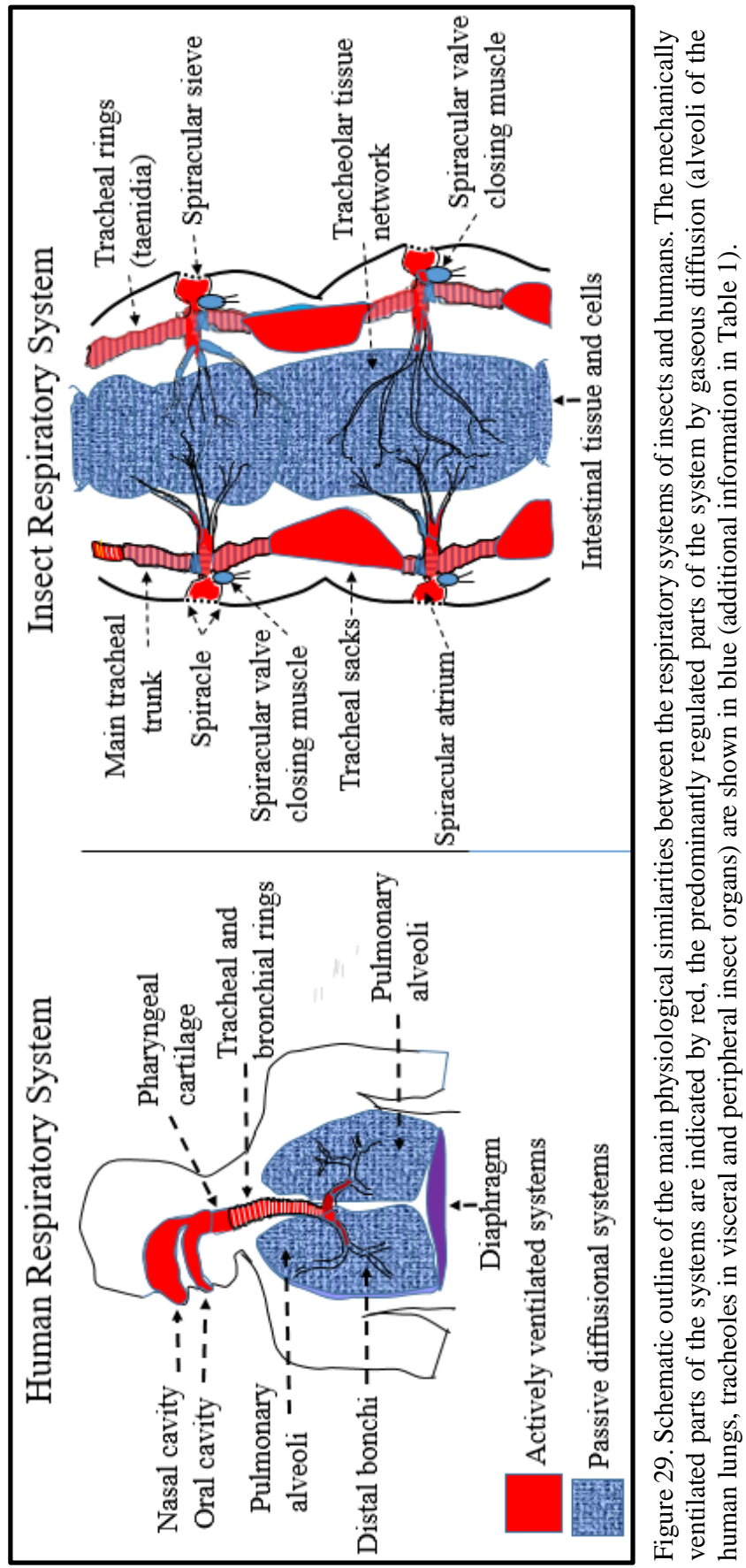




\section{Acknowledgments}

Dr. John W. Brown (Systematic Entomology Laboratory, United States Department of Agriculture, National Museum of Natural History, Washington, District of Columbia, USA), Dr. James Carpenter (Department of Entomology, American Museum of Natural History, New York, NY, USA), Dr. Ramón Muñoz-Chápuli (Department of Animal Biology, Faculty of Science, University of Málaga, Málaga, Spain), and Dr. José Xavier-Neto (Laboratório de Genética e Cardiologia Molecular, Instituto do Coração, Faculdade de Medicina, Universidade de São Paulo, São Paulo-SP, Brazil), are thanked for discussions on various aspects of this paper. Dr. Margaret Schwinghammer (Alexandria, Virginia, USA) made us aware of pertinent references on hissing in arthropods and two anonymous reviewers offered constructive suggestions. Above all, we wholeheartedly thank the Guest Editor for the careful editorial job on this lengthy manuscript.

\section{Literature Cited}

Aboelkassem Y. and A. E. Staples. 2013. Selective pumping in a network: insect-style microscale flow transport. Bioinspiration \& Biomimetics 8 (026004) https://doi.org/10.1088/1748$\underline{3182 / 8 / 2 / 026004}$

Anderson M., K. Sláma, and T. Miller. 1990. Electrical and mechanical recording methods. pp. 189208. In, F. Huber, F., E. P. Masler, and B. R. Rao (Editors). Cockroaches as Models for Neurobiology: Application in Biomedical Research. CRC Press. Boca Raton, Florida, USA. 280 pp.

Babák, E. 1921. Die Mechanik und Innervation der Atmung. D. Tracheaten. pp. 265-1052. In, Winterstein, H. (Editor). Handbuch der vergleichenden Physiologie. 1 Band. 2. Hälfte. Verlag von Gustav Fischer. Jena, Germany. https://archive.org/details/handbuchdervergl0102wint

Babák, E. and O. Foustka. 1907. Untersuchungen über den Auslösungreiz der Atembewegungen bei den Libellulidenlarven (und Arthropoden überhaupt). Pflügers Archiv 119:530-548. [Pflügers Archiv, currently published under the title Pflügers Archiv: European Journal of Physiology, is the oldest physiological journal having been founded by the German physiologist, Eduard Friedrich Wilhelm Pflüger in 1868.]

Blum, M. S. 1981. Chemical Defenses of Arthropods. Academic Press. A Subsidiary at Harcourt Brace Jovanovitch, Publishers. New York, NY, USA. 562 pp.

Buck, J. B. 1962. Some physical aspects of insect respiration. Annual Review of Entomology 7:27-56. https://doi.org/10.1146/annurev.en.07.010162.000331

Chown, S. L., A. G. Gibbs, S. K. Hetz, G. J. Klok, J. R. B. Lighton, and E. Marais. 2006. Discontinuous gas exchange in insects: A clarification of hypotheses and approaches. Physiological and Biochemical Zoology: Ecological and Evolutionary Approaches 79:333-343. https://doi.org/10.1086/499992

Coquillaud M.-S., K. Sláma, and V. Labeyrie. 1990. Regulation of autonomic physiological functions during reproductive diapause of Bruchus affinis. pp. 37-44. In, K. Fujii, A. M. R. Gatehouse, C. D. Johnson, R. Mitchel, and T. Yoshida, T. (Editors). Bruchids and Legumes: Economics, Ecology and Coevolution. Series Entomologica. Kluwer Academic Publishers. Boston, Massachusetts, USA and Dordrecht, The Netherlands.407 pp.

Contreras H. L. and T. J. Bradley. 2009. Metabolic rate controls respiratory patterns in insects. Journal of Experimental Biology 212:424-428. https://doi.org/10.1242/jeb.024091

Crossley II, D. A., W. W. Burggren, C. L. Reiber, J. Altimiras, and K. J. Rodnick. 2017. Mass transport: circulatory system with emphasis on nonendothermic species. Comprehensive Physiology 7:17-66. https://doi.org/10.1002/cphy.c150010

Devillers, J. 2013. Juvenile hormones and juvenoids. Modeling biological effects and environmental fate. CRC Press, Taylor and Francis Group. Boca Raton, Florida, USA. 387 pp. https://doi.org/10.1201/b14899

Farkaš, R. and K. Sláma. 2015. Respiratory metabolism of salivary glands during the late larval and prepupal development of Drosophila melanogaster. Journal of Insect Physiology 81:109-117. https://doi.org/10.1016/j.jinsphys.2015.06.013 
Heinrich, E. C., M. J. McHenry, and T. J. Bradley. 2013. Coordinated ventilation and spiracle activity produce unidirectional airflow in the hissing cockroach, Gromphadorhina portentosa. The Journal of Experimental Biology 216:4473-4482. https://doi.org/10.1242/jeb.088450

Herford, G. 1938. Tracheal pulsation on the fleas. Journal of Experimental Biology 14:327-338.

Hetz, S. K. and T. J. Bradley. 2005. Insects breathe discontinuously to avoid oxygen toxicity. Nature 433:516-519. https://doi.org/10.1038/nature03106

Hurst, J. W., W. B. Fye, and H. G. Zimmer. 2006. August Krogh. Clinical Cardiology 29(5):231-233. doi:10.1002/clc.4960290514.

Imms, A. D. 1925. A General Textbook of Entomology, Including the Anatomy, Physiology, Development and Classification of Insects. E. P. Dutton and Company Publishers. New York, NY, USA. 698 pp.

Jordan, H. 1927. Die Regulierung der Atmung bei Insekten und Spinnen. Zeitschrift für Vergleichende Physiologie 5:179-190. https://doi.org/10.1007/BF00340819

Kestler, P. 1985. Respiration and respiratory water loss. pp 137-183. In, K. H. Hoffmann (Editor) Environmental Physiology and Biochemistry of Insects. Springer, Berlin. 296 pp.

Klowden, M. J. 2013. Physiological Systems in Insects. Third Edition. Academic Press. An imprint of Elsevier. London, England, UK. 682 pp.

Krogh, A. 1920. Studien über Tracheenrespiration. II. Über Gasdiffusion in den Tracheen. Pflüger's Archiv für die gesamte Physiologie des Menschen und der Tiere 179:95-112. https://doi.org/10.1007/BF01722125

Krogh, A. 1941. The Comprehensive Physiology of Respiratopry Mechanisms. Dover Publications, Inc. New York, NY, USA. 172 pp.

Kuznetzoff, N. Y. A. 1953. The Principles of Insect Physiology. Volume 2. Izdatelstvo Akademii Nauk SSSR. Moscow, Leningrad. 402 pp. [in Russian].

Levy, R. I. and H. A. Schneiderman. 1966a. Discontinuous respiration in insects III. The effect of temperature and ambient oxygen tension on the gaseous composition of the tracheal system of silkworm pupae Journal of Insect Physiology 12:105-121. https://doi.org/10.1016/0022$\underline{1910(66) 90069-2}$

Levy, R. I. and H. A. Schneiderman. 1966b. Discontinuous respiration in insects IV. Changes in intratracheal pressure during the respiratory cycle of silkworm pupae. Journal of Insect Physiology 12:465-492. https://doi.org/10.1016/0022-1910(66)90011-4

Lighton, J. R. B. 1996. Discontinuous gas exchange in insects. Annual Review of Entomology 41:309324. https://doi.org/10.1146/annurev.en.41.010196.001521

Lighton, J. R. B. 1998. Notes from underground: towards ultimate hypotheses of cyclic, discontinuous gas exchange in tracheate arthropods. American Zoologist 38:483-491. https://doi.org/10.1093/icb/38.3.483

Lighton, J. R. B. 2008. Measuring Metabolic Rates. A Manual for Scientists. Oxford University Press. Oxford, England, UK. $201 \quad$ pp. https://www.researchgate.net/publication/235945338_Measuring_Metabolic_Rates_A_Manual _for_Scientists, https://doi.org/10.1093/acprof:oso/9780195310610.001.0001

Marais, E., J. S. Terblanche, C. J. Klok, and S. L. Chown. 2005. Insect gas exchange patterns: a phylogenetic perspective. Journal of Experimental Biology 208:4495-4507. https://doi.org/10.1242/jeb.01928

Muñoz-Chápuli, R. 2011. Evolution of angiogenesis. The International Journal of Developmental Biology 55:345-351. https://doi.org/10.1387/ijdb.103212rm

Muñoz-Chápuli, R., R. Carmona, J. A. Guadix, D. Macías, and J. M. Pérez-Pomares. 2005. Evolution_of_angiogenesis. The origin of the endothelial cells: an evo-devo approach for the invertebrate/vertebrate transition of the circulatory system. Evolution \& Development 7(4):351358. https://doi.org/10.1111/j.1525-142X.2005.05040.x

Nation, J. L. [Sr.] 2002. Insect Physiology and Biochemistry. CRC Press. Boca Raton, Florida, USA. $485 \mathrm{pp}$.

Nation, J. L. Sr. 2016. Insect Physiology and Biochemistry. CRC Press. Taylor \& Francis Group. Boca Raton, Florida, USA. 644 pp. 
Nelson, M. C. 1979. Sound production in the cockroach, Gromphadorhina portentosa: The soundproducing apparatus. Journal of Comparative Physiology 132(1):27-38. https://doi.org/10.1007/BF00617729

Newport, G. 1836. On the respiration of insects. Philosophical Transactions of the Royal Society (London, England, UK) 2:529-566. https://doi.org/10.1098/rstl.1836.0026

Plateau, F. 1884. Recherches expérimentales sur les mouvements respiratoires des insectes. Bulletins de l'Academie Royale des Sciences, des Lettres et des Beaux Arts de Belgique 45:1-219.

Poulsen, J. E. 1975. The impact of August Krogh on the insulin treatment of diabetes and our present status. Acta Medica Scandinavica. Supplementum 578:7-14. https://doi.org/10.1111/j.09546820.1975.tb06497.x

Provansal A., N. Baudry-Partiaoglou, and K. Sláma. 1977. Haemolymph pressure pulses in the metamorphosis of Tenebrio molitor. Acta Entomologica Bohemoslovaca 74:362-374.

Rathke, H. 1861. Anatomisch-physiologische Untersuchungen über den Atemprozess der Insekten. Schriften der Physikalisch-Ökonomischen Gesellschaft zu Königsberg 1:99-138 + nine figures.

Rehberg, P. B. 1951. August Krogh, November 15, 1874-September 13, 1949. The Yale Journal of Biology and Medicine 24(2):83-102.

Schmidt-Nielsen, B. 1984. August and Marie Krogh and respiratory physiology. Journal of Applied Physiology: Respiratory, Environmental and Exercise Physiology 57(2):293-303.

Schmidt-Nielsen, B. 1995. August \& Marie Krogh. Lives in Science. American Physiological Society. New York, NY, USA. 295 pp. https://doi.org/10.1007/978-1-4614-7530-9

Schneirderman, H. A. 1956. Spiracular control of discontinuous respiration in insects. Nature 177:1169-1171. https://doi.org/10.1038/1771169a0

Schneirderman, H. A. 1960. Discontinuous respiration in insectrs: role of the spiracles. Biological Bulletin 119:494-528. https://doi.org/10.2307/1539265

Schneirderman, H. A. and A. N. Schechter. 1966. Discontinuous respiration in insects V. Pressure and volume changes in the tracheal system of silkworm pupae. Journal of Insect Physiology 12:11431170. https://doi.org/10.1016/0022-1910(66)90129-6

Schneirderman, H. A. and C. M. Williams. 1955. An experimental analysis of the discontinuous respiration of the cecropia silkworm. Biological Bulletin 109:123-143. https://doi.org/10.2307/1538665

Shotton, R. 2014. Testing the disturbance hiss of the Madagascar hissing Cockroach (Gromphadorhina portentosa) as an anti-predatory response. Bioscience Horizons 7: hzu010. https://doi.org/10.1093/biohorizons/hzu010

Sláma, K. 1960 Oxygen consumption during the postembryonic development of Pyrrhocoris apterus L. (Heterometabola: Heteroptera) and its comparison with that of Holometabola. Annals of the Entomological Society of America 53:606-610.https://doi.org/10.1093/aesa/53.5.606

Sláma, K. 1976. Insect haemolymph pressure and its determination. Acta Entomologica Bohemoslovaca 73:65-75.

Sláma, K. 1984. Recording of haemolymph pressure pulsations from the insect body surface. Journal of Comparative Physiology (B) 154:635-643. https://doi.org/10.1007/BF00684418

Sláma, K. 1986. Cholinergic control of extracardiac pulsations in insects. Experientia 42:5456.https://doi.org/10.1007/BF01975893

Sláma, K. 1988. A new look at insect respiration. Biological Bulletin 175:289-300. https://doi.org/10.2307/1541570

Sláma, K. 1989. Role of the autonomic nervous system (Coelopulse) in insect reproduction. pp. 2338. In, M. Tonner, T. Soldán, and B. Bennett (Editors). Regulation of Insect Reproduction. Academia. Prague, Czechoslovakia.

Sláma, K. 1994. Regulation of respiratory acidemia by the autonomic nervous system (Coelopulse) in insects and ticks. Physiological Zoology 67:163-174. https://doi.org/10.1086/physzool.67.1.30163840

Sláma, K. 1999. Active regulation of insect respiration. Annals of the Entomological Society of America 92:916-929. https://doi.org/10.1093/aesa/92.6.916

Sláma, K. 2003. Mechanical aspects of heartbeat reversal in pupae of Manduca sexta. Journal of Insect Physiology 49:645-657. https://doi.org/10.1016/S0022-1910(03)00065-9 
Sláma, K. 2006. Heartbeat reversal after sectioning of the dorsal vessel and removal of the brain in diapausing pupae of Manduca sexta (Lepidoptera: Sphingidae). European Journal of Entomology103:17-26. https://doi.org/10.14411/eje.2006.003

Sláma, K. 2009. Extracardiac haemocoelic pulsations and the autonomic neuroendocrine system (coelopulse) of terrestrial insects. Terrestrial Arthropod Reviews 1:39-80. https://doi.org/10.1163/187498308X345433

Sláma, K. 2010. A new look at discontinuous respiration in pupae of Hyalophora cecropia (Lepidoptera: Saturniidae): Haemocoelic pressure, extracardiac pulsations and $\mathrm{O} 2$ consumption. European Journal of Entomology 107:487-507. https://doi.org/10.14411/eje.2010.057

Sláma, K. 2012. A new look at the comparative physiology of insect and human hearts. Journal of Insect Physiology 58:1072-1081.

Sláma, K. 2015. A new look at the nature of insect juvenile hormone with particular reference to studies carried out in the Czech Republic. European Journal of Entomology 112:567-590.

Sláma K., N. Baudry-Partiaoglou, and A. Provansal-Baudez. 1979. Control of extracardiac haemolymph pressure pulses in Tenebrio molitor. Journal of Insect Physiology 25:825-831.

Sláma K. and D. L. Denlinger. 1992. Infradian cycles of oxygen consumption in diapausing pupae of the flesh fly, Sarcophaga crassipalpis, monitored by a scanning microrespirographic method. Archives of Insect Biochemistry and Physiology 20:135-143. https://doi.org/10.1002/arch.940200205

Sláma, K. and P. Jedlička. 2012. Respiratory metabolism of the pea aphid, Acyrtosiphon pisum (Hemiptera: Aphididae). European Journal of Entomology 109:491-502. https://doi.org/10.14411/eje.2012.062

Sláma, K. and I. Kryspin-Sørensen. 1979. Hypermetabolic response induced by juvenile hormone analogues in an insect. Zeitschrift für Naturforschung C 34:599-607.

Sláma, K. and J. Lukáš. 2013. Role of juvenile hormone in the hypermetabolic production of water revealed by $\mathrm{O}_{2}$ consumption and thermovision images of larvae of insects fed a diet of dry food. European Journal of Entomology 110:221-230.

Sláma, K. and J. Lukáš. 2016. Hypermetabolic conversion of plant oil into water: endothermic biochemical process stimulated by Juvenile Hormone in the European Firebug, Pyrrhocoris apterus L. International Journal of Insect Science 8:81-93. https://doi.org/10.4137/IJIS.S40566

Sláma K. and T. A. Miller. 1987. Insecticide poisoning: Disruption of a possible autonomic function in pupae of Tenebrio molitor. Pesticide Biochemistry and Physiology 29:25-34. https://doi.org/10.1016/0048-3575(87)90081-2

Sláma K. and T. A. Miller. 2001. Physiology of heartbeat reversal in diapausing pupae of the tobacco hornworm, Manduca sexta (Lepidoptera: Sphingidae). European Journal of Entomology 98:415431. https://doi.org/10.14411/eje.2001.061

Sláma, K. and L. Neven. 2001. Active regulation of respiration and circulation in pupae of the codling moth (Cydia pomonella). Journal of Insect Physiology 47:1321-1336. https://doi.org/10.1016/S0022-1910(01)00122-6

Sláma, K., J. Šobotník, and R. Hanus. 2007. Respiratory concerts revealed by scanning microrespirography in termite Prorhinotermes simplex (Isoptera: Rhinotermitidae). Journal of Insect Physiology 53:295-311. https://doi.org/10.1016/j.jinsphys.2006.12.004

Socha, J. J., T. Förster, and K. Greenlee. 2010. Issues of convection in insects respiration: insights from synchrotron X-ray imaging and beyond. Respiratory Physiology \& Neurobiology 173S S6573. https://doi.org/10.1016/j.resp.2010.03.013

Turbeville, J. M. 1991. Nemertinea. pp. 285-328. In, F. W. Harrison and B. J. Bogitsh (Editor). Microscopic Anatomy of Invertebrates. Volume 3. Platyhelminthes and Nemertinea. Wiley-Liss. A John Wiley \& Sons, Inc., Publication. New York, NY, USA. 347 pp.

Wasserthal, L. T. 1981. Oscillating haemolymph circulation and continuous tracheal ventilation in the giant silk moth Attacus atlas L. Journal of Comparative Physiology B 145:1-15. https://doi.org/10.1007/BF00782587

Wasserthal, L. T. 1996. Interaction of circulation and tracheal ventilation in holometabolous insects. Advances in Insect Physiology 25:297-351. https://doi.org/10.1016/S0065-2806(08)60033-8 
Wasserthal, L. T. 2014. Periodic heartbeat reversals cause cardiogenic inspiration and expiration with coupled spiracle leakage in resting blowflies. Journal of Experimental Biology 217:1541-1554. https://doi.org/10.1242/jeb.097238

Wasserthal, L. T. and A. S. Fröhlich. 2017. Structure of the thoracic spiracular valves and their contribution to unidirectional gas exchange in flying blowflies Calliphora vicina. Journal of Experimental Biology 220:208-219. https://doi.org/10.1242/jeb.149013

West, J. B. 2013. Marcello Malpighi and the discovery of the pulmonary capillaries and alveoli. American Journal of Physiology - Lung Cellular and Molecular Physiology 304(6):L383-L390. https://doi.org/10.1152/ajplung.00016.2013

Westneat M. W., O. Betz, R. W. Blob, K. Fezzaa, W. J. Cooper, and W.-K. Lee. 2003. Tracheal respiration in insects visualized with synchrotron $\mathrm{x}$-ray imaging. Science (Washington, District of Columbia, USA) 299:558-560. https://doi.org/10.1126/science.1078008

Westneat, M. W., J. Socha, and W. K. Lee. 2008. Advances in biological structure, function and physiology using synchrotron x-ray imaging. Annual Review of Physiology 70:119-142. https://doi.org/10.1146/annurev.physiol.70.113006.100434

Wigglesworth, V. B. 1939. The Principles of Insect Physiology. E. P. Dutton and Company Inc. $\begin{array}{llllll}\text { Publishers. New } & \text { York, } & \text { NY, } & \text { USA. } & 434 & \text { pp. }\end{array}$ https://babel.hathitrust.org/cgi/pt?id=wu. $89041296120 ;$ view=1up;seq=7

Wigglesworth, V. B. 1947.The Principles of Insect Physiology. Third Edition. Methuen Co. London, England, UK. 434 pp.

Wigglesworth, V. B. 1965. The Principles of Insect Physiology. Sixth Edition. Methuen, London, England, UK and New York, NY, USA. $741 \mathrm{pp}$.

Xavier-Neto, J., B. Davidson, M. S. Simoes-Costa, R. A. Castro, H. A. Castillo, A. C. Sampaio, and A. P. Azambuja. 2010. Evolutionary origins of hearts. Chapter 1.1. pp. 3-45. In, Rosenthal, N. and R. P. Harvey (Editors). Heart Development and Regeneration. Volume 1. Academic Press, an imprint of Elsevier. Amsterdam, The Netherlands. 565 pp. + 1ndex 31 pp. https://doi.org/10.1016/b978-0-12-381332-9.00001-3 